\title{
The Status of Radionuclide Sorption-Desorption Studies Performed by the WRIT Program
}
R. J. Serne
J. F. Relyea

April 1982

Prepared for the U.S. Department of Energy under Contract DE-AC06-76RLO 1830

Pacific Northwest Laboratory Operated for the U.S. Department of Energy by Battelle Memorial Institute 


\title{
DISCLAIMER
}

This report was prepared as an account of work sponsored by an agency of the United States Government. Neither the United States Government nor any agency thereof, nor any of their employees, makes any warranty, express or implied, or assumes any legal liability or responsibility for the accuracy, completeness, or usefulness of any information, apparatus, product, or process disclosed, or represents that its use would not infringe privately owned rights. Reference herein to any specific commercial product, process, or service by trade name, trademark, manufacturer, or otherwise, does not necessarily constitute or imply its endorsement, recommendation, or favoring by the United States Government or any agency thereof. The views and opinions of authors expressed herein do not necessarily state or reflect those of the United States Government or any agency thereof.

\author{
PACIFIC NORTHWEST LABORATORY \\ operated by \\ BATTELLE \\ for the \\ UNITED STATES DEPARTMENT OF ENERGY \\ under Contract DE-AC06-76RLO 1830
}

\begin{tabular}{|c|c|}
\hline \multicolumn{2}{|c|}{ Printed in the United States of America } \\
\hline \multicolumn{2}{|c|}{ Available from } \\
\hline \multirow{4}{*}{\multicolumn{2}{|c|}{$\begin{array}{c}\text { National Technical Information Service } \\
\text { United States Department of Commerce } \\
5285 \text { Port Royal Road } \\
\text { Springfield, Virginia } 22151\end{array}$}} \\
\hline & \\
\hline & \\
\hline & \\
\hline \multirow{2}{*}{\multicolumn{2}{|c|}{$\begin{array}{l}\text { NTIS Price Codes } \\
\text { Microfiche A01 }\end{array}$}} \\
\hline & \\
\hline \multicolumn{2}{|c|}{ Printed Copy } \\
\hline & Price \\
\hline Pages & Codes \\
\hline $001-025$ & $\mathrm{~A} 02$ \\
\hline 026-050 & $\mathrm{A} 03$ \\
\hline 051-075 & A04 \\
\hline 076-100 & A05 \\
\hline $101-125$ & A06 \\
\hline $126-150$ & $\mathrm{~A} 07$ \\
\hline $151-175$ & $\mathrm{~A} 08$ \\
\hline $176-200$ & A09 \\
\hline $201-225$ & A010 \\
\hline $226-250$ & A011 \\
\hline $251-275$ & $A 012$ \\
\hline $276-300$ & A013 \\
\hline
\end{tabular}


Waste/Rock Interactions Technology Program

THE STATUS OF RADIONUCLIDE SORPTION-DESORPTION STUDIES PERFORMED BY THE WRIT PROGRAM

R. J. Serne

J. F. Relyea

Apri1 1982

Prepared for the U.S. Department of Energy under Contract DE-AC06-76RLO 1830

Pacific Northwest Laboratory

Richland, Washington 99352 


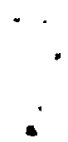

4. 


\section{ABSTRACT}

The most credible means for radionuclides disposed as solid wastes in deep-geologic repositories to reach the biosphere is through dissolution of the solid waste and subsequent radionuclide transport by circulating ground water. Thus safety assessment activities must consider the physicochemical interactions between radionuclides present in ground water with package components, rocks and sediments since these processes can significantly delay or constrain the mass transport of radionuclides in comparison to ground-water movement. This paper focuses on interactions between dissolved radionuclides in ground water and rocks and sediments away from the near-field repository. The primary mechanism discussed is adsorption-desorption, which has been studied using two approaches. Empirical studies of adsorption-desorption rely on distribution coefficient measurements while mechanism studies strive to identify, differentiate and quantify the processes that control nuclide retardation.

The empirical approach quantifies adsorption using a distribution coefficient, Rd, which is the ratio of mass of a radionuclide present on the rock to the mass present in solution. Studies to standardize laboratory methods for measuring Rd are described. However, no one laboratory method best simulates all possible rock/ground water/nuclide combinations, but two methods, batch and once-through-flow column, appear to complement each other and are recommended for further standardization. Details on their strengths and weaknesses are discussed. Results from an interlaboratory batch comparison exercise and comparison of nuclide Rd values among methods are discussed. Much of the past Rd variability attributed to different methods can be explained by the lack of control of ground water and rock parameters, incomplete phase separation, differing tracer addition methods, nonlinear sorption isotherms and variations in protocol for container wall adsorption corrections. Rd values from carefully controlled laboratory experiments and with adequate contact or residence time appear to agree regardless of the testing methods used. Results of generic empirical Rd work are summarized in tables of nuclide Rd values for five potential repository rock types. The quantity and quality of Rd data for 
these rock types are ranked and future improvements in the treatment of nuclide retardation in existing computer safety assessment codes are suggested.

The status of sorption mechanism studies is discussed with emphasis on delineating the usefulness of ideal ion exchange, site-binding electrical double-layer and redox controlled sorption constructs. Studies to date on the applicability of ideal ion exchange and site-binding electrical double-layer models for describing nuclide adsorption onto geologic media show greater potential for the latter construct. Future efforts will concentrate on evaluating site-binding electrical double-layer models.

Laboratory studies are discussed which corroborate the importance of redox reactions in causing nuclide retardation for multivalent elements such as $T c$, $\mathrm{Np}, \mathrm{Pu}$ and $\mathrm{U}$. Results suggest both solution mediated reduction such as the $\mathrm{Fe}$ (II)-Fe(III) couple and solid/solution heterogeneous reduction reactions such as reduction of solution $\mathrm{Pu}(\mathrm{VI})$ at the mineral surface by structural $\mathrm{Fe}$ (II) occur.

Coupled microscopy, microprobe and autoradiography studies have determined actual sorption sites for radionuclides on polymineralic rocks. The studies show that it is possible for minor phases to completely dominate the mass of radionuclides adsorbed. The most active minerals are typically alteration products (clays and zeolites).

Several exercises are discussed which rank radionuclides according to their potential dose hazards. In each of the discussed analyses the top four radionuclides are $\mathrm{I}, \mathrm{TC}, \mathrm{Np}$ and $\mathrm{Ra}$. Other elements which rank high in potential hazards are $\mathrm{Pu}, \mathrm{U}, \mathrm{Am}, \mathrm{Th}, \mathrm{Pb}, \mathrm{Sm}, \mathrm{Pd}$ and $\mathrm{Se}$.

A brief review of field nuclide migration and laboratory Rd comparisons is given which shows that generally the investigators have been pleased with the agreement between field observation and laboratory predictions of nuclide migration. The interplay between laboratory, field nuclide migration and natural analog studies is discussed.

A brief discussion of the status and usage of computer based geochemical models to the overall repository safety assessment process is provided. 


\section{ACKNOWLEDGMENTS}

This work was supported by the Waste/Rock Interactions Technology (WRIT) Program conducted by Pacific Northwest Laboratory. This program is sponsored by the Office of Nuclear Waste Isolation, which is managed by Battelle Memorial Institute under Contract DE-AC06-76RLO 1830 with the Department of Energy.

We gratefully acknowledge the typing assistance of Darla Kennedy, Karin Shupe, Mary Heid and Dee Dee Berg and the graphics assistance of Gene Wattenburger. The technical editing efforts of Pam Partch were greatly appreciated.

Much of the work cited in this paper was performed under subcontract by scientists at the following national laboratories, universities and private institutions: Argonne, Lawrence Berkeley, Lawrence Livermore, Los Alamos and Oak Ridge; Georgia Institute of Technology; Adaptronics, Inc. and Rockwell Hanford Operations. The views presented in this paper and conclusions drawn are solely those of the authors at Pacific Northwest Laboratory and should not be interpreted as representing those of the numerous technical contributors from the above institutions.

Several colleagues supplied detailed and useful comments on the draft version of this document. We wish to acknowledge the time expended and quality of the comments from Mr. Tom Longo (DOE-Headquarters), Dr. Robert E. Meyer (ORNL), Dr. Glen W. Gee (PNL), Mr. John L. Swanson (PNL), Mr. Max R. Kreiter (PNL), and Dr. Dhanpat Rai (PNL).

Finally, we wish to acknowledge the support, both monetary and technical, of the sponsors, Office of Nuclear Waste Isolation and its predecessor Office of Waste Isolation. The support of the following program managers is acknowledged: Drs. William McCl,ain, Clyde Claiborne, Les Dole, Jim Duguid, John Kircher, Norman Hubbard and Judith Moody. 


\section{CONTENTS}






\section{FIGURES}

1 Dependence of Cesium Adsorption by Basalt on Cesium Concentration . . . . . . . . . . . 10

2 Dependence of Cesium Adsorption by Limestone on

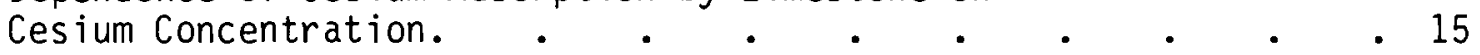

3 Dependence of Cesium Adsorption by Montmorillonite on Amount of Cesium Loaded on the Clay (Amount of Cesium in Solution $(\underline{M})=R d \times$ Loading) . . . . . . . 16

4 Conceptualization of Important Nuclide Retardation Processes, Needed Data and Interactions with System Components for the Far-Field . . . . . . . . 31

5 The Effect of Ground-Water $\mathrm{pH}$ on the Adsorption of Am on Various Rock-Forming Minerals . . . . . . 35

$6 \quad \operatorname{Rd}(C s)$ Values for Adsorption on Montmorillonite Versus $\mathrm{pH}$ at Several Brine Concentrations. (Symbols are experimental data points while solid lines are computer model predictions. The dashed lines represent activity corrections for the model predictions.) . . . . . . . . 45

$7 \quad \operatorname{Rd}(\mathrm{Cs})$ Values for Adsorption on Colloidal Silica Versus $\mathrm{pH}$ at Designated Brine Concentration and Initial Solution Cs Concentration of $10^{-9} \mathrm{M}$. [Symbols are experimental data points while the vertical bars are experimental uncertainties $\left(+l_{0} \sigma\right)$. The solid lines are computer model predictions while the dashed lines are computer model predictions which consider electrical double layer activity corrections.] . . . . 46

8 Adsorption of 239Pu(VI) by Aerated Mineral Suspensions $(34 \mathrm{ml} / \mathrm{g})$ at $\mathrm{pH} 4$. Averages of duplicate samples are plotted. $(0=<7 \%, \square=7-15 \%$, and $\Delta=15-30 \%$ difference between the duplicates) . . . . . . . . . 49

9 Adsorption of $\mathrm{Pu}(\mathrm{VI})$, in the Presence of Ozone at Approximately pH 4 and 34:1 Solution to Solid Ratio, by Mineral Samples Also Pretreated with 0zone. Averages of duplicate samples are plotted. $(0=\langle 4 \%$ and $\square=9-15 \%$ difference between the duplicates) 


\section{TABLES}

1 Interlaboratory Comparison of $\mathrm{Rd}(\mathrm{ml} / \mathrm{g})$ Values for Limestone

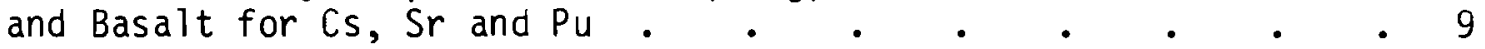

2 Average Rd Values for Tuff as a Function of Tracer Addition

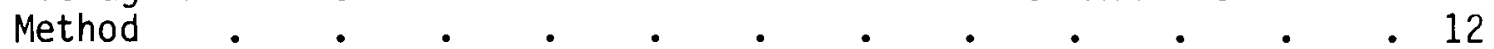

$3 \mathrm{Rd}(\mathrm{Pu})$ Values on Shales, Climax Stock Shear Zone Material and Thirsty Canyon Tuff . $. \quad . \quad . \quad . \quad . \quad . \quad . \quad . \quad 14$

4 Rd Value Comparisons Among Methods . . . . . . . . 23

5 Comparison of Actual and Predicted $\mathrm{Sr}$ and Am Adsorption Rd's

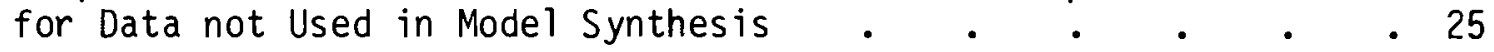

6 Rd Values for Radionuclides not Affected by Redox . . . . . 27

7 Rd Values for Redox Sensitive Elements . . . . . . . . . 28

8 Exchangeable Pu and Selected Properties of

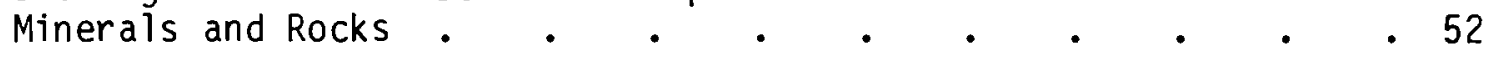

9 An Early Nuclide Priority List. $\quad . \quad$. $\quad . \quad$. $\quad . \quad$. 55

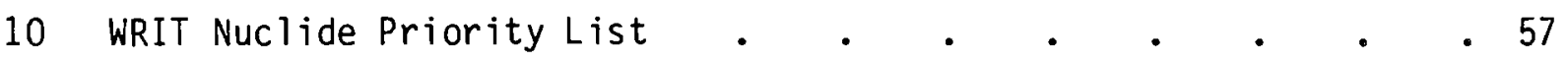


THE STATUS OF RADIONUCLIDE SORPTION-DESORPTION

STUDIES PERFORMED BY THE WRIT PROGRAM

R. J. Serne and J. F. Relyea

Pacific Nor thwest Laboratory

Richland, washington

\section{INTRODUCTION}

Nuclear activities to produce electrical power and fissionable materials for defense purposes have and will continue to generate radioactive waste by-products that must be isolated from the biosphere because of their potential health hazards. At present, the most viable option is deep-geologic disposal in a mined repository [Interagency Review Group (1979), U.S. Department of Energy $(1979,1980)$ and U.S. Environmental Protection Agency (1979)]. Typically, conceptual designs have the repository constructed at depths of 300 to 1000 meters, using conventional mining techniques based on vertical access shafts [Stearns-Roger Engineering Company $(1979,1980)$ and Kaiser Engineers (1979)].

The total area of an underground repository would be 400 to 800 hectares ( 1000 to 2000 acres) with horizontal tunnels leading to emplacement rooms for the waste. The solidified waste forms would be placed in man-made packages (canister, overpack and backfill) and buried in holes drilled in the floors of the emplacement rooms. As specific areas of the repository fill or are decommissioned, they would be filled with various materials such as compacted clay backfill, crushed host rock, cements and grouts. Thus, the mined geologic disposal system would be composed of three major subsystems: the repository, the waste package and the geologic strata (the site). Each of these subsystems would be capable of isolating wastes from the biosphere. Further the sites would be selected using established criteria that the Department of Energy (DOE) has developed [Office of NWTS Integration (1981)].

Once the radioactive wastes are emplaced, few credible means exist for its return to the biosphere. The most credible means is through dissolution of the waste and subsequent radionuclide transport by circulating ground water. 
[Interagency Review Group (1978), Pines (1978), de Marsily et al. (1977) and Arthur D. Little, Inc. (1980)]. Therefore, safety and performance assessments in support of licensing nuclear waste repositories must be concerned with the physicochemical interactions between radionuclides present in waste forms with ground water, engineered barriers, rocks and sediments, since these processes can significantly delay or constrain the mass transport of radionuclides in comparison to ground water movement [Hill (1980), Kaseta and Bond (1980), de Marsily et a1. (1977)]. For licensing purposes these physicochemical interactions must be described in quantitative terms to support assurances that if radionuclides were released from a deep-geologic repository, then the magnitude of release and ensuing migration rate to the biosphere would be sufficiently small such that wastes would not adversely affect the biosphere or accessible environment.

Identifying and characterizing these physicochemical interactions (e.g., adsorption, precipitation and filtration) and subsequent quantification of their radionuclide retardation potential are goals of the Waste/Rock Interactions Technology Program (WRIT) which is directed by Pacific Northwest Laboratory. In addition, WRIT identifies and characterizes package degradation, waste-form leaching and backfill performance.

This paper focuses on interactions between dissolved radionuclides in ground water and rocks and sediments away from the near-field repository influence of intense heat and radiation. It summarizes progress within WRIT from 1976 through mid-1981. A more complete compilation of far-field sorption/ desorption data including other National Waste Terminal Storage (NWTS) and international work with detailed analyses and supporting discussion of conclusions drawn herein will be prepared later. In support of preliminary site comparisons and safety assessment, empirical distribution coefficients for radionuclide adsorption are given for typical ground waters in basalt, tuff, granite, bedded salt and domed salt. Further, as an example of how these research efforts can focus current and future work on radionuclide migration and hazards potential a prioritization exercise is described. Finally brief discussions of the relationships among laboratory, field and natural analog studies and computer based thermodynamic models are presented. 
Other germane studies conducted by WRIT such as waste-form leaching and waste package systems performance testing are the subject of another paper in this book [McVay et al. (1981)]. In addition other NWTS programs conduct complementary work that should be considered to assess the available knowledge and NWTS predictive capabilities on radionuclide migration potential. The status and program descriptions of all earth-science-related activities are succinctly described in ONWM and USGS (1980), Klingsberg and Duguid (1980) and Moody (1981).

BACKGROUND

Among the processes that retard transport of radionuclides are hydrologic, geologic and physicochemical processes. Hydrologic and geologic studies can provide the necessary data to quantitatively describe water velocites and probable pathlengths to the accessible environment. These values provide an upper limit to the rate of radionuclide transport. Sorption-desorption studies are performed to quantitatively estimate the increase in effective travel time for nuclides to the accessible environment. Often the increase is significant, i.e., relative nuclide migration travel times are $10^{3}$ to $10^{6}$ years longer than that of ground water. Such long travel times allow nuclides to decay to lower concentrations and less hazardous elements. Further, some sorption processes irreversibly remove nuclides from ground water, preventing their release to the biosphere.

In studying radionuclide retardation WRIT has followed two approaches: empirical studies that rely on distribution coefficient measurements and mechanism studies that strive to identify, differentiate and quantify the physicochemical processes that control nuclide retardation [Relyea et al. (1979b) and Serne (1978a)]. The former approach allows the rapid determination of the relative affinity of nuclides for solid substrates without concern for the cause or controlling processes involved. An empirical parameter, the distribution coefficient (often called $\mathrm{Kd}$ or $\mathrm{Rd}$ ), is readily measured by laboratory experimentation and allows a quantitative estimate of nuclide migration relative to ground water. Almost every existing computer code for safety assessment and site selection used in licensing support relies on the distribution 
coefficient concept [Logan and Berbano (1978), Campbell et al. (1978), Burkholder et a1. (1979), Arthur D. Little, Inc. (1980), Dillon et al. (1978), DeMier et al. (1979), Washburn (1979), and Robertson (1977)]. Other studies [Cloninger and Cole (1980) and Cloninger et al. (1980)] have shown the importance of far-field nuclide retardation for guiding waste package design. Thus to support preliminary site selection, performance assessment and waste package design activities, WRIT has conducted empirical nuclide retardation studies.

During 1976-1978 WRIT performed generic screening sorption studies on a wide range of ground water/rock/mineral/sediment combinations to develop bounding nuclide retardation values. During 1978-80 empirical work shifted towards more comprehensive studies with specific ground water/rock/sediment combinations more representative of media being considered for radioactive waste disposal. Results of these experiments can be used in identifying probable sorption mechanisms for further study.

The mechanistic studies complement the empirical studies by providing fundamental data and understanding of physicochemical processes that control nuclide retardation. From these more theoretically based studies, WRIT plans to interpret the available empirical data and to develop predictive relationships that address the long-time extrapolations and allow interpolations or extrapolations based on knowledge of controlling physicochemical processes and laws. These studies are neither as rapidly completed nor do they lead to useful results as readily as those of the empirical approach. However, successful mechanism studies are valuable because their results are more general (i.e., site and methodology independent). Thus, WRIT has attempted to meld both theoretical and engineering approaches into a cohesive program to provide the necessary data for repository safety assessment, site selection and waste package performance assessment and design.

Before discussing the efforts to date, certain terms should be defined. Nuclide retardation encompasses all possible processes that hinder nuclide migration in solution including ideal ion exchange, mineral precipitation, 
co-precipitation in amorphic (a) coatings, chemisorption or selective adsorption/complexation onto solid adsorbents, redox or hydrolys is mediated precipitation/sorption and physical filtration of small particulates. More detailed descriptions of the processes may be found in Onishi et al. (1981) and Jenne (1977). As used in this paper adsorption or sorption refers to surface processes wherein radionuclides in solution become incorporated onto the solid phase surface. The terms, adsorption and sorption, are more general and include more processes than ideal ion exchange but where possible exclude precipitation of identifiable mineral or amorphic compounds such as oxides, hydroxides or carbonates [Strickert (1980)]. A goal of WRIT has been to separate precipitation and adsorption studies and to differentiate the processes. At times this approach has been complicated by a lack of knowledge of solubility limits for nuclides in ground waters. In fact, some early adsorption studies were performed inadvertently at radionuclide concentrations that exceeded solubility limits. Future sorption work will incorporate recent advances in knowledge of nuclide solubilities.

To quantify adsorption, one typically measures the distribution of the adsorbate between the solid phase and solution phase. Such a value or distribution coefficient is often called a "Kd", "D", or "Rd". Confusion arises because the term distribution coefficient has been used by other scientists much more selectively to refer to 1) the special case of ideal binary ion exchange where the element of interest is present in such trace concentrations that it does not appreciably affect concentration of the macro-constituent sorbed on the solid or the activity coefficient ratio of the mass action exchange [Meyer (1979) and Routson and Serne (1972)] or 2) a special case of a Freundlich empirical isotherm where sorption is linear [Travis (1978)]. Linear adsorption typically occurs only at trace absorbate concentration in solution and trace loading onto the solid adsorbent surfaces. In both instances the adsorption refers to equilibrium conditions and further when used with mass

(a) Amorphic - amorphous-1ike but in practice those that have a minimal X-ray diffraction (Jenne 1972). The term is used for materials intermediate between totally crystalline and totally amorphous materials as determined by $X$-ray diffraction. 
transport theory generally requires reversibility, i.e., desorption occurs at the same rate and leads to the same equilibrium ratio of adsorbate between the solid and solution.

When used in this paper to describe empirical studies the distribution coefficient will be called Rd and simply refers to the ratio of mass or activity of a radionuclide present in the solid phase (rock or sediment) to the mass or activity present in solution (ground water). This empirical ratio does not require equilibrium conditions, quantitative reversibility or ion exchange as the governing process. In this paper the term $D$ will be used to refer to a thermodynamic distribution coefficient that describes ideal ion exchange of radionuclides onto pure clays and oxide surfaces.

To date when used by safety assessment modelers within extant computer codes, WRIT Rd or D data have been assumed to represent both equilibrium and reversible data as required by model mathematical laws. The implications of these assumptions will be discussed later in this paper.

The WRIT activities on far-field sorption can be broken into three general areas: laboratory adsorption/desorption methods development, generation of empirical Rd values, and physicochemical sorption/desorption mechanism studies. Discussions of laboratory methods development will focus on the two most used methods, batch and once-through-flow column. Details on their strengths and limitations will be discussed. The sensitivity of Rd to procedural steps such as agitation rate, phase separation and pore velocity are discussed. Results from an interlaboratory batch sorption comparison exercise and comparison of nuclide Rd values among methods are discussed. Results of generic empirical Rd experiments are distilled down to tables of Rd values for important nuclides contacting five potential repository rock types: bedded salt, dome salt, basalt, tuff and granite. The quantity and quality of Rd data for these environments are ranked. Finally, the status of sorption mechanism studies is discussed. Results of scouting studies to identify more important variables among temperature, $\mathrm{pH}$, Eh and ground-water composition are given. Detailed descriptions of studies to identify the applicability of ideal ion exchange, site-binding electrical double-layer, and redox controlled sorption constructs are provided. The usefulness of these three constructs is also discussed. 


\section{LABORATORY ADSORPTION-DESORPTION METHODS DEVELOPMENT}

Since data used in license applications will be critically reviewed, the data should be obtained from formalized, standard or commonly accepted methods. In 1976, several types of experimental methodologies were used with numerous variations on specific steps. The sorption values generated were perceived to be quite variable. Therefore, WRIT staff initiated studies with the goal of preparing a method or methods that could be recommended for certification. A wide range of rocks and minerals in contact with radionuclide-laden solutions were used to assess the precision in Rd analysis, ease of method usage, time, equipment and cost expenditures, method limitations and Rd result comparisons. Laboratory methods that have been investigated include batch, axial filtration, channel chromatography, once-through-flow column on disaggregated or naturally permeable media, once-through-flow column on fractured or intact rock core, and recirculating-flow column. The batch and column methods are discussed in some detail as they are the most commonly used methods. The other methods are only briefly discussed. Each method is discussed in terms of its advantages, disadvantages and applicability to providing credible long-term adsorption predictions needed in repository safety assessments. References are provided for those who wish further details on the methods and past uses. [See Serne (1978b), Serne (1979), Relyea (1981), Relyea (1981), and Daniels (1981) for the methods' details and result comparisons. Also see Burkholder et al. (1979) and Brandstetter et al. (1979) for annual summary reports]. From information through mid-1981, WRIT staff concludes that no one laboratory method best simulates a 11 possible rock/ground water/nuclide combinations. Conceptualiy, a once-through-flow column on intact core would best simulate expected long-term nuclide migration in the far-field but costs, time expenditures and core leakage have presented significant practical constraints. As a result, WRIT staff currently recommends the use of at least two methods in concert to bound radionuclide migration for probable environmental conditions. Batch Method

The most commonly chosen laboratory method to evaluate nuclide sorption is the batch test. The batch test involves contacting the adsorbent (disaggregated rocks or sediments or rock tablets, shards, etc.) with a soluble 
adsorbate [nuclide(s)] in ground water within a container. In most instances the system is continually agitated to facilitate mixing and contact. At specified times the solid and solution are separated and the resultant distribution of adsorbate is determined. The equipment, space, cost and time requirements are low and the methodology quite simple, thus the batch method's popularity. However, the seemingly elementary operations mask numerous subtleties that WRIT studies have identified as the probable cause for much of the past variability in reported results.

In 1978 a round-robin exercise on batch sorption was conducted with nine participants. Large quantities of three rocks were homogenized and characterized [Ames (1978)]. General guidelines were given to participants on groundwater compositions, radionuclides and procedural details. Although the concentrations of radionuclides and exact methodology instructions were not specified, details on actual procedures used by each participant were requested. The exercise was performed to gather data on interlaboratory precision and to identify procedural details that cause variability. The results are listed in Table 1. [See Relyea and Serne (1979) for more details.]

It was anticipated that close agreement would be found for $\mathrm{Cs}$ and $\mathrm{Sr}$ adsorption results and that Pu would possibly behave erratically. There was agreement of $\operatorname{Rd}(C s)$ and $R d(S r)$ on both basalt and limestone contacting brine solution and on basalt in a basalt ground water. Adsorption results for Cs in the dilute limestone ground waters were more widely scattered than anticipated. $R d(S r)$ values generally appeared to depend on the final solution pH but not on the tracer concentration. $\operatorname{Rd}(C s)$ values did not appear to be dependent on final $\mathrm{pH}$. The reported data are insufficient to determine why $\mathrm{Rd}(\mathrm{Cs})$ had a range of three orders of magnitude in the limestone rock ground-water system, but other studies [Seitz et al. (1980)] suggest that the variability was caused by a nonlinear $C S$ adsorption isotherm (see Figure 1) or incomplete removal of fine particles from solution.

Batch adsorption determinations of $\mathrm{Rd}(\mathrm{Pu})$ were not satisfactory (two to three orders of magnitude differences) because of adsorption of $\mathrm{Pu}$ on container walls and formation of and Pu adsorption on, filterable particles. The effects 
TABLE 1. Interlaboratory Comparison of $\mathrm{Rd}(\mathrm{ml} / \mathrm{g})$ Values for Limestone and Basalt for $\mathrm{Cs}, \mathrm{Sr}$ and $\mathrm{Pu}$

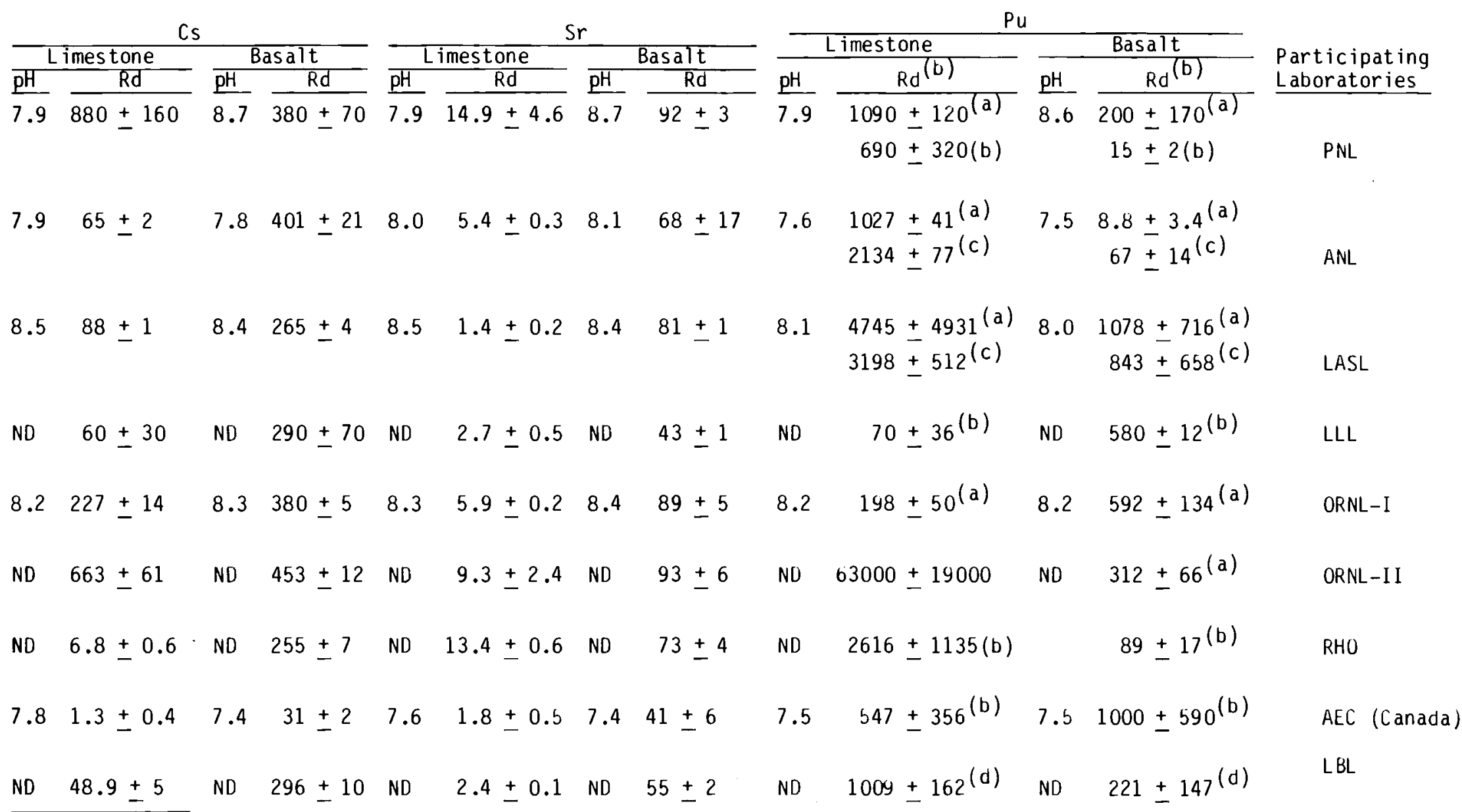

(a) The limestone and basalt samples were crushed to a 297 to $840 \mathrm{~m}$ size. All Rd's are for a 7 day equilibration period except ORNL-II which are for a 29 day equilibration period. The ND in the data means "not determined".

(b) Equilibration solution treatment, $a=$ centrifuged at $\sim 4000 \mathrm{~g}$ and filtered through 0.2 to $0.45 \mu \mathrm{m} f i l$ ter, $\mathrm{b}=$ centrifuged at $\sim 4000 \mathrm{~g}, \mathrm{c}=$ absorbed activity was determined directly from the geomedia sample instead of calculating from the change in concentration of the radionuclide in solution, d = based on original influent which was not corrected for the loss of activity from the solution not containing geomedia. 


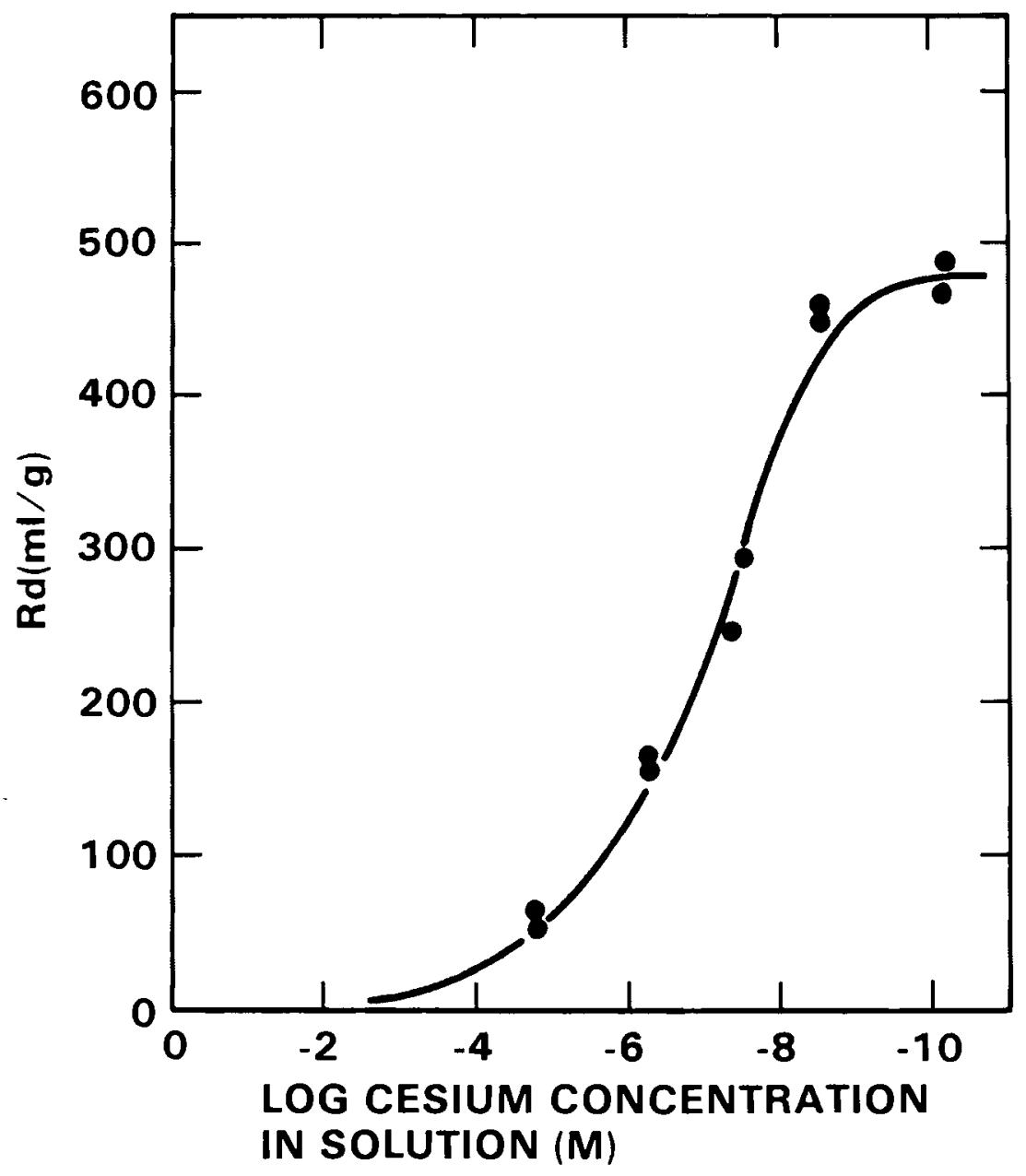

FIGURE 1. Dependence of Cesium Adsorption by Basalt on Cesium Concentration

of other variables (e.g., pH, Pu concentration, spiking method) that can significantly affect adsorption also must be considered. Direct determination of $\mathrm{Pu}$ adsorbed by the rock and $\mathrm{Pu}$ in effluent solution reduced the variability in $\mathrm{Rd}(\mathrm{Pu})$ in a prescribed rock-solution system by only one order of magnitude.

Results indicate that several parameters that were uncontrolled may have affected results. The uncontrolled parameters were: 1) method of tracer addition to solution, 2) solution-to-rock ratio, 3) initial tracer concentration in influent solution, 4) particle size distribution, 5) solid-solution separation method, 6) sample containers, and 7) temperature. These effects are discussed in the following paragraphs. 
A strong system agitation rate is suspected as causing sample abrasion which exposes new surfaces (increases surface area) and increases the chances that fine suspended particulates may be present in solution [Barney and Brown (1980) and Ames and McGarrah (1980)]. In general these fine particles have adsorbed nuclides on their surface and often they remain in the solution phase during solid/solution separation steps. Upon calculation of the Rd ratio this would yield results that were biased low and would introduce large variability in observed solution nuclide concentration [Rai et al. (1980a)]. Apparently disaggregated glassy Columbia Plateau basalt may be particularly susceptible to this particle abrasion. Thus, for all readily weatherable rocks WRIT staff recommend that a very gentle agitation rate (a few oscillations/minute) be utilized to minimize surface grinding.

The method chosen to separate the solid and liquid phase can seriously affect Rd determination. Two approaches are typically used: centrifugation or filtration. Results to date show centrifugation of ten leads to greater variability and lower Rd values than equivalent experiments that use membrane filtration. WRIT staff recommends filtration with polycarbonate membranes $(0.0018$ to $0.015 \mu \mathrm{m})$ as opposed to cellulosic filters because polycarbonate appears to adsorb minimal amounts of tested radionuclides. Studies performed at Los Alamos have shown that filtration may yield values biased high because radionuclides in solution are adsorbed by the membrane filter [Erdal et al. (1980)]. This membrane adsorption phenomenon needs further study because results have not been duplicated and appear to be most evident for the highly insoluble actinide Am and perhaps Pu. The potential filter adsorption impact can be minimized by using a small diameter filter, filtering a larger volume of solution, and discarding the first portion of filtrate.

Another source of variability is the amount and method by which radionuclide tracer is added to the ground water. In the past, a small aliquot of the radionuclide was added to the ground water or rock/ground water slurry from a concentrated stock (typically strong acid) solution. The pH of the system was then adjusted to the desired value with strong base or acid. However, the chances for system supersaturation or formation of radionuclide polymers such as Pu(IV) polymer were great [Cleveland (1979) and Rai and 
Swanson (1981)]. As it is a goal of WRIT to separate nuclide adsorption onto surfaces from nuclide precipitation, this tracer addition technique is not adequate. Therefore, WRIT staff endorse an alternative tracer addition method in which the aliquot of concentrated nuclide is dried at sub-boiling temperatures in a container. Ground water is then added and the container shaken or stirred for several days with $\mathrm{pH}$ adjustment (if needed). The traced ground water is then filtered just prior to usage in sorption tests. Some comparisons of tracer addition techniques for $\mathrm{Am}$ and $\mathrm{Pu}$ in representative solutions in contact with tuff are shown in Table 2 [Erdal et al. (1980)]. Although a thorough understanding of the differences is lacking, the potential for different species being present is suspected. Differences in measured solution nuclide concentrations may not be the only cause for the above variability because Rd sensitivity to $\mathrm{Pu}$ concentration $\left(10^{-7}\right.$ to $\left.10^{-15} \mathrm{M}\right)$ is not great for batch experiments on granite and argillite [Daniels et al. (1981)]. Data on the effect of varying Pu and Am concentrations on Rd values on tuff are currently not available to make a direct comparison. Thus, at present, the cause of the observed (Table 2) Rd variation with tracer addition method is not thoroughly understood.

TABLE 2. Average Rd Values for Tuff as a Function of Tracer Addition Method

\begin{tabular}{|c|c|c|c|c|}
\hline Element & $\begin{array}{c}\text { Tuff } \\
\text { Sample } \\
\end{array}$ & $\mathrm{T}^{\circ}\left({ }^{\circ} \mathrm{C}\right)$ & $\begin{array}{l}\text { Rd Adsorption } \\
\text { Tracer Dried } \\
\end{array}$ & Tracer pH Adjust \\
\hline \multirow[t]{3}{*}{ Am } & 1 & $\begin{array}{l}22 \\
70\end{array}$ & $\begin{array}{l}180 \pm 30 \\
230 \mp 30\end{array}$ & $440 \pm 5$ \\
\hline & 2 & $\begin{array}{l}22 \\
70\end{array}$ & $\begin{array}{l}130 \pm 30 \\
110 \pm 30\end{array}$ & $1100 \pm 120$ \\
\hline & 3 & $\begin{array}{l}22 \\
70\end{array}$ & $\begin{array}{l}670 \pm 210 \\
970 \pm 240\end{array}$ & $\begin{array}{r}8800 \pm 1100 \\
34000 \mp 6000\end{array}$ \\
\hline \multirow[t]{3}{*}{$\mathrm{Pu}$} & 1 & 22 & $140 \pm 30$ & - \\
\hline & 2 & 22 & 110 & $1200 \pm 210$ \\
\hline & 3 & 22 & $280 \pm 100$ & $3300 \pm 1200$ \\
\hline
\end{tabular}


The methods for correcting container adsorption and for Rd calculation have been important sources of variability. Because it is most convenient to analyze only the solution phase (both before and after contact with the rock) in a batch test, the Rd calculational scheme assumes that the difference in solution activities represents the amount adsorbed on the rock or sediment. No container appears to be totally inert to interaction with trace constituents in solution [Struempler (1973), Robertson (1968), Relyea et al. (1980b) and Erdal et al. (1979)]. To increase the chance of producing conservative Rd values WRIT staff has normally run blank containers (nuclide-laden solutions but no rock or sediment) alongside the batch tests. The loss of activity from solution in these blanks has been monitored and corrections made to the amount of nuclide presumed to be adsorbed in the batch tests. This method also corrects for inadvertent supersaturation and subsequent precipitation provided that the blanks are maintained at the same $\mathrm{pH}$ and Eh as the rock slurries.

More detailed studies in which the solids were also counted have shown that for elements such as Am, $\mathrm{Pu}$, and lanthanides blank corrections are in fact biasing results low [Relyea and Serne (1979)]. In the containers with rock present, the greater available surface area of the rocks tend to outcompete the container for nuclide adsorption. Thus much smaller percentages of the radionuclide are actually adsorbed on sample container walls than blank tubes would lead one to believe. WRIT staff now recommends that for Rd measurements where accuracy is the major goal (as opposed to scouting and bounding studies) that the actual radioactivity on the solid phase be determined. A novel approach which utilized a container fabricated out of the rock itself was also tested but not pursued further because of its limitations for several porous rock types [Seitz et a1. (1979)]. The effect of choosing different values for the original nuclide solution concentration and whether a blank correction is utilized is dramatically shown in Table 3 [Coles et al. (1980)].

The round-robin results and interpretations lead to the first detailed recommendation for a proposed batch method [Relyea et al. (1980a)]. Further findings have identified steps in the batch methodology that should be specified such that a revised standard batch method recommendation should be issued in FY 1982. The revision should emphasize the need to develop adsorption 
TABLE 3. Rd(Pu) Values on Shales, Climax Stock Shear Zone Material and Thirsty Canyon Tuff

\begin{tabular}{|c|c|c|c|}
\hline Sample & Groundwater & $\begin{array}{c}\text { Method } \\
\text { Calculation } \\
\end{array}$ & $\begin{array}{l}\text { Method }(\mathrm{a}) \\
\text { Calculation }(\mathrm{c}) \\
\end{array}$ \\
\hline Thirsty Canyon Tuff & "Granite" & $190 \pm 20 \%$ & $8,000 \pm 18 \%$ \\
\hline $\begin{array}{l}\text { Green Argillaceous } \\
\text { Shale (20-50 Mesh) }\end{array}$ & "Limestone" & $\geq 10,000$ & $\geq 20,000$ \\
\hline $\begin{array}{l}\text { Conasauga Shale } \\
(20-50 \text { Mesh })\end{array}$ & "Limestone" & $\geq 6,000$ & $\geq 72,000$ \\
\hline $\begin{array}{l}\text { Climax Stock Shear } \\
\text { Zone } 1 \text { (100-325 Mesh) }\end{array}$ & "Granite" & $400 \pm 83 \%$ & $20,000 \pm 80 \%$ \\
\hline $\begin{array}{l}\text { Shear Zone } 2 \\
\text { (100-325 Mesh) }\end{array}$ & "Granite" & $470 \pm 18 \%$ & $19,000 \pm 17 \%$ \\
\hline $\begin{array}{l}\text { Shear Zone } 2 \\
(50-100 \text { Mesh })\end{array}$ & "Granite" & $500 \pm 58 \%$ & $20,000 \pm 56 \%$ \\
\hline $\begin{array}{l}\text { Shear Zone } 3 \\
(<325 \text { Mesh })\end{array}$ & "Granite" & $80 \pm 30 \%$ & $3,700 \pm 25 \%$ \\
\hline $\begin{array}{l}\text { Shear Zone } 3 \\
(100-325 \text { Mesh })\end{array}$ & "Granite" & $30 \pm 65 \%$ & $1,700 \pm 43 \%$ \\
\hline $\begin{array}{l}\text { Shear Zone } 3 \\
(50-100 \text { Mesh })\end{array}$ & "Granite" & $8 \pm 72 \%$ & $900 \pm 24 \%$ \\
\hline
\end{tabular}

(a) Mean \pm lo S.D. of 3 replicates. All experiments run for 7 days.

(b) Using blank as "influent" solution.

(c) Using filtered stock solution as "influent" solution.

isotherms (Rd as a function of nuclide concentration). Results of isotherm studies are proving that distribution coefficients for rocks are exceptionally sensitive to nuclide concentration down to extremely low values. Results for cesium adsorption onto rocks such as basalt and limestone [Seitz et al. (1980)] show Rd dependence on Cs concentrations even as low as $10^{-12} \underline{\mathrm{M}}$ (see $\mathrm{Fig}-$ ures 1 and 2). Clay minerals and soils appear to be less sensitive and exhibit the linear isotherm (constant Rd) versus nuclide concentration at higher concentrations. An example is shown in Figure 3 [Meyer (1979)]. 


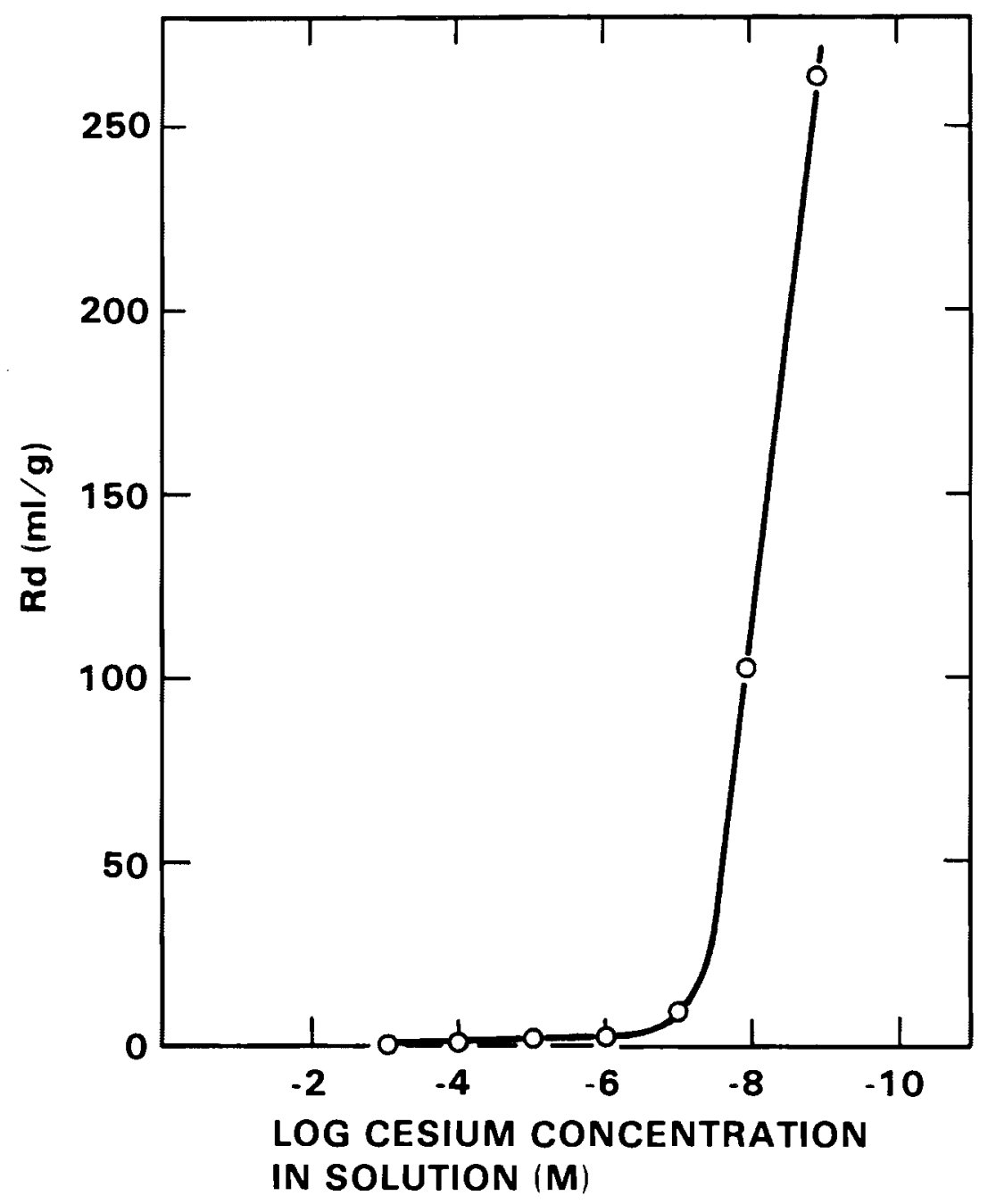

FIGURE 2. Dependence of Cesium Adsorption by Limestone on Cesium Concentration

WRIT batch adsorption studies to date show that Rd results with a precision of 5 to $25 \%$ around the mean value are typical if experimental details such as agitation rate, solution/solid phase separation techniques, tracer addition technique and calculational scheme are standardized and provided the resultant rock surface composition, nuclide concentration, and ground-water composition including Eh and $\mathrm{pH}$ are controlled within a narrow range.

The batch sorption test because of its strengths such as simplicity and cost efficiency [Brandstetter et a1. (1979)] remains the most frequently used test to obtain empirical Rd values. The WRIT staff endorse its use for screening purposes and further recommend that once site-specific Rd values are 


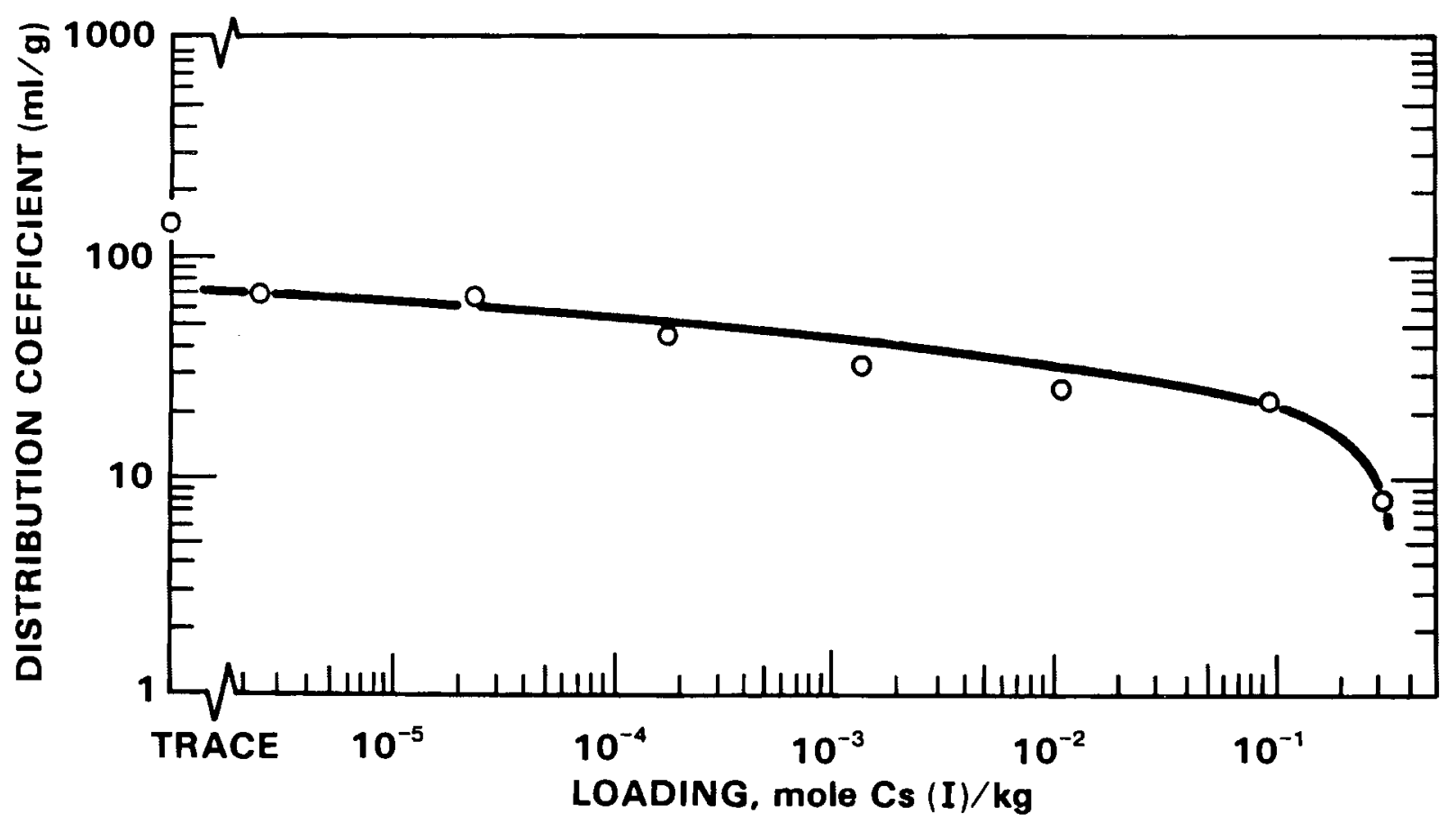

FIGURE 3. Dependence of Cesium Adsorption by Montmorillonite on Amount of Cesium Loaded on the Clay (Amount of Cesium in Solution $(\underline{M})=\operatorname{Rd} \times$ Loading)

necessary that adsorption-desorption isotherms such as the empirical Freundlich isotherm [Travis (1978)] be determined over a realistic range of nuclide concentrations and ground-water compositions as opposed to single Rd determinations. Such empirical relationships could be used for overall safety assessment sensitivity studies and offer insight into probable mechanisms such as precipitation [Barney and Brown (1981)].

Further work is necessary to evaluate the observed Rd dependency on solution to solids ratio [Daniels et al. (1981), Dosch and Lynch (1980) and Ames and McGarrah (1980)] and to quantify the surface area relationship between disaggregated and intact material.

One significant limitation is inherent in the batch methodology. The typical analytical procedure of counting total radioactivity in solution and perhaps the solid does not differentiate multiple species should they be present. The calculational scheme to generate a distribution coefficient using total activities represents a gross average value and cannot separate the distinct sorption values for different species. For instance if a radionuclide 
happened to be equally distributed in a deep ground water between two species that do not rapidly interconvert, one which did not sorb (Rd $=0$ ) and one of which exhibited strong sorption (for example Rd $=1000$ ), the laboratory batch method would yield an intermediate Rd of about $30 \mathrm{ml} / \mathrm{g}$ in an experiment with a solution-to-solid ratio of 30 . The use of the $R d$ value $30 \mathrm{ml} / \mathrm{g}$ in subsequent mass transport calculations would not be conservative as $50 \%$ of the radionuclide would move at the speed of the carrier solution. For this reason when there is any suspicion that multiple species with significantly differing distribution coefficients may be present, a second sorption methodology such as a once-through-flow column sorption experiment should be run to search for early breakthrough. One could also perform a second batch experiment with the effluent from the first experiment to verify whether sorption continues.

\section{Column Methods}

Once-through-flow column sorption experiments are the second most used laboratory method. The classical use of once-through-flow column sorption testing has been on permeable sediments and soils. The method has been used for many years to verify Rd values determined by batch methods LRoutson and Serne (1972)]. WRIT has funded the development of procedures and high-pressure apparatus to modify the flow-through method to allow experimentation on intact and fissured rock with low permeability.

Once-through-flow column experiments are appealing in that they allow observation of nuclide migration rates without significant rock alteration (such as crushing). Hydrodynamic effects (dispersion, colloidal transport etc.) as well as chemical phenomena (multiple species, reversibility, etc.) can be studied. Ideally once-through-flow column experiments would be used exclusively but equipment costs, time constraints, experimental complications and data reduction uncertainties often discourage potential users.

Typical equipment used in column experiments include a cylindrical holder for the rock or sediment, a pump to control the solution flow rate, an automatic fraction collector to collect effluent aliquots and connecting tubing and end caps to constrain and support the rock or sediment. For very slow flow 
situations, typical of deep geologic repositories, a controlled atmospherel humidity chamber is necessary to simulate redox conditions and minimize effluent evaporation. For disaggregated or porous materials such as soils, the experimental methodology is well developed [Serne et al. (1974), Nielsen and Biggar (1961), Passioura and Rose (1971), van Genuchten et a1. (1977)]. For low permeability material such as crystalline rock, special high-pressure confining jackets and pumps are needed to promote reasonable water flow rates. Costs for such equipment often reach $\$ 15,000$ to $\$ 25,000$. Further, the highpressure apparatus used for sorption studies are generally small scale and accept cores of only a few centimeters in diameter by a few centimeters in length. Sample homogeneity problems can become quite serious for such small samples, especially for fractured or fissured rock which necessitate samples of several meters dimensions to accurately simulate field hydrologic conditions. The greatest experimental problem in performing core sorption tests on low permeability samples has been solution short-circuiting along the interface of the rock and the confining jacket or column. Solution traveling down the interface does not interact appreciably with the rock and yields premature breakthrough of radionuclides [Daniels et al. (1981)]. It is often difficult to judge whether short-circuiting is occurring so applicability of results is often indeterminable.

Two other practical constraints are time available for experimentation and frequency of equipment failure. The flow of water through low permeability rock is extremely slow unless large hydraulic gradients are imposed. This, coupled with the retardation most radionuclides encounter, creates breakthrough times often exceeding a few years for centimeter-long columns. Few experimenters will accept these long periods, and they usually resort to small columns (millimeters), high-pressure-induced increased pore velocities or both. The short column and increased water velocity significantly reduce water and nuclide residence times within the rock. The reduced residence time increases the likelihood that kinetic effects will become significant within the laboratory experiment.

Further, failure of equipment, especially pumps and fraction collectors, put practical constraints on laboratory experimentation. Experience at PNL 
shows that one can expect some sort of equipment failure about every 3 or 4 months. To minimize down-time, it is advantageous to have an extra complete set-up so that a pump or fraction collector may be exchanged while the broken one is being serviced.

Seitz et al. (1979, 1980) discuss several column experiments where kinetics appears to be creating more rapid breakthrough because the short residence times do not allow nuclide interactions to reach equilibrium. Kuhn and Peters (1981) present mathematical arguments which conclude that the repository setting includes ground-water velocities and pathlengths sufficiently low and long, respectively, to allow nuclide sorption equilibrium to occur. Pickens et al. (1981) remark that for some near-surface aquifers (coarse grained sediments) pore velocities are such that nuclide adsorption equilibria do not occur. Pickens et als' results perhaps represent the opposite end of the spectrum from deep-geologic repositories. More evaluation of the kinetic aspects of nuclide adsorption under plausible repository conditions is warranted and kinetics definitely must be considered in evaluating laboratory sorption studies. Otherwise, the results obtained at less than realistic residence times can bias nuclide retardation results.

A final complication in using column data has been interpretation of asymmetric or peakless breakthrough curves. When ideal chromatographic peaks are observed in column tests of porous or fractured rock, Rd can be calculated or Rf, a nuclide retardation factor (ratio of the travel time of the radionuclide to the travel time of the carrier ground water), can be directly evaluated using well-established equations [Burkholder et al. (1979), Inoue and Kaufman (1963), and Harada et a1. (1980)]. There also exist several solutions that can describe slightly asymetric breakthrough peaks, such as those discussed in van Genuchten et a1. (1974), Pigford et al. (1981), Gee and Campbel1 (1980), and Gee et al. (1981). In several WRIT-sponsored column nuclide adsorption experiments peakless breakthroughs of solution have been observed [Rickert (1981), Vine et a1. (1981) and Daniels et a1. (1981)]. The frequent occurrence of these peakless curves warrants attention to ascertain whether experimental artifacts such as core/holder interface leakage or selective channeling over 
the small core lengths is occurring. Should the peakless breakthrough curves prove to be accurate reflections of expected deep geologic nuclide transport, methods to calculate a distribution coefficient (Rd), nuclide retardation factor $(R f)$ or to predict radionuclide solution concentrations will be needed.

Further work is needed to advance the state-of-the-art for column experimentation on low permeability rock. The observable short-circuit leaking malfunction rate still exceeds $30 \%$ of the experiments attempted and other peakless results occur and are presently uninterpretable.

Column methods on disaggregated or porous rock are available but are of limited usefulness because of residence time constraints for nuclides with appreciable adsorption. Current techniques that force rapid flow under highpressure gradients may be biasing results low due to nonequilibrium kinetic effects.

Two WRIT-sponsored topical reports on flow-through-column sorption methodology will be prepared in 1981 by Los Alamos National Laboratory and Lawrence Livermore National Laboratory, respectively. Shortly thereafter a review report that recommends a column procedure which should be submitted for certification will be prepared by WRIT staff. [See Serne (1978b), Serne (1979), Relyea (1980) and Relyea (1981) for discussions leading up to these reports.]

At present WRIT staff recommend that once-through-flow column experiments be used in concert with batch sorption experiments to produce the most credible bounding values for nuclide retardation. Replicated batch tests should be performed over a range of nuclide concentrations and ground-water compositions on several samples of rock to delineate the probable range of Rd values for each nuclide. In addition, such batch tests would delineate the concentration of nuclides at which confounding reactions such as precipitation or polymerization might occur. Rd studies versus time should allow estimates of the importance of kinetics on sorption. To support the batch Rd values, oncethrough-flow column experiments at nuclide concentrations below solubility constraints and at realistic residence times should be performed. Effluent breakthrough curves should be monitored for low sorbing elements and for "leakage" of highly sorbing elements. Attempts should be made to verify whether the "leakage" is caused by actual mobile species, colloid transport or 
column short-circuiting. After a reasonable period of time ( 3 to 6 months) the column should be sectioned and the distribution versus distance of strongly adsorbing nuclides determined to qualitatively verify batch Rd values.

Other Methods

Two laboratory methods under study in 1976 through 1978, axial filtration and channel chromatography, have been dropped from further consideration due to their large equipment and complex data reduction requirements, respectively. Descriptions of these methods and a discussion of their strengths and weaknesses are found in Meyer et al. (1978 and 1980), Meyer (1979), Triolo et al. (1979), Francis and Reeves (1978) Francis et al. (1979) and Brandstetter et al. (1979).

Recently a recirculating-column technique [Daniels et al. (1981)] has been used to investigate whether self-grinding in batch systems is the cause of slow increases in Rd with time and larger Rd values than comparable column experiments. The recirculating column is a hybrid technique that is a closed system like the batch test and relies on recirculating flow to provide solution/rock contact. The porous rock, disaggregated or intact, is fixed such that particle abrasion is minimal. A reservoir of solution is present to adjust the system solution-to-solid ratio to be equal to that used in comparable batch tests. Contact time can also be adjusted to equal that in a batch test. At this writing too few results are available to determine whether the recirculating-column method offers advantages over the batch and once-through-flow methods or complements these commonly used methods.

\section{Rd Value Comparisons by Different Laboratory Sorption Techniques}

Ideally the distribution coefficient obtained via experimentation for a particular radionuclide for any given rock/ground water system at equilibrium should not vary or depend upon the experimental technique used. The previous discussions on the laboratory methods indicated the subtleties and difficulties encountered in assurring that the actual rock/ground water radionuclide system being studied by one experimental technique can be reproduced by a second technique. Although the large number of variables present make it nearly impossible to duplicate all conditions, studies have been performed on the sensitivity 
of Rd to changes in individual parameters. However, it is still difficult to provide sweeping and general conclusions about the sensitivity of Rd to any one parameter while allowing other parameters to vary over plausible deep-geologic environmental ranges. As more variables are fixed or allowed only small changes, it becomes more sensible and possible to describe the effects of perturbations of a few select parameters on the Rd value. That is, empirical Rd values are unique only when site-specific conditions are chosen and set.

The following types of Rd value comparisons have been obtained when experimenters applied different test methods but carefully held constant as many variables as possible among the rock/ground water/nuclide parameters. Table 4 gives examples of Rd comparisons among two or more methodologies. These comparisons are based on studies where care was taken to maximize the experimental variables that remained similar between tests. Results do not cover a large number of nuclides but concentrate on more well-behaved elements such as $\mathrm{Sr}, \mathrm{Cs}$ and $\mathrm{Ba}$. Thus, a definitive and comprehensive comparison is not possible at present. The comparisọn, for the cases cited, shows batch Rd values are greater than or equal to Rd values from once-through disaggregated or intact cores by a factor of three to six, and in one instance, a factor of ten. An exception is the sandstone sorption of $\mathrm{Sr}$ from brine in which case the intact core data yield a larger Rd value. At present this observation is not explainable. For other isotopes that exhibit large ( $>500 \mathrm{ml} / \mathrm{g}$ ) Rd values, such as typically found for lanthanides and Am and Pu, column experiments will need to run for very long times or at significantly increased velocities to produce breakthrough. Because of kinetic and potential short circuit effects mentioned previously, it is not too surprising that available comparisons that rely on small columns and shortened residence times yield lower Rd results than batch.

Until more definitive work is available, such as studies using both batch and once-through-flow column methods, WRIT staff suggest that batch Rd values for elements that exhibit moderate sorption (Rd $<50 \mathrm{ml} / \mathrm{g}$ ) could be reduced by a factor of three while batch Rd values between 50 and $300 \mathrm{ml} / \mathrm{g}$ could be reduced by a factor of five when being used in conservative safety assessments. For elements which exhibit batch Rd values $>300 \mathrm{ml} / \mathrm{g}$ batch values could be 


\section{TABLE 4. Rd Value Comparisons Among Methods}

\begin{tabular}{|c|c|c|c|c|c|c|}
\hline Rock/GW Type & $\begin{array}{l}\text { Axial } \\
\text { Filter } \\
\end{array}$ & $\begin{array}{l}\text { Channe } 1 \\
\text { Chrom. }\end{array}$ & Batch & $\begin{array}{l}\text { Crushed } \\
\text { Column }\end{array}$ & Intact Core & $\begin{array}{l}\text { Recirculating } \\
\text { Column }\end{array}$ \\
\hline $\begin{array}{l}\text { Shale/0.1 M/Ca }\left(\mathrm{NO}_{3}\right)_{2} \\
\mathrm{Rd} \mathrm{Ni} \\
\mathrm{Rd} \mathrm{Sr}\end{array}$ & & $\begin{array}{l}5-9 \\
2-4\end{array}$ & $\begin{array}{l}6.5 \\
2.4\end{array}$ & & & \\
\hline $\begin{array}{l}\text { Montmorillonite/0.6M NaCl } \\
\quad \mathrm{Rd} \mathrm{Sr}\end{array}$ & 3.8 & & 4 & 4.2 & & \\
\hline $\begin{array}{l}\text { Kazenta, Berea } \\
\text { St. Peter Sandstone/ } \\
\text { WIPP Brine B } \\
\text { Rd Sr }\end{array}$ & & & $\begin{array}{l}-0.11 \text { to } \\
-0.13\end{array}$ & & 0.012 to 0.019 & \\
\hline $\begin{array}{l}\text { San Felipe Sandstone/ } \\
\text { WIPP Brine B } \\
\text { RD Sr }\end{array}$ & & & 0.01 & & 0.098 & \\
\hline $\begin{array}{l}\text { Yucca Mt. Tuff/Tuff GW } \\
\text { Rd Sr } \\
\text { Rd Cs } \\
\text { Rd Ba }\end{array}$ & & & $\begin{array}{l}50,84(a) \\
290,250 \\
900,620\end{array}$ & $\begin{array}{l}30,44 \\
120,100 \\
360,120\end{array}$ & 20 & $\begin{array}{l}23,45 \\
410,120 \\
105,130\end{array}$ \\
\hline $\begin{array}{l}\text { Jackass Flats Tuff/ } \\
\text { Tuff GW }\end{array}$ & & & & & & \\
\hline $\begin{array}{l}\mathrm{Rd} S \mathrm{Sr} \\
\mathrm{Rd} \mathrm{Cs} \\
\mathrm{Rd} \mathrm{Bd}\end{array}$ & & & $\begin{array}{l}300 \\
740 \\
835\end{array}$ & $\begin{array}{l}110 \\
>600(a)\end{array}$ & & $\begin{array}{l}390 \\
1770 \\
860\end{array}$ \\
\hline $\begin{array}{l}\text { Climax Stock Granite/ } \\
\text { Granite GW } \\
\text { Rd Sr } \\
\text { Rd Cs } \\
\text { Rd Ba }\end{array}$ & & & $\begin{array}{l}14 \text { to } 18 \\
330 \text { to } 350 \\
150 \text { to } 180\end{array}$ & $\begin{array}{l}10 \text { to } 25 \\
>600 \\
32 \text { to } 44\end{array}$ & & \\
\hline $\begin{array}{l}\text { Eleana Argillite/ } \\
\text { Argillite GW } \\
\text { Rd Sr } \\
\text { Rd Cs }\end{array}$ & & & $\begin{array}{l}140 \text { to } 160 \\
1500 \text { to } 1800\end{array}$ & $\begin{array}{l}40 \text { to } 50 \\
7600(a)\end{array}$ & & \\
\hline $\begin{array}{l}\text { Columbia Plateau Basalt/ } \\
\text { Basalt GW } \\
\text { Rf (Cs) at } \mathrm{Cs}<10-8 \mathrm{M} \\
\text { at } \mathrm{Cs}>10-7 \mathrm{M}\end{array}$ & & & $\begin{array}{l}1000 \text { to } 1100 \\
170 \text { to } 300\end{array}$ & $\begin{array}{l}170 \text { to } 190 \\
25 \text { to } 125\end{array}$ & & \\
\hline $\begin{array}{l}\text { Oolitic Limestone } \\
\text { Limestone GW } \\
\text { Rd Cs }\end{array}$ & & & 80 & 120 & & \\
\hline
\end{tabular}

(a) Two distinct Yucca Mt. samples.

reduced by a factor of 10 to increase conservatism. For elements with a batch Rd less than $20 \mathrm{ml} / \mathrm{g}$ WRIT staff recommend that actual column experiments be performed at realistic residence times to gather more data to evaluate methodology dependence. Finally, NWTS systems modelers should perform sensitivity calculations to ascertain whether differences in Rd factors of a factor of three to ten are in fact significant in preliminary safety assessment and site selection exercises. 
AVAILABILITY OF EMPIRICAL Rd VALUES

Thousands of Rd values have been generated in the past decade in efforts to support shallow-land and deep-geologic nuclear waste disposal. In addition, WRIT has generated Rd values while evaluating laboratory methodology and while investigating sorption mechanisms. In the latter instance a wealth of characterization data on the rocks, sediments, minerals, macro and trace constituents (including the radionuclides) and the experimental details have been generated. Experiments have been performed to ascertain the sensitivity of Rd to parameters such as temperature (up to $\sim 80^{\circ} \mathrm{C}$ ), equilibration time (up to approximately eight months), changes in ground water $\mathrm{pH}$, Eh and dissolved solids content (up to $\underline{5} \mathrm{M} \mathrm{NaCl}$ ) and changes in nuclide concentration. These parametric studies were performed with the intent to focus more detailed mechanism studies on only the more important parameters. In addition, these wellcharacterized studies yield valuable empirical data that can be statistically analyzed to produce Rd relationships that are functions of important independent variables (rock, ground water and nuclide characteristics). Although the calculated relationships do not prove "cause and effect" they do allow predictions. Thus, from finite generic Rd data, estimates can be made of Rd values for environmental conditions not directly studied.

A statistical analysis was performed on a selected Rd data base developed at PNL [Relyea et al. (1978), (1979a)] consisting of seven radionuclides, four synthetic ground waters, 12 minerals and four rocks. The analysis showed that Rd empirical models are feasible and lead to valuable predictor capabilities. Table 5 shows empirical model predictions versus actual experimental values for studies not included in the data base used to create the model. The nonlinear statistical technique, adaptive learning networks (ALN), was employed [Mucciardi et al. $(1979,1980)]$. The analys is of the minerals suggests that better predictive models can be developed when mineral groups (phyllosilicates, tektosilicates, inosilicates, etc.) are treated separately. The analyzed data also suggest that extremely high ionic strength (salt brine) ground waters should be treated separately from typical fresh waters. The large gap in solution concentrations between freshwaters $(\leq 0.3 \underline{M})$ and the brine $(5 \underline{M})$ and nonlinear mathematical relationships made intermediate interpolations difficult. 
TABLE 5. Comparison of Actual and Predicted $\mathrm{Sr}$ and Am Adsorption Rd's for Data not Used in Model Synthes is

\begin{tabular}{|c|c|c|}
\hline \multirow{2}{*}{$\begin{array}{l}\text { Observation } \\
\text { Number } \\
\end{array}$} & \multicolumn{2}{|c|}{$R_{d}(S r)$} \\
\hline & Actual & Predicted \\
\hline 1 & 2.0 & 1.7 \\
\hline 2 & 3.2 & 2.8 \\
\hline 3 & 43.7 & 44.4 \\
\hline 4 & 293.0 & 246.7 \\
\hline 5 & 2.7 & 1.6 \\
\hline 6 & 2.6 & 2.7 \\
\hline 7 & 51.0 & 43.7 \\
\hline 8 & 123.0 & 192.5 \\
\hline 9 & 5.6 & 6.3 \\
\hline 10 & 3.9 & 3.8 \\
\hline 11 & 69.1 & 61.0 \\
\hline 12 & 635.0 & 653.7 \\
\hline
\end{tabular}

Correlation Coefficient Between Actual and Predicted $R_{d}(S r)=0.991$

13

14

15

16

17

18

19

20

21

22

23

24

25

26

27

\begin{tabular}{rr}
$\mathrm{R}_{\mathrm{d}}$ & \\
\hline 18,170 & $($ Am $)$ \\
1,593 & 2,957 \\
7,162 & 12,198 \\
450 & 822 \\
250 & 159
\end{tabular}

$$
71,455
$$

105

1,815

153

4,469

14,258

213

246

4,473

16,430
22,157

103

1,770

150

2,248

18,996

182

387

2,267

10,016

Correlation Coefficient Between Actual and Predicted $R_{d}(A m)=0.804$ 
It is important to realize that empirical Rd relationships are more powerful tools than Rd values themselves because Rd values only represent sorption for a unique set of rock, ground water and nuclide conditions whereas empirical relationships such as ALN models can be created to describe Rds as a function of important rock and ground water characteristics. Safety assessment codes based on numerical approximation techniques as opposed to closed-form analytical solutions can accommodate Rd relationships, however complicated, as well as accept single Rd values. Statistical relationships such as ALN models allow predictions of the sorption distribution coefficients with changes in the environmental parameters.

The WRIT generic Rd data bank presently includes data on many long-lived nuclides for rocks, sediments and minerals common to six potential repository rock types (domed salt, bedded salt, granite, shale, basalt and tuff) with a wide range of plausible ground-water compositions. Rd data from other NWTS programs (tuff data from Nevada Nuclear Waste Storage Investigations, NNWSI, and basalt data from the Basalt Waste Isolation Program, BWIP), the Waste Isolation Pilot Program (WIPP) (sedimentary rocks in contact with brines) and international programs (granite data from Sweden and granite and metamorphic rock data from (anada) supplement the WRIT data. These data and others will be critically reviewed, and selected data will be installed into a computer data management system fashioned after the Sorption Information Retrieval System (SIRS) [Hostetler et a1. (1979, 1980)]. The computerized information retrieval system will 1) greatly increase the efficiency in managing the mass of available data, 2) provide an auditable method for choosing sorption distribution coefficients for safety assessments, site selection and licensing pursuits and 3 ) aid research on mechanism studies and statistical studies to identify controlling parameters.

To aid preliminary safety, siting and licensing activities WRIT staff have reviewed available sorption data and constructed Tables 6 and 7 which present empirical sorption distribution coefficients for redox insensitive elements and redox sensitive elements, respectively. Rd values were selected from actual experimental data when possible. Conservative values (low values) were selected from the range of values available because the quantity and quality 
TABLE 6. Rd Values for Radionuclides not Affected by Redox

\begin{tabular}{|c|c|c|c|c|c|}
\hline \multirow[b]{2}{*}{ Isotope } & \multicolumn{5}{|c|}{$\operatorname{Rd}(\mathrm{ml} / \mathrm{g})^{(a)}$} \\
\hline & $\begin{array}{c}\text { Bedded }(b) \\
\text { Salt } \\
\end{array}$ & $\begin{array}{l}\text { Dome } \\
\text { Salt } \\
\end{array}$ & Basalt & Tuff & Granite \\
\hline $3_{H}$ & 0 & 0 & 0 & 0 & 0 \\
\hline $14_{H}$ & 0 & 0 & 0 & 0 & 0 \\
\hline${ }^{36} \mathrm{Cl}$ & 0 & 0 & 0 & 0 & 0 \\
\hline $59,63 \mathrm{Ni}$ & 1 & 10 & 50 & 50 & 10 \\
\hline $85 \mathrm{kr}$ & 0 & 0 & 0 & 0 & 0 \\
\hline $90 \mathrm{Sr}$ & 0.5 & 8 & 100 & 100 & 12 \\
\hline $93 \mathrm{Zr}$ & 500 & 500 & 500 & 500 & 500 \\
\hline${ }^{94} \mathrm{Nb}$ & 50 & 50 & 100 & 100 & 100 \\
\hline $107 \mathrm{Pd}$ & 1 & 5 & 50 & 50 & 10 \\
\hline${ }^{129} 9_{I}$ & 0 & 0 & 0 & 0 & 0 \\
\hline $135,137 \mathrm{Cs}$ & 1 & 800 & 300 & 100 & 300 \\
\hline${ }^{154} \mathrm{Eu}$ & 50 & 50 & 50 & 50 & 100 \\
\hline${ }^{151_{S m}}$ & 50 & 50 & 50 & 50 & 100 \\
\hline $210_{\mathrm{Pb}}$ & 0.5 & 5 & 25 & 25 & 5 \\
\hline${ }^{226} \mathrm{Ra}$ & 0.5 & 8 & 50 & 200 & 50 \\
\hline${ }^{227} \mathrm{AC}$ & 50 & 50 & 50 & 50 & 200 \\
\hline${ }^{230} \mathrm{Th}$ & 50 & 100 & 500 & 500 & 500 \\
\hline $231_{\mathrm{Pa}}$ & 50 & 50 & 100 & 100 & 100 \\
\hline $241,243 \mathrm{Am}$ & 300 & 300 & 50 & 50 & 200 \\
\hline $242,244 \mathrm{Cm}$ & 300 & 300 & 50 & 50 & 200 \\
\hline
\end{tabular}

(a) Rd ( $\mathrm{ml} / \mathrm{g})$ is utilized for porous flow, for fracture flow one must normalize the values to available surface area not mass.

(b) Sorption values are for typical sedimentary rocks associated with salt, not the salt per se. 
TABLE 7. Rd Values for Redox Sensitive Elements $\operatorname{Rd}(\mathrm{ml} / \mathrm{g})^{(\mathrm{a})}$

(a) Rd $(\mathrm{ml} / \mathrm{g})$ is utilized for porous flow, for fracture flow one must normalize the values to available surface area not mass

(b) Sorption values are for typical sedimentary rocks associated with salt, not the salt per se.

(c) Red = reducing conditions sufficient for radionuclide to be more stable in lower valence state.

(d) $\quad 0 X$ = oxidizing conditions sufficient to oxidize radionuclide from lower to upper valence state.

of available data varies and it is difficult to select most probable values without more specific information. Many available Rd values were found to be invalid because radionuclide concentrations used in the experiments were too high, resulting in precipitation as well as sorption. Other values were discarded because of lack of or improper control of redox conditions. Nearly all available data were determined on disaggregated material.

For nuclides where no experimental data were found, estimates were made based on the known chemical behavior of that radionuclide or the behavior of similar elements. As mentioned, Table 6 lists those Rd values for radionuclides that are not expected to be directly affected by redox reactions, i.e., they are expected to exist in the same oxidation state under both oxidizing and reducing conditions. Elements in Table 6 may be affected indirectly by redox conditions (changes in ground-water chemistry and mineral 
stability) and thus the terminology "redox insensitive" should not be taken literally. Table 7 gives Rd values for those elements that are expected to exhibit different behavior under differing oxidation-reduction conditions.

The concept of Rd for those radionuclides that are affected by redox potential may be only marginally applicable (for example Pu, Se, Np, Tc and Mo). Under reducing conditions, their removal from solution appears to be primarily caused by the precipitation of a lower oxidation state compound [Bondietti and Francis (1979)]. Solubilities of the precipitated compounds are poorly known but believed to be extremely low; thus, there may be no need to invoke sorption to explain the low solution concentrations observed. This behavior is similar to the behavior of phosphate in soils, which is more likely controlled by the precipitation of its solid compounds.

Of the five media considered in these two tables, Rd data availability for rocks associated with domed salt is poorest, while availability of data for basalt, tuff and granite is best. In general laboratory data for sorption under reducing conditions needs improvement in quantity and especially quality.

For preliminary assessments, available laboratory values of Rd (typified by data presented in Tables 6 and 7) should be adequate. If these values, which most likely are lower than values to be expected over very long time periods, are large enough to reduce environmental effects to acceptable levels, more comprehensive studies at longer contact times may not be necessary. Longterm processes such as weathering of rock to secondary minerals (e.g., clays, zeolites and amorphous hydrous oxides) should increase the sorption of nuclides by increasing available surface area and exchange sites. In addition, nuclide diffusion into the bulk matrix over long-time periods should also increase retardation in low permeability rocks. Further, studies discussed later show that nuclides tend to desorb off rocks, sediments and minerals more slowly and reach larger steady state Rd values than those measured during adsorption. Presently WRIT cannot explain thoroughly why the desorption process differs from adsorption but several plausible hypotheses are given later. Even without an understanding of the controlling mechanisms, second generation safety assessment models might incorporate at a minimum a two-valued-Rd variable (Rd adsorption and Rd desorption). An even more defensible empirical approach 
would be incorporation of adsorption and desorption isotherms that would describe the distribution coefficient dependency on total elemental concentration.

\section{ADSORPTION-DESORPTION MECHANISM STUDIES}

Results from the empirical approach to describing adsorption-desorption, although useful in assessing the migration potential of radionuclides, are very specific to the particular host rock and ground water studied. Thus, the empirical approach in itself does not lead to a general understanding of the physicochemical processes controlling the interactions among rocks, ground waters and trace concentrations of radionuclides. Nor do the empirical results lend themselves to extrapolation to other conditions not studied. Therefore, mechanism studies are used to investigate those factors and interactions that control the adsorption-desorption behavior of actinides, long-lived fission products, and activation products in rocks. With knowledge of nuclide retardation mechanisms, more defensible migration rate predictions can be performed for any proposed storage environment. The use of theoretical constructs and fundamental data will enhance the credibility of long-term predictions and should reduce the costs of quantifying the migration rates of nuclides at specific sites.

For a full understanding of radionuclide behavior, one must understand the radionuclide chemistry as it affects various retardation mechanisms. Figure 4 identifies two processes (formation-dissolution of minerals and precipitates; exchange and surface adsorption) which largely determine radionuclide concentrations in solution that are available for ground-water transport. Figure 4 also lists the types of data required to understand these processes: 1) accurate thermodynamic data on solid phases and solution species that may be present or may form, 2) adsorption-desorption isotherms, 3) equations that quantify effects of different factors as they influence exchange, adsorption, precipitation and dissolution, and solution species, and 4) mineralogical and physicochemical properties of the rocks and sediments. The figure emphasizes far-field interactions away from the near-field thermal and radiation zone neighboring the waste container. 


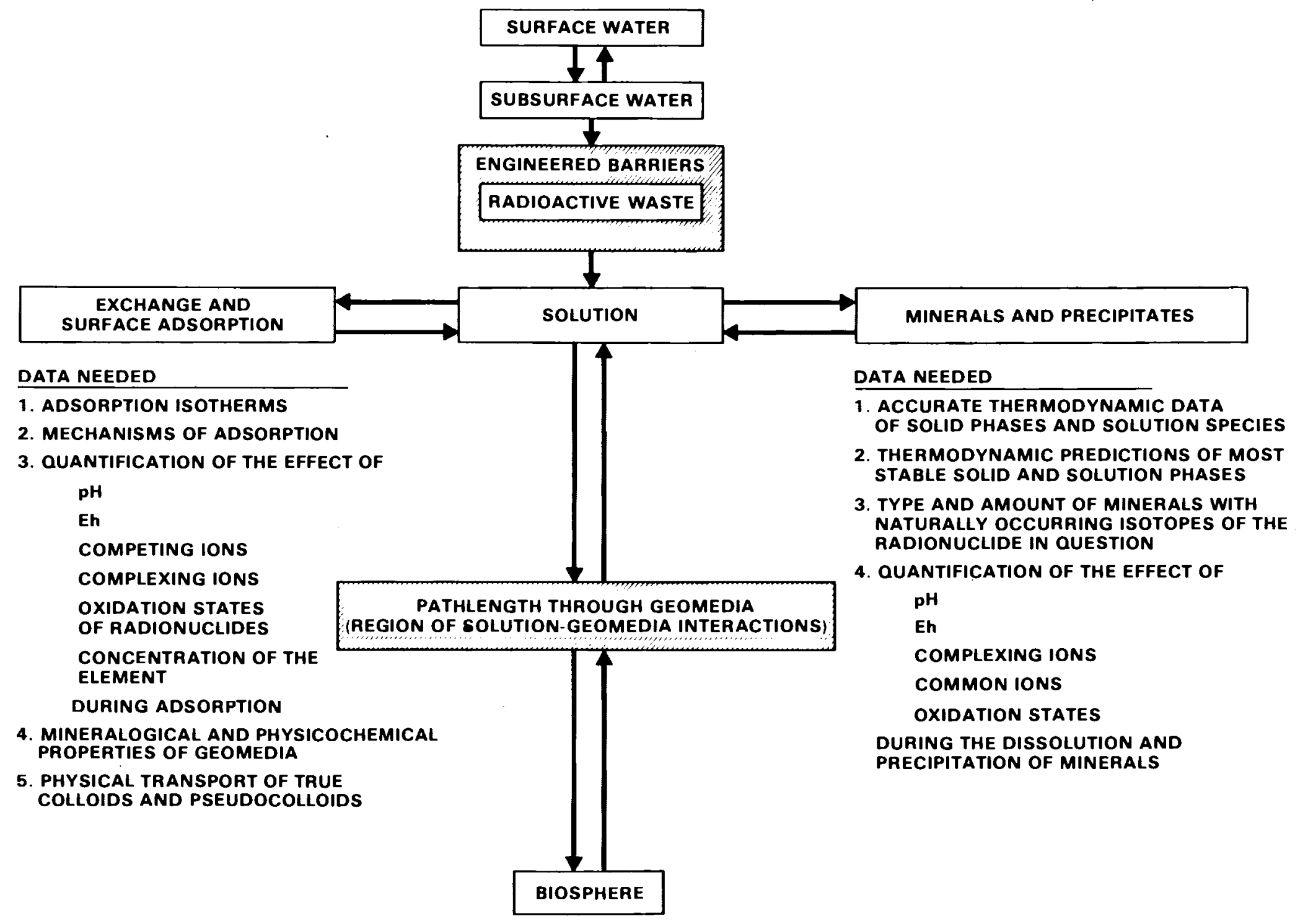

FIGURE 4. Conceptualization of Important Nuclide Retardation Processes, Needed Data and Interactions with System Components for the Far-Field 
Although WRIT performs studies to determine solubility products and solution complex stability constants [see Rai et al. (1980a,b) and Wood and Rai (1981)], such important studies are not discussed herein only to focus the discussion on adsorption-desorption. However, the reader should consider that solubility and solution complexation processes act in conjunction with adsorption to control the overall nuclide behavior.

The following five subsections discuss details on specific mechanism studies which are underway. The first subsection, Scouting Studies, describes WRIT's first efforts which were similar to a parametric study to identify the most important ground-water and rock characteristics that control adsorption. Once identified, specific mechanism studies were developed. The second subsection describes efforts to identify the applicability of ideal ion exchange theory to nuclide adsorption on rocks and minerals. The theory of ion exchange is well developed for industrial purposes and, if applicable to radionuclide adsorption onto rocks, would provide a well-understood prediction capability. The third subsection discusses the status of work to assess the applicability of a more generalized adsorption theory, the site-binding electrical doublelayer model. This model considers ion exchange and surface adsorption as the formation of a complex between the solid substrate and a solution species. The fourth subsection presents findings on redox mediated nuclide retardation. The scouting studies identified the redox potential as a key parameter that affected the retardation of radionuclides, especially multivalent elements. For these redox mediated reactions the actual mechanism of nuclide retardation appears to be a precipitation process. Results will be discussed to reinforce the fact that surface adsorption and precipitation processes work in concert to restrict nuclide migration. The fifth subsection discusses detailed rock and sediment studies to identify actual sites within the solid substrate where nuclides are bound. In the past most studies concentrated on detailed solution characterization. To better identify adsorption mechanisms WRIT has instituted detailed characterization of both the solid and solution. Recent advancements in surface science instrumentation should greatly improve the scientists' ability to study solids and to identify adsorption sites. 
Scouting Studies

Many of the empirical sorption studies were performed with a dual purpose: 1) to generate generic Rd values to support safety assessment, waste package design and site selection activities, and 2) to select the important parameters (temperature, $\mathrm{pH}$, Eh, ground-water composition, etc.) for subsequent mechanisms studies. Rd sensitivity to such parameters gives indications of which processes might be controlling nuclide retardation. For instance, when Rd is sensitive to ground-water macro-cation concentrations $\left(\mathrm{Na}^{+}, \mathrm{Ca}^{+2}, \mathrm{Mg}^{+2}\right.$ and $\mathrm{K}^{+}$), the retardation mechanism is likely a cation exchange process if other variables were held constant. When Rd is sensitive to changes in Eh and the solution chemistry of the nuclide is known to exhibit multi-valent species, the change in predominant solution species (Eh mediated) is the probable process causing different Rd values.

Variables which have been systematically studied include temperature, particle size of rock or sediment used, $\mathrm{pH}$, atmospheric gas composition (an attempt at Eh control), ground-water ionic strength, nuclide concentration or exchange site loading, equilibration time and reversibility between adsorptiondesorption. [See Serne (1978b, 1979) and Relyea (1980, 1981) for details].

Studies of temperature effects have shown that sorption of most radionuclides is not significantly affected by temperature variations within the range $20^{\circ}$ to $80^{\circ} \mathrm{C}$. Thus, for expected far-field environments the effects of temperature variations on radionuclide sorption need not be a concern and laboratory or field studies performed near room temperature should be applicable.

The particle size of disaggregated rocks used in laboratory experiments has been varied from about $50 \mu \mathrm{m}$ up to cubic centimeter sized tablets. In general Rd values reported on a weight basis show that Rd increases as the particle size decreases or available surface area increases. Measurements of surface area by either the BET [Branauer, Emmet and Teller (1938)] or ethylene glycol methods [Bower and Goertzen (1959), Rai and Franklin (1978)] do not correlate consistently with observed Rd values. The increase in Rd with decrease in particle size (over the range studied) is seldom as large as two orders of magnitude, often a factor of 3 to 10 or less. Thus compared to other variables the particle size is of moderate importance. An important and as 
yet unresolved problem is to obtain scaling factors to convert laboratory sorption data on freshly disaggragated material to equivalent sorption values on in-situ fractured rock with low matrix porosity. The use of measured surface areas for disaggragated material has yielded inconclusive results.

Ground waters are typically well buffered by the geologic setting through which they flow. Thus for far-field studies large pH changes are not expected. The few studies performed by WRIT show that actinide, rare earth and transition metal adsorption is sensitive to $\mathrm{pH}$ changes. The most dramatic changes (for example see Figure 5) occur between $\mathrm{pH} 4$ and 6 which is below the range of expected deep ground-water pH values. [The data plotted in Figure 5 are taken from Allard and Beall (1979)]. WRIT studies typically show increased nuclide adsorption as the $\mathrm{pH}$ increases. In the $\mathrm{pH}$ region 6 to 10 the $\mathrm{pH}$ effects on apparent Am sorption (shown in Figure 5) appear to be explained by a solubility constraint [Rai et al. (1981)]. WRIT staff conclude that over the pH range of interest ( 6 to 10) surface adsorption reactions on layer-type clays are not significantly affected but that overall nuclide solution concentrations can be very dependent on hydrolysis reactions that limit solubility and change nuclide speciation. Further adsorption by hydrous oxides which exhibit variable capacity and surface charge with $\mathrm{pH}$ is significantly effected by changes in $\mathrm{pH}$ [Shiao et al. (1981)]. Thus the overall nuclide retardation potential (adsorption plus precipitation) can be significantly affected by changes in $\mathrm{pH}$.

Several WRIT studies have shown that the oxidation-reduction potential present in the rock/ground-water system can significantly affect the observed nuclide retardation properties for multivalent elements such as TC and Np [Bondietti and Francis (1979) and Daniels et al. (1981)]. The increased Tc and Np apparent adsorption at lower-than-atmospheric oxygen fugacites (assumed to be equivalent to reducing conditions) appears to be explained by the large solubility decrease predicted thermodynamically for these elements when conditions change from oxidizing to reducing. The experiments to date which use controlled atmosphere chambers are too limited by atmospheric leaks to readily reach the low oxygen levels projected for some deep geologic environments such as basalt [Smith et a1. (1980)]. Therefore, acceptable methods to create and 


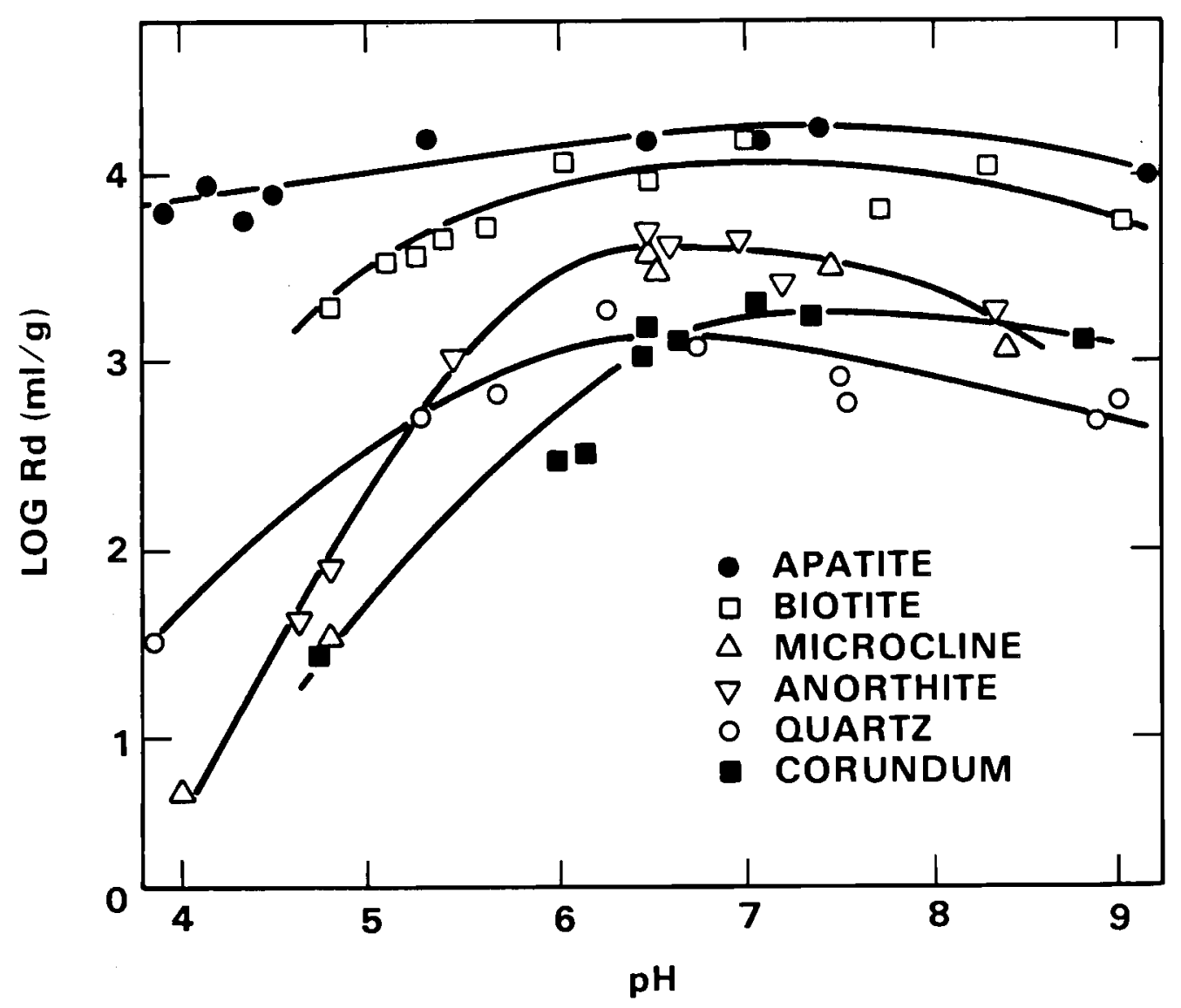

FIGURE 5. The Effect of Ground-Water pH on the Adsorption of Am on Various Rock-Forming Minerals

control reducing (low Eh) conditions in the laboratory to allow nuclide solubility, adsorption and solution complexation studies should be a high priority endeavor within the NWTS program.

The effect of ionic strength changes in ground water on nuclide adsorption has been studied with emphasis on variations in sodium and calcium [Meyer et al. (1978), Meyer (1979, 1980), Silva et al. (1980, 1981) and Relyea et al. 1978]. In general nuclide adsorption for alkali and alkaline earth elements show consistent decreases in $\mathrm{Rd}$ values as the ground water $\mathrm{Na}^{+}$or $\mathrm{Ca}^{2+}$, concentration increases. Theoretical predictions based on ideal ion exchange relationships model the data adequately. For lanthanides elements such as Eu and for the actinides the Rd values at neutral pHs are much less sensitive to ionic strength. Uranium and neptunium actually show increased adsorption in 
brines. It appears that except for Sr, Cs, Ra and a few other long-lived nuclides, ideal ion exchange processes are of limited utility in explaining nuclide retardation.

On the other hand, recent work by Shiao et al (1981) and Shiao and Meyer (1981) on the adsorption of trace Cs, Sr, Eu, Co and Cd onto aluminum oxide $\left(\mathrm{Al}_{2} \mathrm{O}_{3}\right)$ versus salt concentration appear to be explainable from more general ion exchange theory. In the general ion exchange theory, one does not require constancy in exchange capacity or activity coefficient ratios. For pH values between 5 and 9 , the adsorption of CS, Sr, Eu, Co and Cd onto alumina increases strongly with $\mathrm{pH}$ and there is generally little observable effect on varying the ionic strength of the solution. At pH values above 9 there appears to be a salt dependence for Sr and Cs (adsorption decreases with increasing ionic strength but at a rate less than predicted by ideal exchange theory). Eu sorption is so large at high pH values that experimental scatter in remaining solution concentrations precluded determination of solution ionic strength effects. For Co and $C d$ no ionic strength effects on sorption at high $\mathrm{pH}$ values were observed provided complexation effects ( $\mathrm{Cd}$ chloride solution species) are considered.

As previously mentioned the traditional derivation and usage of Rd assumes that the nuclide adsorption isotherm is linear, i.e., the Rd is constant with changes in nuclide concentration. WRIT studies have found that adsorption of most nuclides including Cs exhibit nonlinear sorption isotherms for rock material even at extremely low nuclide concentration ranges (10 $0^{-9} \mathrm{M}$ and lower). For clay minerals and weathered rocks with high clay contents more nuclides approach linear isotherms but the majority continue to exhibit nonlinearity [Barney 1981]. In most cases the Rd value increases as the nuclide concentration decreases and the empirical Freundlich isotherm equation (Equation 1 ) is useful for describing results:

$$
S=a C^{N}
$$

where $S=$ mass of nuclide adsorbed on the solid per gram,

$C=$ mass of nuclide in solution per liter, and

$\mathrm{a}$ and $\mathrm{N}=$ empirical constants. 
When $N=1$, the isotherm is linear and assuming, equilibrium conditions prevail $\mathrm{a}$ is equivalent to $\mathrm{Kd}$. Two examples of the dependence of $\mathrm{Rd}$ on nuclide concentration are shown in Figures 1 and 2, taken from Seitz et al. 1980. Thus, one must develop the adsorption isotherm over the plausible range of total elemental concentration for nuclide and stable natural isotopes to collect necessary empirical adsorption data for radionuclides.

The time of rock and solution contact has been varied from a period of hours to about 8 months. In general surface adsorption of radionuclides that appear to be controlled by ion exchange ( $S r, C S, B a, R b$ ) occur rapidly (hours to at most a few days). On clay materials Meyer et a1. (1978) found these elements reached steady-state solution concentrations within 10 hours, although Am took 21 days. This suggests the controlling mechanism for Am adsorption dif-fers from that for elements like $\mathrm{Sr}$ and $\mathrm{CS}$. Investigators at Los Alamos [Erdal et al. (1979) and Daniels et al. (1981)] performed batch Rd experiments on granite, argillite (shale) and tuff and measured Rd values at $1,2,3,4$ and 8 weeks. In general Rd values for most elements increased with time. Europium and cerium which are hydrolyzable often showed an Rd increase over eight weeks of up to an order of magnitude. Data for Am, $U$ and Pu showed no sorption trends versus time.

Sorption of actinides onto rock tablets was followed for 32 days [Silva et al. (1979)]. For the elements $\mathrm{Pu}, \mathrm{Am}$, and $\mathrm{Cm}$, adsorption was essentially complete after 10 to 15 days with only a few percent of activity left in solution. The decrease in solution activity was quite rapid with less than 10 of the initial activity left in solution after 5 days. $U$ and Np sorption was much smaller and, excepting $N p$ sorption on shale and $U$ sorption on basalt, did not show any trends versus time. For the two exceptions, adsorption slowly increased over the observation period.

Long-term ( $>200$ day) experiments on nuclide adsorption are underway at Rockwell Hanford Operations [Barney and Anderson (1979) and Barney (1981)]. After 110 days, the sorption of CS was still increasing on granite and had possibly leveled off for basalt and argillite. For Sr, the adsorption onto granite was increasing and appeared to be decreasing for basalt and shale. Np 
sorption onto basalt was increasing and perhaps was very slowly increasing on granite and shale. Americium sorption on granite and shale became constant after 30 days but appeared to be decreasing for basalt. Plutonium adsorption appeared to be increasing for granite and shale and decreasing for basalt. The macro constituents (major cations and anions and selected trace metals) were also monitored over these times. Apparently slow ground water-rock reactions were occurring. The systems continued to be dynamic and thus the variation in sorption is not surprising. The apparent decrease in sorption with time for some of the nuclides contacting basalt was found to be caused by formation of colloidal particles which remained suspended in solution [Barney and Anderson (1979) and Ames and McGarrah (1980)]. The unstable glassy matrix of the basalt appears to generate fine siliceous particles into solution. These particles are not easily removed by centrifugation yet are retained on submicron filters. Altered basalt and basalt secondary minerals show less longterm changes in nuclide concentrations with time which suggests that once the rock material has weathered and approaches equilibrium with the ground water, surface adsorption reactions will approach steady state in a matter of days.

Desorption studies have been performed to evaluate the reversibility of nuclide adsorption. Ion exchange and other selected surface adsorption processes are expected to be reversible. All existing computer codes that rely on the distribution coefficient approach assume reversibility. This assumption when coupled to mass transport analyses makes the sorption process a delay function only. That is, after the waste form is totally dissolved, the mass of radionuclides which has not decayed radioactively will eventually reach the biosphere if ground water continues to flow through the contaminated rock. Assuming reversible sorption and relying on the delay function only is conservative because some sorption and precipitation reactions may be considered irreversible. Experiments performed by WRIT in general have found that Rd values calculated from desorption of contaminated rocks and sediments are significantly larger than or equal to Rd values calculated from adsorption studies even when the period of desorption is allowed to be greater than the adsorption time period. The increase in Rd desorption over Rd adsorption often reaches an order of magnitude for elements such as Am, Pu, Ce, Eu and a factor of two for elements such as Cs, Ba and Sr. 
One can speculate that the difference in Rd values are caused by some of the following processes: 1) collapse of interlayers of 2:1 lattice clays such as illite when nuclides such as Cs diffuse into the clay [Frink (1971)], 2 ) precipitation of insoluble minerals or coprecipitation and entrapment in amorphous coatings, 3) reduction to more insoluble species or solid complexation by crystal lattice elements such as $\mathrm{Fe}^{2+}$ [Rai et al. (1980c)], 4) nonlinear isotherms where Rd increases as total mass of nuclide in system is reduced, 5) diffusion of nuclides deep into rock matrix [Neretnieks (1980)] and 6 ) presence of multiple sorption sites with a few with extremely high affinity for the particular nuclide (often referred to in the literature as specific adsorption).

The parametric studies described in this section have identified several variables to which nuclide distribution coefficients are quite sensitive and have suggested areas for further detailed mechanism activities. As mentioned the empirical approach based on nuclide distribution coefficients does not provide a physical understanding of controlling processes. Further, Rd values themselves are very specific to the rock/ground water/nuclide conditions present during the determination. More general relationships that describe the sensitivity of sorption to important rock/ground water/nuclide parameters, especially ones based on established laws of physics and chemistry are being sought. WRIT's approach has been to assess the applicability of theoretical constructs and models for describing laboratory results. Based on the parametric studies and desire to incorporate models, WRIT has focused its sorption mechanism efforts on 1 ) delineating the utility of classical ion exchange and site-binding layer mathematical constructs and theories, 2) redox mediated adsorption processes and 3 ) mineralogical sorption site identification by autoradiography.

The constructs and models presently considered include thermodynamic (equilibrium) geochemical models of solution species and crystalline and amorphic compounds that describe complexation in solution and dissolution/ precipitation of solid phases and ion exchange and site-binding electrical double layer models for adsorption. A detailed discussion of the thermodynamic 
equilibrium models and their use by WRIT is beyond the scope of this paper; however, Deutsch (1980), Jenne (1981) and Deutsch et al. (1981) discuss the topic in some depth.

\section{Ideal Ion Exchange Studies}

The use of ideal ion exchange constructs have been explored by Meyer et a1. (1978 and 1981), and Meyer (1979 and 1980). Laboratory results of nuclide adsorption studies onto solid adsorbents from one metal component salt solutions were compared to mathematical descriptions based on the following ideal ion exchange equation

$$
a M_{1}^{+b}+b\left(M_{2}^{+a}-x\right) \leftrightharpoons a\left(M_{1}^{+b}-x\right)+b M_{2}^{+a}
$$

where

$$
\begin{aligned}
a & =\text { the valence of the radionuclide ion } \\
b & =\text { the valence of the macro ion } \\
M_{1} & =\text { macro component in the salt solution } \\
M_{2} & =\text { the trace radionuclide } \\
-X & =\text { the solid adsorbent. }
\end{aligned}
$$

A mass action equilibrium expression which yields a thermodynamic equilibrium constant $K$, is

$$
K=\frac{\left[M_{1}-x\right]^{a}\left[M_{2}\right]^{b}}{\left[M_{1}\right]^{a}\left[M_{2}-x\right]^{b}}
$$

where

[ ] = thermodynamic activities of the species (valence states on the metals $M_{1}$ and $M_{2}$ have been deleted for clarity).

The activities can be broken down into concentrations and activity coefficients to yield

$$
K=\frac{\left(M_{1}-X\right)^{a}\left(M_{2}\right)^{b}}{\left(M_{1}\right)^{a}\left(M_{2}-X\right)^{b}} \cdot \Gamma
$$


where

() = concentrations

$\Gamma=$ the quotient of the four activity coefficient terms

When one assumes that the exchange capacity, $C$, of the solid adsorbent is constant (equivalents per unit weight) and that $M_{2}$ is present in the system at trace concentrations, then $\left(M_{2}-X\right) \ll C$ such that the distribution of ions on the exchange sites

$$
b\left(M_{1}-X\right)=c-a\left(M_{2}-X\right)
$$

reduces to

$$
\left(M_{1}-X\right) \simeq C / b
$$

Further $\left(M_{2}-X\right) /\left(M_{2}\right)$ is the definition of the equilibrium distribution coefficient, $(D)$, for the radionuclide. Substituting Equation (5) and the definition of (D) into Equation (4) yields

$$
\begin{gathered}
\frac{K}{\Gamma} \simeq(C / b)^{a}\left(\frac{1}{M_{1}}\right)^{a}\left(\frac{1}{D}\right)^{b} \\
D=\left(\frac{C / b}{M_{1}}\right)^{a / b} \cdot\left(\frac{\Gamma}{K}\right)^{1 / b}
\end{gathered}
$$

When $\Gamma$ is constant (a condition likely in a system where a trace constituent is being adsorbed onto a solid medium with constant exchange capacity) $D$ becomes a function of only the solution concentration of the macro ion solution, $M_{1}$. Taking the logarithm of Equation (6) yields

$$
\log D=a / b \log \frac{C / b}{M_{1}}+\frac{1}{b} \log \frac{\Gamma}{K}=a / b \log C / b-a / b \log M_{1}+\frac{1}{b} \log \frac{\Gamma}{K}
$$

which can be differentiated with respect to $M_{1}$ to yield Equation 7 ( $C, \Gamma$ and $K$ are constant and the other terms drop out)

$$
\frac{d \log D}{d \log M_{1}}=-a / b
$$


Thus, if the trace element constituent is cesium and the macro element is sodium a plot of the logarithm of the cesium distribution coefficient versus the logarithm of the sodium solution concentration would be -1 . For strontium exchange with sodium the slope would be -2 . For americium exchange the slope would be -3 . If ideal ion exchange laws describe the adsorption of a radionuclide one can measure a $D$ or laboratory Rd (assuming equilibrium was attained) for a nuclide and predict the distribution coefficient at other concentrations of the electrolyte. Such relationships would be quite useful for ground waters such as $\mathrm{NaCl}$ brines of various strengths which might be found around bedded salt and domed salt sites. Mathematical equations where the trace loadings, $\left(M_{2}-X\right)$, are not readily approximated by zero and for mixtures of solid adsorbates are also available [Triolo and Lietzke (1980), Meyer et al. (1981)].

Comparisons of theory and experiment have progressed from the study of $\mathrm{Sr}$ and $C S$ exchange on purified clays as a function of $\mathrm{Na}^{+}$and $\mathrm{Ca}^{+2}$ electrolyte concentrations to the exchange of $E U(I I I), U(V I), C S(I), \operatorname{Sr}(I I)$ and $T c(V I)$ onto clay mixtures, oxide surfaces and oxide mixtures. Results show good predictive abilities for only a few elements such as $\mathrm{Sr}$ and $\mathrm{Cs}$ onto pure clays and clay mixtures. The adsorption of other ions such as actinides onto clays or oxides and even $\mathrm{Sr}$ and $\mathrm{CS}$ adsorption onto oxides $(\mathrm{Al}, \mathrm{Si}$ ) is not readily modeled by these ideal equations. Reasons identified for the unsuccessful usage of ideal ion exchange contructs include the nonconstancy of the exchange capacity and activity coefficients of the adsorbents, release of other competing ions such as $\mathrm{Al}^{+3}$ (under acidic conditions) from solution interactions with the solid and probable changes in radionuclide speciation distribution via hydrolysis and conplexation (e.g., Eu, Pu, etc.) as pH and ground water ionic strength are changed. All these complications require separate exchange equations for each nuclide species and for each type of exchange site on the solid. As previously mentioned, Shiao et al. (1981) and Shiao and Meyer (1981) have had some success using the general ion exchange equations (Equations 3 and 4 ) to model sorption on aluminum oxide.

Site-Binding Electrical Double-Layer Model Studies

A site-binding electrical double-layer model is a more general sorption model, which when coupled to solution thermodynamic equilibrium models, allows 
a complete description of nuclide chemical interactions. [See Silva et al. (1980) and Davis et al. (1978) for a detailed description of the model]. Briefly, the model assumes that most solid materials acquire a surface charge when placed in contact with a polar solvent such as water. The net charge may be positive, negative or neutral (point of zero charge) depending on the nature of the solid and the solution composition, particularly the $\mathrm{pH}$. The most common mechanism for a surface to obtain a net electrical charge is through the uptake or release of potential-determining ions on the surface $\left(\mathrm{e} . \mathrm{g} ., \mathrm{H}^{+}\right.$ or $\mathrm{OH}^{-}$). Charged surfaces tend to adsorb ions of opposite charge to maintain electrical neutrality and thus develop an electrical double-layer. Permanent charges are also present on solid surfaces because of isomorphous substitution in the crystal structure, such as $\mathrm{Al}^{+3}$ substituting for $\mathrm{Si}^{+4}$ or $\mathrm{Mg}^{+2}$ for $A 1^{+3}$. The permanent charges are treated as ionizable sites in the site binding-model. If a surface is assumed to have only one kind of ionizable sites, two reactions determine the surface charge:

$$
\begin{aligned}
& \mathrm{SOH}_{2}^{+} \leftrightharpoons \mathrm{SOH}+\mathrm{H}_{\mathrm{S}}^{+} ; \mathrm{Ka}_{1} \\
& \mathrm{SOH} \leftrightharpoons \mathrm{SO}^{-}+\mathrm{H}_{\mathrm{S}}^{+} ; \mathrm{Ka}_{2}
\end{aligned}
$$

where $S$ in the equations refers to the surface to which the oxygen is bonded and the subscript $s$ refers to an ion at the surface (but not adsorbed) and differs from the ion in bulk solution by the amount of energy needed to move the charged ion across the difference in electrical potential between the surface and bulk solution. $\mathrm{Ka}_{1}$ and $\mathrm{Ka}_{2}$ are the surface ionization constants for these two dissociation reactions.

Normally, when a supporting electrolyte is present, ions other than $\mathrm{H}^{+}$ balance the surface charge. If the solution contains only $\mathrm{NaCl}$, the reactions describing the cation/anion charge balance are:

$$
\begin{aligned}
& \mathrm{SO}^{-}+\mathrm{Na}^{+} \leftrightharpoons \mathrm{SO}^{-} \mathrm{Na}^{+} ; \mathrm{K}_{\mathrm{Na}}^{+} \\
& \mathrm{SOH}_{2}^{+}+\mathrm{Cl}^{-} \leftrightharpoons \mathrm{SOH}_{2}^{+} \mathrm{Cl}^{-} ; \mathrm{K}_{\mathrm{Cl}^{-}}
\end{aligned}
$$


The electrical work needed to bring an ion from bulk solution to the charged surface results in a difference in activity for that ion at the two different positions. The model makes this correction so that the reaction constants can be related to quantities measured in solution. In a normal ground water numerous other cations and anions are found. These may be treated by writing equations similar to Equations (10) and (11).

Exchange reactions such as $\mathrm{Na}^{+}$for $\mathrm{H}^{+}$can then be written as:

$$
\mathrm{SOH}+\mathrm{Na}_{\mathrm{S}}^{+} \leftrightharpoons \mathrm{SO}^{-}-\mathrm{Na}^{+}+\mathrm{H}_{\mathrm{S}}^{+} ; \mathrm{K}_{\mathrm{Na} / \mathrm{H}}=\mathrm{Ka}_{2} \cdot \mathrm{K}_{\mathrm{Na}}^{+}
$$

The constant $\mathrm{K}_{\mathrm{Na} / \mathrm{H}}$ is frequently referred to as the selectivity coefficient. If more than one kind of exchange site exists on the surface, another set of equations similar to Equations (8) through (12) can be added to the model.

The resulting set of equations can then be solved algebraically to predict both the solution concentration and surface concentration for a particular element. If a distribution coefficient is needed, it may be calculated in a straightforward manner from the predicted surface and solution concentrations.

Estimates of the surface ionization constants $\left(K a_{1}\right.$ and $\left.K a_{2}\right)$ are made from acid and/or base titrations of the adsorbing solids over a suitable range of electrolyte concentrations. Naturally, care must be taken that the $\mathrm{pH}$ range during titration does not extend outside the range in which the solid phase is stable. The selectivity coefficients that describe the exchange of one cation (or anion) for another (for example $\mathrm{Cs}^{+}$exchange with $\mathrm{Na}^{+}$) must also be determined experimentally or calculated from existing data for the system of solids and solutions being studied.

Perhaps the most important aspect of this sorption model is that it is compatible with thermodynamic-based geochemical models. The surface ionization and exchange equations [Equations (8) through (12)] are written in the form of chemical reactions with their respective equilibrium constants as are the solubility and complexation reactions present in thermodynamic models. At the Lawrence Berkeley Laboratory, this adsorption submodel has been included in MINEQL [a computerized thermodynamic code developed by Westal1, Zachary and 
Adsorption of $\mathrm{Cs}^{+}$on $\mathrm{SiO}_{2}$ powder in two sodium chloride solutions is shown in Figure 7. Again, the activity correction (dashed lines) did little to improve the fit of experimental and predicted results. Below pH 7 the observed and predicted data for Cs sorption on the $\mathrm{SiO}_{2}$ deviate, but fair agreement is found in the environmentally important range, $\mathrm{pH} 7$ to $\mathrm{pH} 10$.
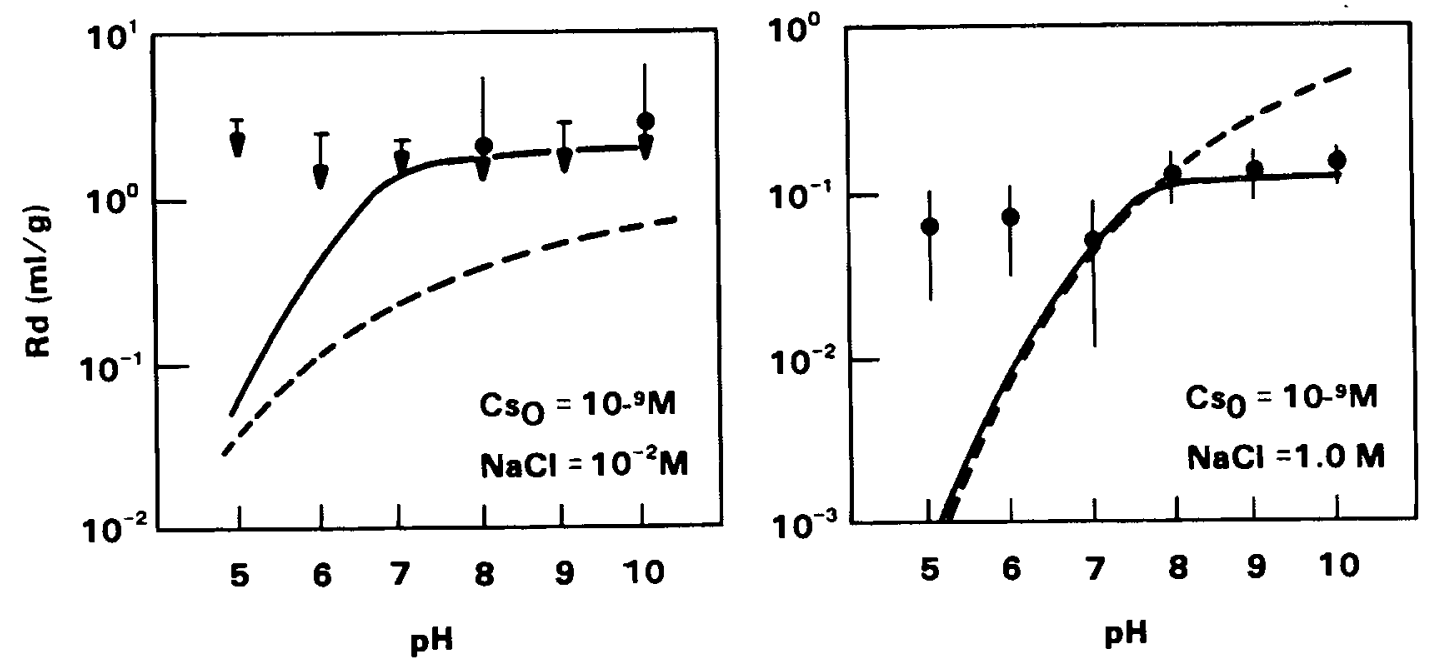

FIGURE 7. Rd(Cs) Values for Adsorption on Colloidal Silica Versus pH at Designated Brine Concentration and Initial Solution Cs Concentration of $10^{-9} \mathrm{M}$. [Symbols are experimental data points while the vertical bars are experimental uncertainties $\left(+1_{\sigma}\right)$. The solid lines are computer model predictions which consider electrical double-layer activity corrections.]

Further work is in progress [Silva et al. (1981)] to model the adsorption of $U(V I)$ solution species onto $\mathrm{SiO}_{2}$ and montmorillonite. The described Cs predictions compare adequately with experimental results. Coupled with other studies of transition element adsorption onto oxide surfaces [Davis and Leckie (1978), James and Healy $(1972,1975)$ and Schindler et al. (1976)] WRIT has decided to focus adsorption modeling efforts on the site-binding electrolyte double-layer model. 
Morel (1976)] so that precipitation, dissolution, complex-ion formation, oxidation-reduction and adsorption reactions can be considered simultaneously in a single geochemical model. If the initial surface and solution ion concentrations are known, a radionuclide may be added to the system and its distribution between the solid and solution phases can be predicted.

Figure 6 shows a comparison between $\mathrm{Cs}^{+}$Rd values determined experimentally [data points] and those predicted [lines] by MINEQL for Belle Fourche. clay (a montmorillonite) over a wide range of $\mathrm{pH}$ and $\mathrm{NaCl}$ solution concentrations. The dashed lines were calculated using the activity correction for the difference between bulk solution and surface potentials and the solid line was calculated without the correction. The predicted $\mathrm{Rd}$ values for $\mathrm{Cs}^{+}$exchange with $\mathrm{Na}^{+}$show a good correlation with the experimental data. It can be seen that the inclusion of the activity correction term (dashed line) did little to improve the fit.

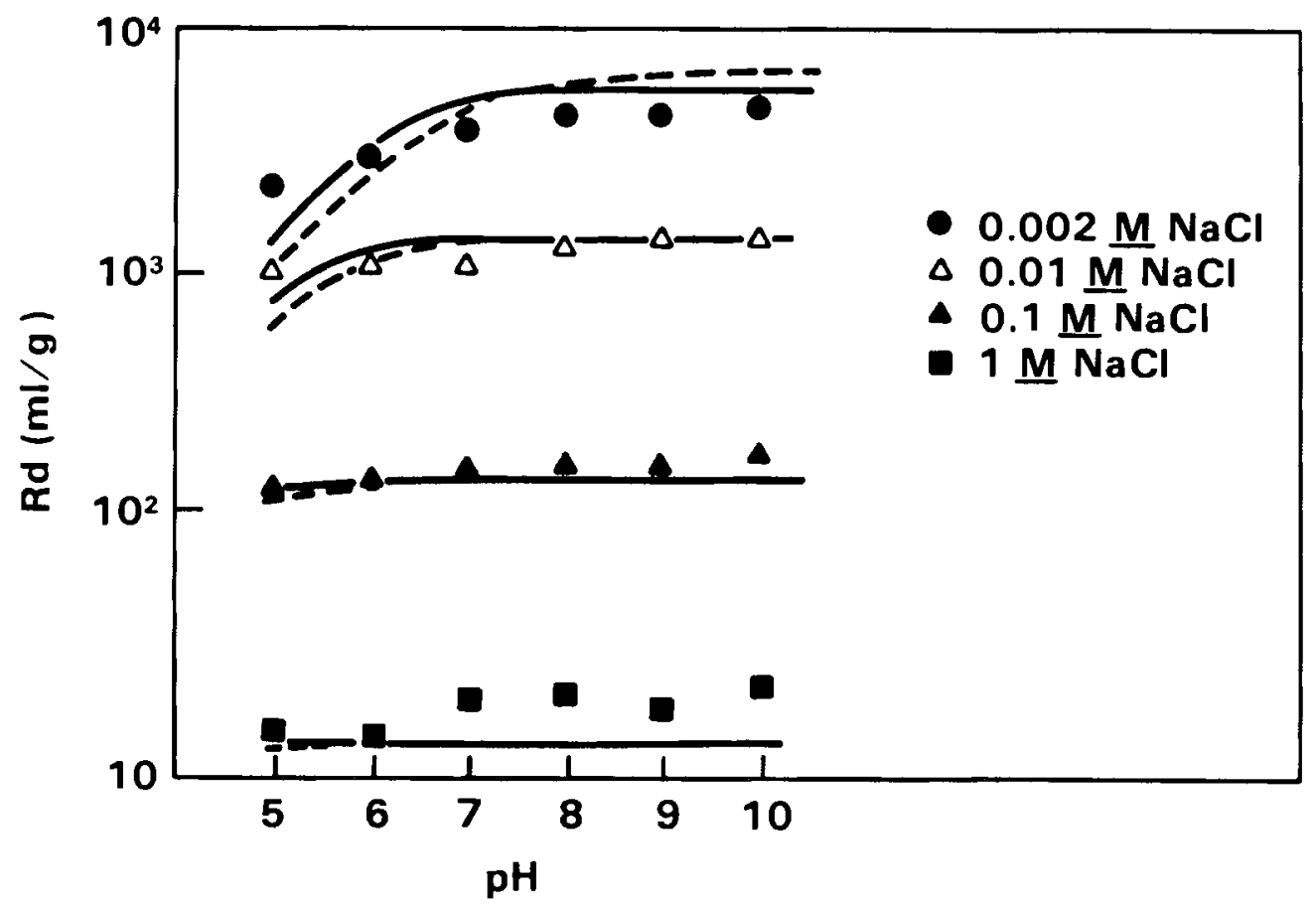

FIGURE 6. Rd(Cs) Values for Adsorption on Montmorillonite Versus pH at Several Brine Concentrations. (Symbols are experimental data points while solid lines are computer model predictions. The dashed lines represent activity corrections for the model predictions.) 
Oxidation-Reduction Mediated Nuclide Retardation Studies

The oxidation-reduction potential has been identified as a key variable in controlling radionuclide retardation [Ames and Rai (1978) and Rai and Serne (1978)] for several long-lived isotopes such as ${ }^{239} \mathrm{Pu},{ }^{238} \mathrm{U},{ }^{237} \mathrm{~Np},{ }^{79} \mathrm{Se}$ and ${ }^{99}$ Tc. Further, most studies of nuclide adsorption performed before 1978 did not measure or consider the oxidation-reduction potential during characterization or reporting of results. Thus, empirical data for background information was virtually nonexistent, although thermodynamic constructs were available. The range of oxidation-reduction potentials expected in deep geologic environments is open to wide speculation as very few measurements of Eh are available for deep geologic environments. Baas-Becking et a1. (1960) present ranges for near-surface ground waters and aquatic environments that can be used as a guide. The perceived importance and dearth of knowledge led WRIT staff to embark on studies of oxidation-reduction processes and their effects on nuclide adsorption. In studies performed at Oak Ridge National Laboratory [Francis et al. (1979), Francis and Bondietti (1980), Bondietti and Francis (1979) and Bondietti et a1. (1981)], experiments were conducted to see if redox measurements of igneous rock suspensions and nuclide solution valence states in anoxic stirred cells agreed with thermodynamic aqueous stability diagram prediction. Thermodynamic predictions show that the species $\mathrm{TCO}_{4}^{-}$and $\mathrm{NpO}_{2}^{+}$would not be the stable forms of these elements under reducing conditions probable in deep repositories. Experiments where $\mathrm{TCO}_{4}^{-}$and $\mathrm{NpO}_{2}^{+}$in solution were added to anoxic rock suspensions showed that their solution concentration did decrease and that they perhaps were reduced in part to less soluble species. The rocks used included Sentinel Gap basalt, Westerly granite, Climax Stock granite, Conasauga shale and a green argillaceous shale. Under $\mathrm{N}_{2}$ atmospheric conditions the granites and basalt readily removed $\mathrm{TcO}_{4}^{-}$from solution by a reduction process evidenced by the inability to remove adsorbed Tc by ion exchange but the ability to remove adsorbed Tc by addition of oxidants. Neither shale exhibited this reduction-sorption capability but some $(10 \%)$ of the $\mathrm{TCO}_{4}^{-}$was removed by weathered Conasauga shale suggesting anion sorption by positively charged sesquioxides. Thermodynamic predictions suggested that $\mathrm{NpO}_{2}^{+}$, would be even more unstable in solution than $\mathrm{TCO}_{4}^{-}$as the redox potential is decreased. Rock sorption studies of $\mathrm{Np}(V)$ showed that all of the above rocks excepting 
the argillaceous shale rapidly removed $>90 \%$ of the $\mathrm{Np}(\mathrm{V})$ in solution. Column verification of the $\mathrm{TcO}_{4}^{-}$rapid reduction, by basalt was attempted. Only at a residence time of five days was there any indication of reduction. Thus, loss of $\mathrm{TcO}_{4}^{-}$was much slower in columns than in the stirred cell.

Later Tc studies which included variation of $\mathrm{Eh}, \mathrm{pH}$, solution $\mathrm{Fe}^{+2}$ and $\mathrm{S}^{-2}$ concentrations and time lead to the following conclusions. The loss of $\mathrm{TCO}_{4}^{-}$anion from solutions in contact with rocks under reduced oxygen fugacites is not due to sorption of the anion onto the rock but rather due to the reduction of $\mathrm{TcO}_{4}^{-}$to a lower valence state and precipitation most likely as $\mathrm{Tc}(\mathrm{OH})_{4}$. Addition of $\mathrm{Fe}^{+2}$ and $\mathrm{S}^{-2}$ to solutions containing $\mathrm{TCO}_{4}^{-}$were also capable of reducing the solution concentrations of technetium. $\mathrm{Fe}^{+2}$ was more effective than $\mathrm{S}^{-2}$ when added singly but the largest decreases in $\mathrm{TcO}_{4}^{-}$concentration occur upon addition of both. Experiments suggest that precipitates of amorphic iron hydroxides, technetium sulfides and iron-technetium sulfides are formed. Addition of $\mathrm{Fe}^{+2}$ and $\mathrm{S}^{-2}$ to rock suspensions in contact with $\mathrm{TcO}_{4}^{-}$solutions enhances the removal of $T c$. The reactions continue with Tc removal increasing slowly over the ten day observation period. In nature it appears plausible that the $\mathrm{Fe}(\mathrm{II})$ - $\mathrm{Fe}$ (III) solution system may mediate reduction of $\mathrm{TC}$ and removal from solution. The authors show a few data and speculate that Pu and $U$ may also be reduced and removed from solution. The "adsorbed" Tc was found to be slowly released back into solution as oxygen or oxidizing agents were allowed to enter the system. Thus kinetics of the redox process should be considered further before quantitative retardation estimates can be made.

Rai et a1. (1980c) studied the adsorption of plutonium from aerated $5 x$ $10^{-3} \mathrm{M} \mathrm{CaCl}_{2}$ solutions containing $7.3 \times 10^{-9} \mathrm{M}{ }^{239} \mathrm{Pu}$ (VI). The adsorption of $\mathrm{Pu}$ from this solution by several minerals and a basalt (see Table 8 ) was determined for $\mathrm{pH}$ values from 4 to 9.5. At $\mathrm{pH} \sim 4$ and a solution to rock ratio of $34: 1$, adsorption was dependent upon mineral type and increased from approximately $10 \%$ to nearly $100 \%$ in the following order: gibbsite < kaolinite < vesicular basalt < montmorillonite < nontronite < hematite < vermiculite < biotite. At pH values between 6.4 to 9.5 , the minerals did not differ 
significantly from each other in their adsorption properties and adsorption of $\mathrm{Pu}$ exceeded $93 \%$ for the four minerals studied: kaolinite, gibbsite, montmorillonite, and vermiculite.

At $\mathrm{pH}$ values of $\sim 4$, the exchangeable $\mathrm{Pu}$ in all the minerals studied ranged from one to thirty-two percent of the total adsorbed. The exchangeable Pu did not correlate with either the cation exchange capacity or the surface area of the samples. Therefore, ion exchange did not appear to be the dominant mechanism for the adsorption of Pu. The montmorillonite, nontronite, and vermiculite had nearly the same cation exchange capacity, but differed significantly in $\mathrm{Pu}$ adsorption affinity (Figure 8) and exchangeable Pu. The biotite, which had a much lower cation exchange capacity than montmorillonite, nontronite, or vermiculite, was similar in its percentage of $\mathrm{Pu}$ adsorption and exchangeable $\mathrm{Pu}$ to vermiculite. In general the 2:1 type clays (montmorillonite, nontronite, vermiculite, biotite) showed higher adsorption than the 1:1 type clay (kaolinite), although no such pattern was obvious in the amount of exchangeable Pu.

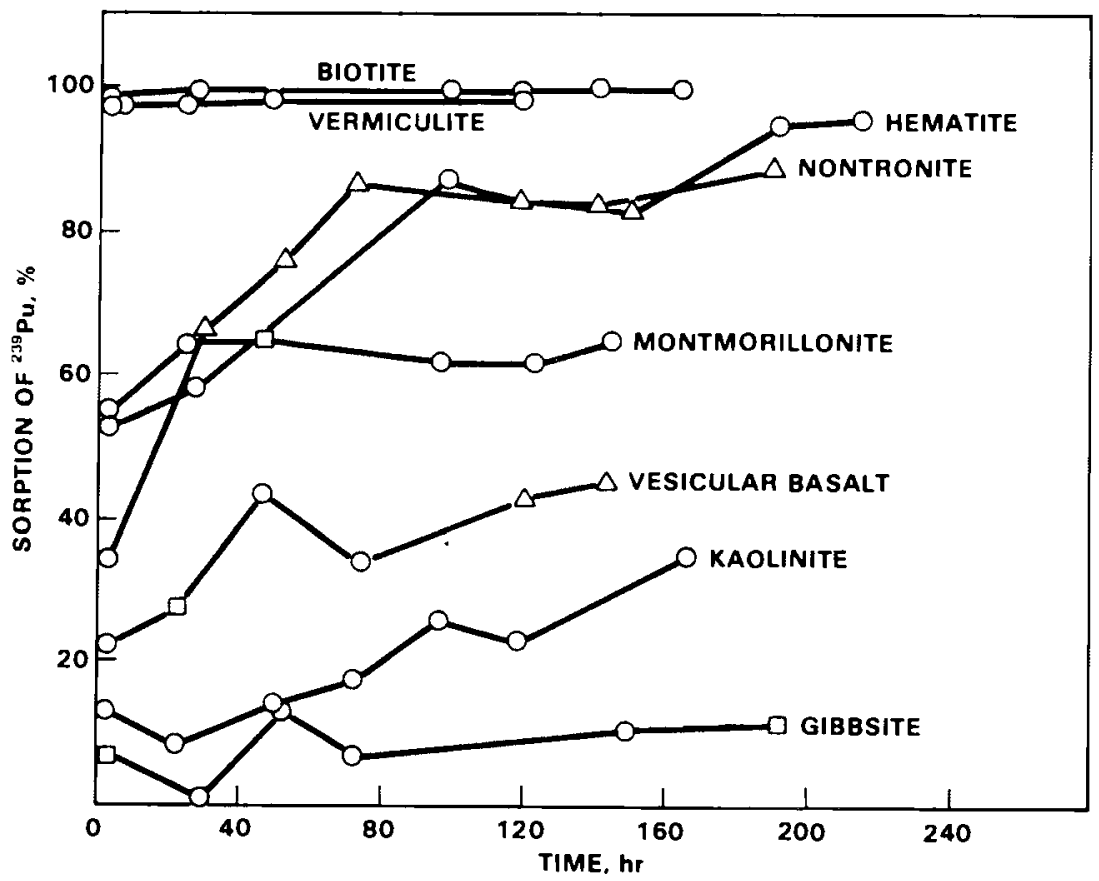

FIGURE 8. Adsorption of 239pu(VI) by Aerated Mineral Suspensions (34 $\mathrm{ml} / 1 \mathrm{~g})$ at $\mathrm{pH} 4$. Averages of duplicate samples are plotted. $(0=<7 \%, \square=$ $7-15 \%$, and $\Delta=15-30 \%$ difference between the duplicates) 
The oxidation state of $\mathrm{Pu}$ in solutions in equilibrium with different samples was also studied. The results showed that essentially all solution Pu was in an oxidized state $[\mathrm{Pu}(\mathrm{V})$ and/or $\mathrm{Pu}(\mathrm{VI})]$ but the presence of oxidized Pu is no guarantee that the adsorbed $\mathrm{Pu}$ is also oxidized.

Ozone-treated vermiculite and biotite, at $\mathrm{pH} \sim 4$, showed considerably less adsorption of $\mathrm{Pu}(<50 \%)$ when the adsorption experiment was carried out in the presence of ozone (Figure 9). Ozone had little effect on the adsorption of $\mathrm{Pu}$ by kaolinite. These results suggest that a large amount of $\mathrm{Pu}$ adsorption by vermiculite and biotite is due to reduction of plutonyl ions, whereas the adsorption of $\mathrm{Pu}$ by kaolinite is not predominantly caused by the reduction of plutonyl.

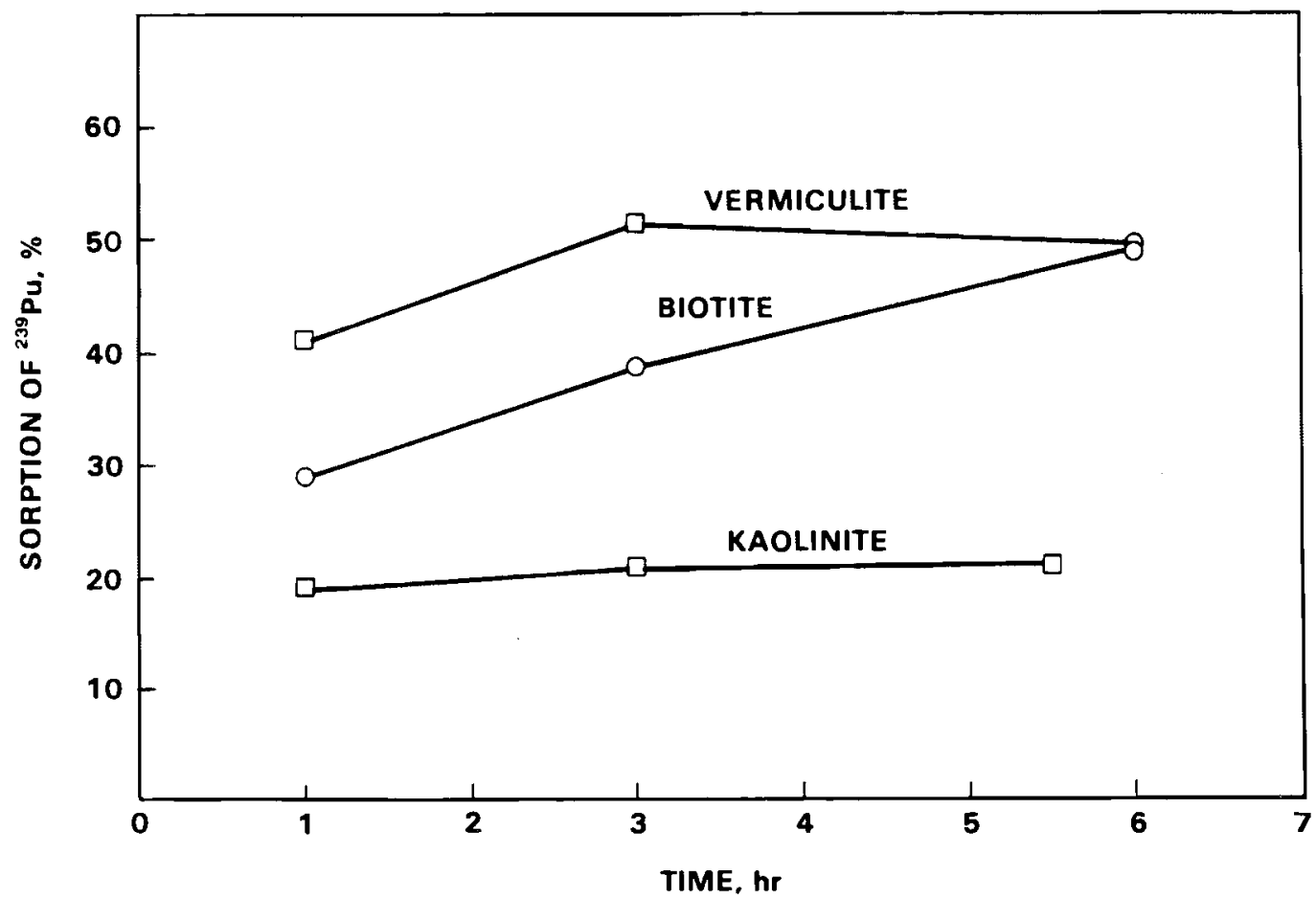

FIGURE 9. Adsorption of Pu(VI), the Presence of 0zone at Approximately $\mathrm{pH} \mathrm{4}$, and $34 \mathrm{ml} / 1 \mathrm{~g}$ Solution to Solid Ratio by Mineral Samples Also Pretreated with 0zone. Averages of duplicate samples are plotted. $\quad(0=<4 \%$ and $\square=9-15 \%$ difference between the duplicates) 
Vermiculite and biotite are known to contain Fe(II) which, when in solution, is a rapid reductant for plutonyl ions [Cleveland (1979)]. To determine whether the amount of $\mathrm{Fe}$ (II) in the minerals could explain the reducing nature of the minerals and the differences in their adsorption behavior (Figure 8 ), all the minerals were analyzed for $F e(I I)$ and Fe(III). The results show that the concentration of $\mathrm{Fe}$ (II) in the minerals varied from less than 0.01 to 11.4 wt\% (Table 8). All the minerals (vermiculite, biotite, and hematite) that had high concentrations of $\mathrm{Fe}$ (II) also showed very high adsorption of the $\mathrm{Pu}$ originally present in solution as Pu(VI). Vesicular basalt, however, although containing a high concentration of $\mathrm{Fe}(\mathrm{II})$, did not show high adsorption. The reasons for this anomalous behavior of vesicular basalt are not known. Kaolinite and gibbsite had relatively low concentrations of $\mathrm{Fe}$ (II) and also showed low adsorption. Montmorillonite and nontronite are similar in structure and chemical properties except that the octahedral layer in montmorillonite consists predominantly of aluminum and the octahedral layer in nontronite consists mainly of iron. There were no significant amounts of $\mathrm{Fe}(\mathrm{II})$ found in montmorillonite, nontronite, and kaolinite. Therefore, the differences in Pu adsorption and desorption by these minerals may be specifically related to their structure and chemical composition. The results indicate that Pu(VI) may be reduced at the mineral surface interface by crystalline lattice iron such that an enhanced adsorption or precipitation reaction occurs even though the bulk solution exhibits high oxygen fugacites. Detailed mechanistic studies of redox mediated nuclide retardation will continue to receive high priority within WRIT.

\section{Studies of Specific Adsorption Sites}

Laboratory sorption studies such as empirical Rd measurements delineate data on the gross sorption affinity of rocks, minerals and sediments. Much more detailed studies of the solid phase are needed to identify the actual sorption sites active in polymineralic rocks. Acquiring a basic understanding of sorption mechanisms would be greatly aided by studies that identify the specific minerals or amorphic phases that are the active adsorbents on the rock surfaces. Autoradiography coupled with optical and electron microscopy studies are being performed by WRIT on rock thin sections to identify specific sorption sites. 
TABLE 8. Exchangeable Pu and Selected Properties of Minerals and Rocks

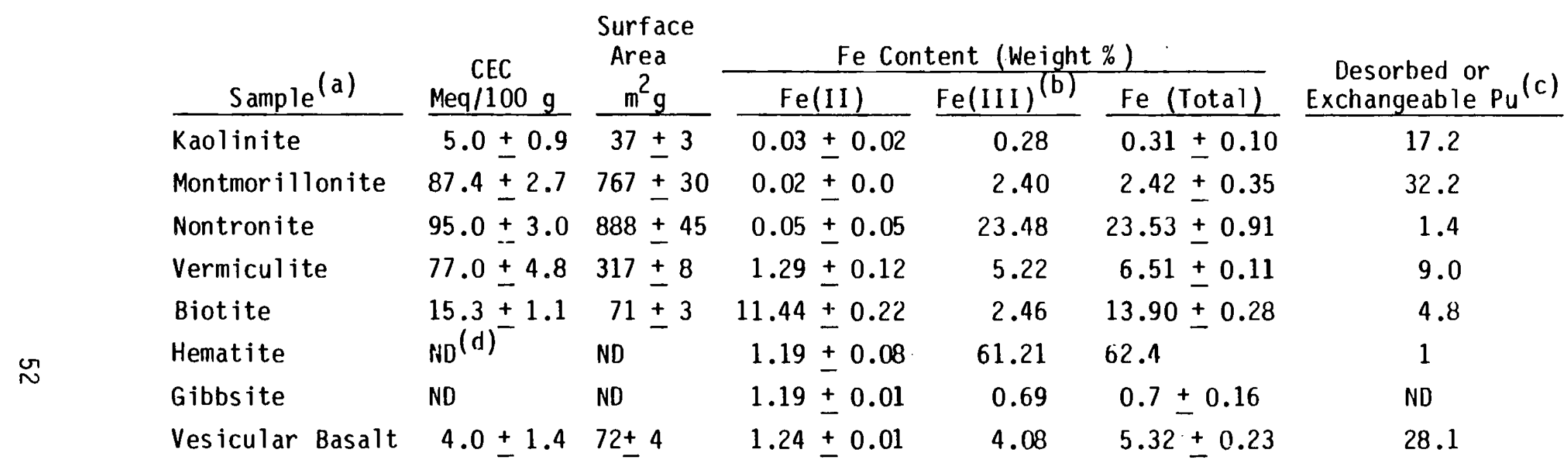

(a) The particle size used were $<2 \mu \mathrm{m}$ (kaolinite, montmorillonite, nontronite, vermiculite, and biotite) and $<105 \mu \mathrm{m}$ (hematite, gibbsite and basalt). X-ray diffraction patterns showed the montmorillonite, nontronite and biotite to be free of detectable amounts of crystalline impurities. The kaolinite sample contained a small amount of mica. The vermiculite sample was found to contain a small amount of interstratified vermiculite-mica. Hematite and gibbsite were found to contain small amounts of quartz.

(b) Fe(III) was calculated by subtracting Fe(II) from Fe(total).

(c) At the end of sorption (at pH 4 period noted in Figure 8 , the exchangeable $\mathrm{Pu}$ at $\mathrm{pH} 4$ was determined with $1 \mathrm{M} \mathrm{NaCl}$ (except in vesicular basait where $0.005 \mathrm{M} \mathrm{CaCl}_{2}$ was used). The results are presented as percentage of the total Pu originally adsorbed.

(d) $N D=$ not determined. 
Hinkebein and Hlava (1978, 1979) contacted flat rock chips with solutions which contained high concentrations $(\geq 0.0006 \underline{M})$ of either CS, Sr, Gd or U. The rock surfaces were then rinsed and adsorbed CS, Sr, Gd or U detected by electron microprobe X-ray fluorescence. By matching the qualitative information given in the photomicrograph with known mineral analyses, many mineral phases can be identified and the location of the adsorbed test elements determined. Four rocks were studied: Eleana argillite, Bell Canyon sandstone, Magenta dolomite and Salado Formation halite; the latter three are of interest to the WIPP site. Cs was detectable only on the Eleana argillite and was possibly associated with illite or vermiculite minerals. The Sr predominately precipitated as carbonates and sulfates on the dolomite, sandstone and clay partings in the halite. The $U$ was detectable in the dolomite and clay partings of the halite probably as a carbonate precipitate. Gd was detectable on all four rocks partly due to hydrolysis and precipitation and possibly due to adsorption onto chlorite.

This scouting study supported the concept that selected minerals within the bulk rock matrix could be the predominant sorption sites. The microprobe work, although qualitatively useful, suffered from a lack of adequate sensitivity for the adsorbed elements such that unrealistically high concentrations were used. The high concentrations lead to the adsorption process being confounded by precipitation reactions, which might not have occurred at trace concentrations expected under repository conditions.

Smyth et al. (1980) and Thompson and Wolfsberg (1979) performed microautoradiographic studies on Eleana argillite, Climax Stock graite, Jackass Flat tuff and tuffaceous alluvium all obtained from the Nevada Test Site. Polished thin sections were spotted with several drops of radioactive ground water ( $U$ or Am) in a $100 \%$ humidity chamber. After several hours to days of contact, the thin sections were rinsed with distilled water and prepared for autoradiography. The alpha tracks from $U$ or Am were counted and photographed through a microscope. The concentration of adsorbed nuclide was indicated by the track density. Sites of particularly high sorption gave rise to "stars" with many tracks radiating from a single point. 
For the granite $>90 \%$ of the adsorbed uranium was confined to a clay-rich alteration band in the plagioclase even though this phase makes up only $1 \%$ of the bulk rock. In-situ, the zonation bands in plagioclase would not likely be readily accessible to ground water, thus laboratory studies on crushed rock or thin sections which expose these bands may give unrealistic sorption values.

The uranium adsorbed onto argillite surfaces was associated with clay phases and was not associated with detrital quartz. The uranium adsorbed onto the tuff sample was associated with the zeolite clinotilolite which comprised $65 \%$ of the sample. The primary minerals quartz, feldspars and biotite adsorbed very little uranium. The alluvium sample also showed that the uranium was adsorbed onto zeolites in preference to quartz and feldspar sand.

The americium autoradiographs for all rocks did not correlate to specific minerals in the thin sections. It is believed that the track patterns originate from randomly precipitated americium. The original Am solution concentrations $\left(6 \times 10^{-7}\right.$ to $6 \times 10^{-6}$ M) do in fact exceed solubility values Rai et al. (1981) find in simulated ground water in equilibrium with an unknown americium solid.

Two other non-WRIT funded autoradiography studies [Beall et al. (1980) and Vandergraaf et al. (1981)] also corroborate that alteration minerals (smectite clays, illite clays, zeolites) adsorbed radionuclides greater than mafic minerals such as pyroxenes, micas and hornblende and that quartz and feldspars exhibit the least adsorption. Elements such as Am and Pm exhibit random autoradiographs suggesting precipitation can greatly influence laboratory adsorption experiments for the very slightly soluble actinides and lanthanides.

These studies illustrate that it is possible for minor phases to completely dominate the mass of radionuclides adsorbed. These minor phases may not be identified or quantified in even detailed rock characterization efforts and may explain why two seemingly similar rock samples can yield very different Rd values. The identification of sorption sites and adsorbing phases will increase our understanding of adsorption mechanisms. 


\section{PRIORITIZATION OF NUCLIDES AND RECOMMENDATIONS FOR FUTURE NUCLIDE}

\section{RETARDATION WORK}

Preliminary nuclide priorities were offered at the conclusion of the first WRIT workshop [Serne $(1978 b)]$. Although the prioritization process was not quantified or discussed in detail, attributes such as element solubility, adsorption affinity, radionuclide half-life and results of past safety assessments were considered. The prioritization included three general categories: first, second, and lower. Table 9 lists the prioritized elements.

\section{TABLE 9. An Early Nuclide Priority List}

First Priority: Tc, Pu, Np, I, U, Cs, Ra, Sr, C

Second Priority: Am, Sm, Ni, Se, Cm

Lower Priority: $\mathrm{Zr}, \mathrm{Sm}, \mathrm{Mo}, \mathrm{Eu}, \mathrm{Pd}, \mathrm{Th}, \mathrm{Pb}, \mathrm{Pa}, \mathrm{Nb}$

Since the above prioritization, WRIT staff and BWIP staff [Barney and Wood (1980)] have performed several quantitative nuclide prioritizations, the latter study concerns itself with the Columbia Plateau basalt environs only. Both studies rely on quantitative estimates of waste-form nuclide inventories as a function of decay time, the biological toxicity of each radionuclide and finally the propensity of the radionuclide to retardation. A combination of these factors was used by both studies to generate hazard indices.

The index for hazard selected for this WRIT study is the "Hazards Available Index" (HA). The HA is given by

$$
H A=\log \left[\frac{(Q)(T F)}{M P C}\right]
$$

where $Q$ is the amount of radionuclide present (Curies); MPC is the maximum permissible concentration of that radionuclide in water, $\mu \mathrm{Ci} / \mathrm{ml}$, found in the Code of Federal Register (10CFR20) and TF is a transport factor for the radionulide. The transport factor selected here is the inverse of the retardation factor (Rf) since HA should be larger (all other things equal) for a radionuclide having a low retardation factor (high mobility) than for an element with a high Rf (or low mobility). 
Inventories for the radionuclides (Q) were taken from the Final Environmental Impact Statement of Management of Commercially Generated Radionuclide Waste (DOE/EIS-0046F). Table A.2.3A, was used for spent fuel, and Table A.2.6b, was used for high-level waste. If a radionuclide was not present at times greater than 1000 years (due to decay) it was not included in the analysis.

The logarithmic average retardation factors for the five geologic environments under consideration (domed salt, bedded salt, basalt, granite and tuff) were calculated from Rd values shown in Tables 6 and 7 . For the "redox sensitive" elements in Table 7 the lower values were chosen to maintain conservatism. The Rd value was converted to a $R f$ value using $R f=1+10 \mathrm{Rd}$, where the constant 10 represents a gross average of the ratio of rock bulk density to porosity or fracture surface area to a fracture volume respectively for porous or fractured rock. Hazards Available Indices for each radionuclide were calculated for three times; $10^{3}, 10^{4}$, and $10^{5}$ years. In Table 10 radionuclide rankings and the average $H A$ are listed. For this table both spent fuel and high-level waste forms are averaged as are the hazards availability indices for each of the three times. The exact ratings are a function of time and are available upon request from the authors. For example, at 1000 years ${ }^{241}$ Am has an average $H A$ of 10.4 while at $10^{5}$ years a value of 3.9 . The remarks column identifies isotopes whose hazard availability indices significantly change with time.

The priority listing in Table 10 based on all five rock types compares with Barney and Wood (1980) on basalt except that Table 10's rating significantly increases the hazard of ${ }^{239} \mathrm{Pu}$ and Barney and Wood's increases the hazards of ${ }^{107} \mathrm{Pd}$ and ${ }^{230} \mathrm{Th}$. In the basalt environment under reducing conditions Pu is expected to be quite insoluble [Wood and Rai (1981)] and thus less hazardous. The estimated Rd values used by Barney and Wood for Pd and Th (10 and $100 \mathrm{ml} / \mathrm{g}$ respectively) seem too conservative to WRIT staff. If increased the priorities would drop and agree better with Table 10.

WRIT staff have also reviewed the safety assessment calculations presented in Swedish, English, and American waste isolation literature. A list of key nuclides that contribute to potential doses to man was constructed [see Chikalla and Powel1 (1981)], assuming the scenarios chosen for study in the various rocks (granite, basalt, salt) were reasonable. The most frequently 
TABLE 10. WRIT Nuclide Priority List

\begin{tabular}{|c|c|c|c|}
\hline Ranking & Isotope & $\begin{array}{l}\text { Average } \\
\mathrm{HA}(\mathrm{a})\end{array}$ & Remarks \\
\hline 1 & ${ }^{129} 9_{I}$ & 11.1 & \\
\hline 2 & ${ }^{99} \mathrm{Tc}$ & 10.0 & \\
\hline 3 & $226 \mathrm{Ra}$ & 9.8 & HA increases with time \\
\hline 4 & ${ }^{237} \mathrm{~Np}$ & 9.6 & \\
\hline 5 & ${ }^{239} \mathrm{Pu}$ & 9.6 & \\
\hline 6 & $210_{\mathrm{Pb}}$ & 9.4 & HA increases with time \\
\hline 7 & ${ }^{79} \mathrm{Se}$ & 8.9 & \\
\hline 8 & $126 \mathrm{Sn}$ & 8.9 & \\
\hline 9 & $240 \mathrm{Pu}$ & 8.6 & $H A$ is greater at $t<10^{4}$ years \\
\hline 10 & ${ }^{234} U$ & 8.5 & \\
\hline 11 & ${ }^{107} \mathrm{Pd}$ & 8.1 & \\
\hline 12 & $243 \mathrm{Am}$ & 7.9 & $H A$ is greater at $t<10^{4}$ years \\
\hline 13 & ${ }^{242} \mathrm{Pu}$ & 7.9 & \\
\hline 14 & ${ }^{59} \mathrm{Ni}$ & 7.8 & \\
\hline 15 & ${ }^{238} U$ & 7.6 & \\
\hline 16 & $236 u$ & 7.5 & \\
\hline 17 & $233 \mathrm{U}$ & 7.3 & HA increases with time \\
\hline 18 & ${ }^{241}{ }_{A m}$ & 7.1 & HA decreases with time \\
\hline 19 & ${ }^{235} \mathrm{U}$ & 6.6 & \\
\hline 20 & ${ }^{229} \mathrm{Th}$ & 6.6 & HA increases with time \\
\hline 21 & ${ }^{14} \mathrm{C}$ & 6.5 & $H A$ is greater at $t<10^{4}$ years \\
\hline 22 & ${ }^{230}$ Th & 6.3 & \\
\hline 23 & ${ }^{245} \mathrm{Cm}$ & 6.2 & HA is greater at $t<10^{4}$ years \\
\hline 24 & ${ }^{227} A C$ & 6.0 & \\
\hline 25 & ${ }^{135} \mathrm{Cs}$ & 5.9 & \\
\hline 26 & $231_{\mathrm{Pa}}$ & 5.4 & \\
\hline 27 & ${ }^{93} \mathrm{Zr}$ & 5.0 & \\
\hline 28 & ${ }^{241} \mathrm{Pu}$ & 4.9 & \\
\hline 29 & ${ }^{238} \mathrm{Pu}$ & 2.7 & $H A$ is greater at $t<10^{4}$ years \\
\hline 30 & ${ }^{63} \mathrm{Ni}$ & 2.3 & $H A$ is greater at $t<10^{3}$ years \\
\hline 31 & ${ }^{242} \mathrm{Cm}$ & 2.1 & \\
\hline 32 & ${ }^{151} \mathrm{Sm}$ & 1.9 & \\
\hline 33 & ${ }^{90} \mathrm{Sr}$ & 1.5 & \\
\hline 34 & ${ }^{137} \mathrm{Cs}$ & 0.9 & \\
\hline
\end{tabular}

(a) HA averaged over 5 rock types and three times, 103, $10^{4}$ and $10^{5}$ years 
identified isotopes that contribute the majority of calculated dose are ${ }^{129} \mathrm{I}$, ${ }^{99} \mathrm{Tc},{ }^{237} \mathrm{~Np},{ }^{226} \mathrm{Ra}$ and ${ }^{14} \mathrm{C}$. Neptunium daughter products ${ }^{233} \mathrm{U},{ }^{229} \mathrm{Th}$ and $225 \mathrm{Ra}$ and radium daughter products ${ }^{234} \mathrm{U}, 210_{\mathrm{Pb}}$ and ${ }^{210} \mathrm{Po}$ also frequently appear. For extremely short travel times to the biosphere ${ }^{90} \mathrm{Sr}$ and ${ }^{137} \mathrm{Cs}$ will contribute significantly.

Considering available funds and that areas requiring support are large, this nuclide prioritization exercise may be used to make objective recommendations on which nuclides deserve detailed study. In each of the discussed analyses the four most hazardous radionuclides are I, TC, Np and Ra. It would thus appear that they should receive top priority in experimentation. WRIT has focused on $\mathrm{TC}$ and $\mathrm{Np}$ and has used $\mathrm{Ba}$ as an analog for Ra. Adsorption studies of I have been performed but natural rocks show little affinity for sorption of iodine. Outside of WRIT certain minerals and insoluble-iodidegenerating-salts are being investigated for addition to backfills and engineered barriers [Bird and Lopata (1980) and Strickert et al. (1980)].

There are several other recommendations which WRIT staff formulated after reviewing the available knowledge of nuclides present in Table 10. Very little work has been performed on adsorption of selenium Lsee Ames and McGarrah (1980) and Coles et al. (1980)], tin, lead, palladium and thorium. Some efforts should be started on these elements although we recommend continued efforts on I, Tc, Np, Ra, Pu, $U$ and Am until the basic retardation mechanisms are clearly identified. Continued work on $\mathrm{Sr}, \mathrm{Cs}$ and lanthanides such as $\mathrm{EU}$ and $\mathrm{Ce}$ aside from studies needed to elucidate nuclide adsorption mechanisms does not seem warranted.

Thermodynamic data suggest that solubility constraints similar to those discussed by wood and Rai (1981) may be used to lower the concentrations of tin, palladium and thorium to acceptable levels and thus diminish the need for comprehensive nuclide adsorption studies. Should thermodynamic solubility constraints lower the hazards of Sn, Pd and Th below those currently perceived, the two remaining priority elements which have not as yet received adequate study are $\mathrm{Se}$ and $\mathrm{Pb}$. 
BRIEF DISCUSSION OF RELATIONSHIPS BETWEEN LABORATORY AND FIELD NUCLIDE MIGRATION STUDIES

The NWTS program has several on-going field nuclide migration experiments. Two of the tests are being performed at the Nevada Test Site in fractured granite [Isherwood et al. (1980)] and fractured tuff [Erdal et al. (1981)]. A third on-going effort is an international cooperative program entitled "Migration in a Single Fracture--Experiments in Stripa" which is being directed by Dr. Ivars Neretnieks of the Royal Institute of Technology, Stockholm, Sweden. In the former two tests the WRIT program maintained formal ties and participated in several program plan reviews and technical discussions during 1979 and 1980. WRIT staff plans to keep abreast of all three projects and to work cooperatively with the respective project managers to ascertain the degree to which laboratory nuclide migration predictions agree with actual field observations of nuclide transport. It is hoped that these collaborative assessments and future written findings can address and alleviate most of the concerns on the applicability of laboratory sorption studies to deep geologic disposal raised by review groups [Bredehoeft et al. (1978) and Giletti et al. (1978)] and other scientists [de Marsily et al. (1977)].

Although it is premature to close the debate on this issue and outside the scope of this paper, several available references compare laboratory predictions and field observations of radionuclide migration. For example, Landstrom et al. (1978) discuss a joint laboratory-field program performed at Studsvik, Sweden on nuclide migration in granite. Robertson (1977) discusses the migration of radionuclides below waste seepage ponds in Idaho. Several other field tracer experiments using reactive solutes have been performed in near-surface porous media [e.g., Pickens et a l. (1981), Kaufman (1960), Inoue and Kaufman (1963), Parsons (1963), and Sterneau et al. (1967)].

At the Nevada Test Site, a few of the underground bomb tests which detonated below the water table are being monitored. At one test site, the Cambric event, a satellite well has been drilled about $100 \mathrm{~m}$ away. Since October 1975, this well has been pumped at rates between 1 and $2.3 \mathrm{~m}^{3} /$ min. To date on $1 \mathrm{y}^{3} \mathrm{H}$, $85_{\mathrm{Kr}}$ and a trace amount of ${ }^{106} \mathrm{Ru}$ have been detected in the water samples even 
though over one billion gallons of water have been removed. Within the bomb cavity upon re-entry ten years after the detonation, isotopes such as ${ }^{3} \mathrm{H}$, ${ }^{85} \mathrm{Kr},{ }^{90} \mathrm{Sr},{ }^{106} \mathrm{Ru},{ }^{125} \mathrm{Sb},{ }^{137} \mathrm{Cs},{ }^{144} \mathrm{Ce},{ }^{147} \mathrm{Pm},{ }^{155} \mathrm{Eu}$, and ${ }^{239} \mathrm{Pu}$ were readily detected in the water and fused rock. Except for the ${ }^{106}$ Ru results, 1aboratory empirical distribution coefficients support the observed satellite well data and predict very long travel times to the well (80 to $10^{4}$ years) for the radionuclides present. The discrepancy in nuclide migration predictions for Ru based on batch distribution coefficients with the field measurements may be caused by multiple species of Ru. As mentioned the batch sorption test measures a gross average distribution ratio and perhaps the Ru observed in the satellite well water represents a mobile species. It should be noted that the Ru observed in the satellite well represents only $1 \%$ of the total Ru present in the ground water, melt glass and fused rock found within the cavity upon re-entry. Details on field tests and laboratory studies of nuclide sorption which have been performed at Nevada Test Site can be found in Borg et al. (1976), Hoffman et al. (1977), Hoffman (1979), Hoffman and Daniels (1980), and Coles and Ramspott (1982).

In general most of the referenced authors were pleased with the agreement found between radionuclide migration predictions based on laboratory experiments and observations in the field. Thus, laboratory data can be expected to predict nuclide migration in the field. It should be acknowledged that most of the mentioned field studies were performed within simple and well characterized hydrologic regimes and that the elements chosen for study are known for their simple and "well behaved" chemistry (e.g., Sr, H, I). These ideal circumstances need to be expanded upon and more complicated field tests which use a wider range of radionuclides need to be performed. The three ongoing studies in fractured granite and tuff are designed to expand on past studies.

Field testing of nuclide migration expands on the time and spatial scales typically used in laboratory testing but still lacks several orders of magnitude in comparison to long-term safety assessment requirements. Thus, observation of natural systems, often called natural analogs, is actively being pursued by NWTS. Two such studies are the natural reactor OKLO [Bryant et al. (1976), Cowan (1977)] and the Morro do Ferro thorium deposit [Eisenbud et al. $(1981)]$. 
Presently it appears difficult to compare nuclide migration from either of these sites quantitatively with laboratory distribution coefficients. The complexity and numerous changes in the hydrologic and geochemical environments over the geologic time frames $\left(10^{9}\right.$ years) since the formation of the original ore deposits makes the calculation of a retardation factor (Rf) or empirical distribution coefficient (Rd) very difficult. On the other hand qualitative and semiquantitative evaluations of element migration are possible. These field evaluations can then be compared with theoretical constructs such as thermodynamics. Eh-pH diagrams for important radionuclides based on dissolution/precipitation and solution complexation reactions have been constructed for the probable environment right after the fissioning process ended at OKLO. From these diagrams a qualitative prediction on expected nuclide mobility is possible. These predictions were then compared with field observations [see Brookins (1978a,b and 1979)]. The thermodynamic predictions (based on Eh-pH diagrams) and field observations were found to agree for the elements $Y, Z r$, $\mathrm{Nb}, \mathrm{Mo}, \mathrm{Rh}, \mathrm{Pd}, \mathrm{Ag}, \mathrm{Cd}$, In, rare earths, Pb, Bi, Po, Th, U, Np and Pu. Predictions for Ru and TC were difficult due to sensitivity to assumed temperatures between 25 and $200^{\circ} \mathrm{C}$. Gancarz et a1. (1980) present data which show Tc mobilized relative to Ru. These studies reinforce the point made earlier that nuclide migration is best studied using both adsorption and solubility concepts. Combined, the two approaches are quite successful in explaining observations of nuclide migration from laboratory and field experiments or natural analogs.

Although not directly performing field or analog studies, the WRIT program maintains close ties with and offers theoretical, experimental and computer modeling tools and data to investigators active in these types of pursuits. Together investigators are ascertaining the potential for nuclide migration from all avenues. The various activities in concert supply test data to make comparisons and to verify each others' models and hypotheses. 
BRIEF DISCUSSION OF RELATIONSHIPS AMONG ADSORPTION MODELS, GEOCHEMICAL MODELS AND SAFETY ASSESSMENT MODELS

A hierarchical model approach currently is used by scientists with in the NWTS program to describe the diverse processes and interactions which control overall repository performance. The complexity of these interactions and sheer numbers of parameters and constituents which are important necessitates the use of computers. The computer codes that represent the various models may be linked or integrated to create an overall system safety assessment model. Such an approach is actively being pursued (Burkholder 1980).

In the interim and perhaps as a companion alternative, systems safety assessment codes are available that consider only the more important processes, selected repository components and that simplify the descriptions of the processes. For example, as previously mentioned numerous radionuclide transport models and codes exist which describe nuclide geochemical interactions by invoking the concept of a distribution coefficient. These simplified codes often treat the waste form and engineered barriers as one entity, a "black box", which supplies radionuclides to the ground water at some characteristic leach rate [Cloninger et al. (1980), Burkholder et al. (1979), and Logan and Berbano (1978)].

The understanding of radionuclide adsorption and more generally radionuclide chemical interactions in the earth's crust (geochemistry) is a primary goal of the WRIT program. The development of both detailed adsorption and geochemical models and codes is being pursued. A detailed computer code that describes adsorption will be combined with existing geochemical codes which are based upon thermodynamics. WRIT staff have concluded that it would be unwise to keep adsorption reactions separate from solubility and species distribution reactions because adsorption is dependent upon speciation and often difficult to differentiate from solubility. Distribution of species and solubility form the core of existing geochemical models such as WATEQ [Ball et al. (1979)] and EQ3/EQ6 [Wolery $(1979,1980)$ ], thus addition of an adsorption subroutine seems prudent.

The exact form of the adsorption subroutine will be established in the future but previous discussions within this document have identified the site-binding electrical double-layer model as a likely candidate. 
The incorporation of more detailed adsorption and radionuclide geochemistry models into systems safety assessment codes will occur within the waste Isolation Performance Assessment Program (WIPAP) which is briefly described in Burkholder (1980).

It is our opinion that only "stripped-down" versions of detailed adsorption/geochemical codes will be incorporated into an overall system safety assessment code because of core storage and computer processing time constraints. The "stripped-down" versions would consider only key radionuclides and selected chemical reactions. The comprehensive codes could be used to generate back-up details for specific cases as needed.

Several recent documents that review available geochemical codes, present examples of their applications to deep-geologic waste disposal, and discuss the current relationships of nuclide retardation activities to the overall NWTS mission are Jenne (1979, 1981); Wolery (1980, 1981), Deutsch (1980), and Deutsch et al. (1981); and Moody (1981), respectively. 
SUMMARY AND CONCLUSIONS

Numerous studies have identified radionuclide transport by ground water as the most credible means for nuclear wastes buried in deep geologic repositories to impact the biosphere. Physicochemical interactions such as adsorption, precipitation and filtration can significantly delay or reduce the mass transport of such radionuclides. Thus these interactions should be described in quantitative terms to credibly assess the effects of disposing nuclear waste in deep geologies. The identification and quantification of these interactions are goals of the WRIT program and their status is the subject of this paper.

Two approaches have been pursued in concert to identify and quantify adsorption processes; 1) an empirical approach which al lows rapid measurement of distribution coefficients (Rd), and 2) mechanism studies that strive to identify, differentiate and quantify the various physicochemical processes that control nuclide adsorption. The empirical distribution coefficient, Rd, is readily measured by laboratory studies and currently is the basis for nuclide mass transport calculations for almost every existing safety assessment and site selection model. Other studies are cited that show the usage and importance of nuclide retardation in guiding waste package design and preliminary site selection.

From 1976 through 1980 WRIT performed empirical sorption studies on a wide range of ground water/rock/nuclide combinations to develop bounding nuclide retardation values.

The WRIT program has pursued laboratory methodology standardization. A wide range of rocks, sediments and minerals in contact with radionuclide-laden solutions have been used to assess the precision in Rd analysis, ease of methods usage, time, equipment and cost expenditures and method limitations. Laboratory methods which have been investigated include batch, axial filtration, channel chromatography, once-through-flow column on disaggregated or permeable rock, high pressure once-through-flow column on fractured or intact low permeability rock and recirculating flow column. WRIT staff conclude that no one laboratory method best simulates all possible rock/ground water/nuclide combinations. As a result, WRIT staff currently recommend the use of at least 
two methods in concert to bound radionuclide migration. The two most used methods are the batch and once-through-flow column. In concert these two methods alleviate most of the identified limitations that each individually exhibit. Further the observed nonlinearity in radionuclide sorption isotherms on rocks leads to the recommendation that $\mathrm{Rd}$ values be determined over a realistic range of nuclide concentrations and ground-water compositions as opposed to only one analysis at fixed conditions. The empirical Freundlich sorption isotherm is a suggested approach to reducing the numerous experimental observations to mathematical descriptions.

These two laboratory methods, batch and once-through-flow column, are described in some detail. The results of the first WRIT round-robin batch sorption exercise and numerous WRIT methodology sensitivity studies have identified the cause of much of the previously observed variability in reported Rd values. Phenomena which contributed to past variability include: fine particulate formation during slurry agitation, incomplete solid/liquid phase separations, tracer addition technique, variations in container sorption corrections, variations in defining the influent nuclide concentration, variable solution-to-solids ratio, and nonlinear adsorption. Knowledge gained in these studies allowed the first detailed recommendation for a proposed standard batch sorption method (Relyea et a1. 1980a). However, further work is necessary to discover the cause of Rd dependency on solution-to-solids ratio and to evaluate the surface area relationship between disaggregated and intact rock and to quantify conversion factors that allow Rd values based on rock weight to be recalculated as $\mathrm{Rd}$ values based on surface area.

The greatest limitation of the batch method is its inability to differentiate multiple species of a radionuclide. The use of total radioactivity in the original and post-contact solutions or post-contact solution and on the solid cannot separate the distinct sorption values for different species. This inadequacy in the batch sorption method, as typically performed, may be the cause of the recent discrepancy between laboratory predictions (based on batch Rd's) and field observations of ${ }^{106} \mathrm{Ru}$ migration at the Nevada Test Site [Coles and Ramspott (1982)]. 
Once-through-flow column sorption experiments are the second most used laboratory method. Strengths include allowing nuclide migration study without significant rock alteration, differentiation of multiple species, study of reversibility, colloid transport and hydrodynamic effects. Limitations include large equipment requirements, long time frames needed for quantitative study of nuclides which exhibit appreciable sorption, experimental problems such as water short-circuiting or channeling along the interface between the rock and the column wall, and data reduction complications for asymmetric or peakless breakthrough curves.

At present WRIT staff recommends that once-through-flow column experiments be used in conjunction with batch sorption experiments to produce the most credible bounding values for nuclide retardation. Replicated batch tests should be performed over a range of nuclide concentrations and ground-water compositions on several samples of the rock to delineate the probable range of Rd values for each nuclide. In addition such batch tests would delineate the concentration of nuclides at which confounding reactions such as precipitation or polymerization might occur. Rd studies versus time should allow estimates of the importance of kinetics on sorption. To verify the batch Rd values, once-through-flow column experiments at nuclide concentrations below solubility constraints and at realistic residence times should be performed. Effluent breakthrough curves should be monitored for low sorbing elements and for "leakage" of highly sorbing elements. Attempts should be made to verify whether the "leakage" is caused by actual mobile species, colloid transport or column short-circuiting. After a reasonable period of time ( 3 to 6 months), the column should be sectioned and the distribution versus distance of strongly adsorbing nuclides determined to qualitatively verify batch Rd values.

As few complementary batch and once-through-flow column adsorption studies have been performed to allow detailed comparisons, the following recommendations are offered. To facilitate conservatism in safety assessment calculations on crystalline or fractured rock where only batch Rd values are available, one should reduce the batch Rd values by a factor of 3 for batch $\mathrm{Rd}$ values $<50 \mathrm{ml} / \mathrm{g}$, by a factor of 5 for Rd values between 50 and $300 \mathrm{ml} / \mathrm{g}$, and 
by a factor of 10 for batch Rd values $>300 \mathrm{ml} / \mathrm{g}$. Such a policy should be acceptable for preliminary safety assessment and/or site selection activities but one should gather detailed laboratory and field data for final licensing activities.

The types of empirical Rd data available are discussed and two summary tables which contain average conservative Rd values for the five most promising host rocks are included. The five rocks are: bedded salt, domed salt, basalt, granite and tuff. Of the five rocks considered, Rd data availability for domed salt is poorest, while availability of Rd data for basalt, tuff and granite is best. Bedded salt Rd data availability is intermediate. In genera 1, laboratory data for sorption under reducing conditions for all rock types needs improvement in quantity and quality. The tables can be used to aid preliminary safety, siting and licensing activities.

The advantages of computerized Rd data management and statistical analysis to create empirical mathematical predictive equations are briefly discussed. Example results for $\mathrm{Sr}$ and Am Rd predictions based on the non-linear statistical analysis method, adaptive learning networks, are discussed.

Results from the empirical approach to describing adsorption-desorption, although useful in assessing the migration potential of radionuclides, are very specific to the particular rocks and ground water studied. That is, the empirical results do not lend themselves to extrapolation to other conditions not studied. Therefore, mechanism studies are used to investigate the factors and interactions that control the adsorption-desorption behavior of nuclides. With knowledge of the nuclide retardation mechanisms, more defensible migration rate predictions can be performed for any proposed storage environment.

Five types of mechanism studies are discussed: 1) scouting studies to identify the most important ground-water and rock sorption controlling parameters, 2) ideal ion exchange studies, 3) site-binding electrical double-layer model studies, 4) redox mediated nuclide retardation studies, and 5) rock surface adsorption site identification studies.

Results of ideal ion exchange theory show this theoretical construct favorably predicts the adsorption behavior of only a few elements such as Sr 
and $\mathrm{Cs}$ onto clays and clay mixtures. The adsorption of other elements such as actinides and lanthanides are not readily modeled by ideal ion exchange constructs. Several possible reasons for the narrow range of applicability of ideal ion exchange theory to deep geologic isolation are discussed. In contrast preliminary experimental studies are described which agree favorably with predictions based on generalized ion exchange and site-binding electrical double-layer constructs. These preliminary results and available literature on transition metal sorption on oxide surfaces have lead WRIT staff to focus adsorption modeling efforts on the site-binding electrical double-layer model although the generalized ion exchange model also appears useful.

Experimental studies of redox mediated nuclide retardation have concentrated on three multivalent elements $T c, N p$ and $\mathrm{Pu}$. It appears that dominant solution redox couples such as $\mathrm{Fe}$ (II)-Fe(III) can cause reduction of nuclides and removal as insoluble precipitates. Thermodynamic calculations based on measured $\mathrm{Fe}$ (II)-Fe(III) solution concentration in laboratory experiments predict that for igneous rocks such as basalt and granite reduction of TC(VII), $\mathrm{Pu}(\mathrm{V}$ or $\mathrm{VI})$ and $\mathrm{Np}(\mathrm{V})$ should occur. Experimental results do show significantly reduced nuclide solution concentrations. It appears that $\mathrm{TC}$ (VII) reduction forms Tc(IV) hydroxide precipitates and it is reasonable to surmise that $\mathrm{Pu}$ and Np would also. In addition some laboratory studies are described in which the reduction of $\mathrm{Pu}$ appears to occur at the solid/solution interface even though the bulk solution is oxidized. Minerals with large percentages of structural $\mathrm{Fe}$ (II) appear to reduce the plutonium in a heterogeneous solid/ solution redox reaction.

Autoradiography, microscopy and electron microprobe studies of rock surfaces upon which radionuclides were adsorbed have identified specific adsorption sites. These studies have shown that it is possible for minor phases within the bulk rock to completely dominate the mass of radionuclides absorbed. Minor phases identified to date to be most active in adsorption include the alteration products, clays and zeolites. Further, slightly soluble actinides and lanthanides have been found to give random autoradiographs suggesting that precipitation reactions are a dominant nuclide retardation mechanism for these elements. 
As an aid to future laboratory experimentation a quantitative exercise on ranking radionuclide hazard's potential was performed. The WRIT findings on radionuclide hazard's potential were compared to three other analyses. All four analyses conclude that the four most hazardous elements in the long term are I, Tc, Np, and $\mathrm{Ra}$. Thus continued nuclide retardation studies of these four elements should receive top priority. Other elements which exhibit significant hazards potential include Pu, U, Am, Se, Sn, Pb, Pd and Th. Numerous studies of $\mathrm{Pu}, \mathrm{U}$ and $\mathrm{Am}$ nuclide retardation properties are under way. For the other elements solubility constraints may lower the hazards and thus diminish the need for detailed study for Sm, Pd and Th. Thus, two elements, Se and Pb, appear to require new efforts to generate enough data to assess the ir retardation potential.

A brief review of field nuclide migration experiments is given. In general, past studies in which nuclide migration was monitored in the field and compared with prediction based on laboratory studies show satisfactory agreement. However, the range of hydrologic conditions and nuclides studied has been quite limited. Three on-going field nuclide migration projects in fractured rock should help expand the range of environments and nuclides studied.

The limitations of both laboratory and field testing in addressing geologic time scales necessitate a third type of study called natural analogs. Qualitative comparisons between field observations of nuclide migration at OKLO and thermodynamic predictions have been quite successful.

A brief discussion of computer-based geochemical and adsorption modeling and their relationship to overall safety assessment modeling is provided. The combination of laboratory and computer-based modeling studies, field testing and natural analogs appears to address the long-term potential of nuclide migration adequately. The WRIT program's main activities fall within the former area but close ties are maintained with other NWTS participants to facilitate data and model verification. 


\section{REFERENCES}

Allard, B. and G. W. Beall (1979) "Sorption of Americium on Geologic Media," J. Environ. Sci. Health, A14(6) pp. 507-518.

Ames, L. L. (1978) "Controlled Sample Program Publication No. 1: Characterization of Rock Samples," PNL-2797, Pacific Northwest Laboratory, Richland, Washington.

Ames, L. L., and D. Rai (1978) "Radionuclide Interactions with Soil and Rock Media" EPA 520/6-78-007.

Ames, L. L., and J. E. McGarrah (1980) "Basalt-Radionuclide Distribution Coefficient Determinations FY-79 Annual Report," PNL-3146, Pacific Northwest Laboratory, Richland, Washington.

Arthur D. Little, Inc. (1980) "Technical Support of Standards for High-Level Radioactive Waste Management Vol. D Release Mechanisms" EPA 520/4-79-007 D.

Baas-Becking, L. G. M., I. R. Kaplan and D. Moore (1960) "Limits of the Natural Environment in Terms of $\mathrm{pH}$ and Oxidation-Reduction Potentials," J. of Geology, Vol. 68, pp. 243-284.

Bal1, J. W., E. A. Jenne, and D. K. Nordstrom (1979) "WATEQ2-A Computerized Chemical Model for Trace and Major Element Speciation and Mineral Equilibria of Natural Waters," in Chemical Modeling in Aqueous Systems. ACS Symposium Series 93, American Chemical Society, Washington, D.C. pp. 815-835.

Barney, G. S. (1981) "Radionuclide Reactions with Ground Water and Basalts from Columbia River Basalt Formations," RHO-SA-217, Rockwell Hanford Operations, Richland, Washington.

Barney, G. S., and P. D. Anderson (1979) "The Kinectics and Reversibility of Radionuclide Sorption Reactions with Rocks - Progress Report for 1978," in Task 4 Second Contractor Information Meeting, Vol. II, R. J. Serne editor, PNL-SA-7352 Vol. II, Pacific Northwest Laboratory, Richland, Washington, pp. 161-218.

Barney, G. S., and B. J. Wood (1980) "Identification of Key Radionuclides in a Nuclear Waste Repository in Basalt," RHO-BWI-ST-9, Rockwell Hanford Operations, Richland, Washington.

Barney, G. S., and G. E. Brown (1980) "The Kinetics and Reversibility of Radionuclide Sorption Reactions with Rocks," in Task 4 Third Contractor Information Meeting Vol. II, edited by J. F. Relyea, PNL-SA-8571, Pacific Northwest Laboratory, Richland, Washington, pp. 261-308. 
Barney, G. S., and G. E. Brown (1981) "Radionuclide Sorption Parameters for Basalt and Basalt Alteration Products," in Waste/Rock Interactions Technology Program FY80 Information Meeting, edited by J. F. Relyea, PNL-3887, Pacific Northwest Laboratory, Richland, Washington, pp. 229-238.

Beal1, G. W. et al. (1980) "An Autoradiographic Study of Actinide Sorption on Climax Stock Granite," ORNL-5617, Oak Ridge National Laboratory, Oak Ridge, Tennessee.

Bird, G. W., and V. J. Lopata (1980) "Solution Interaction of Nuclear Waste Anions with Selected Geological Materials," in Scientific Basis for Waste Management Vol. 2, Plenum Press, New York, pp. 419-426.

Bondietti, E. A., and C. W. Francis (1979) "Geologic Migration Potentials of Tc-99 and Np-27," Science, Vol. 203, pp. 1337-1340.

Bondietti, E. A., S. Y. Lee and S. K. Hall (1981) "Technetium Behavior in the Presence of Fe(II) and Sulfide," in Waste/Rock Interactions Technology Program FY-80 Information Meeting, edited by J. F. Relyea, PNL-3887, Pacific Northwest Laboratory, Richland, Washington, pp. 258-267.

Borg, I. Y. et a1. (1976) "Information Pertinent to the Migration of Radionuclides in Ground Water at the Nevada Test Site," UCRL-52078, Lawrence Livermore National Laboratory, Livermore, CA.

Bower, C. A., and J. 0. Goertzen (1959) "Surface Area of Soils and Clays by an Equilibrium Ethylene Glycol Method," Soil Science, Vol. 87, pp. 289-295.

Brandstetter, A. et al. (1979) "Waste Isolation Safety Assessment Program Technical Progress Report for FY-1978," PNL-2874, Pacific Northwest Laboratory, Richland, Washington.

Branauer, S., P. H. Emmet and R. Teller (1938) "Adsorption of Gases in Multimolecular Layers," J. Am. Chem. Soc., Vol. 60, pp. 309-315.

Bredehoeft, J. D. et a1. (1978) "Geologic Disposal of High-Level Radioactive Wastes-Earth Sciences Perspectives," Professional Paper 779, United States Geologic Survey, Reston, VA.

Brookins, D. G. (1978a) "Retention of Transuranic, Other Actinide Elements and Bismuth at the OKLO Natural Reactor, Gabon," Chem. Geol., pp. 307-323.

Brookins, D. G. (1978b) "Eh-pH Diagrams for Elements from Z-40 to Z-52: Application to the OKLO Natural Reactor," Chem. Geol., pp. 324-341.

Brookins, D. G. (1979) "Thermodynamic Considerations Underlying the Migration of Radionuclides in Geomedia: OKLO and Other Examples," in Scientific Basis for Waste Management, Vol. 1, Plenum Press, New York, pp. 355-366. 
Bryant, E. A. et a1. (1976) "OKLO, an Experiment in Long-Term Geologic Storage," in Actinides in the Environment, ACS Symposium Series No. 35, American Chemical Society, New York, NY.

Burkholder, H. C. et al. (1979) "Waste Isolation Safety Assessment Program Technical Progress Report for FY-77," PNL-2642, Pacific Northwest Laboratory, Richland, Washington.

Burkholder, H. C. (1980) "Waste Isolation Performance Assessment - A Status Report," in Scientific Bas is for Nuclear Waste Management, Vol. 2, Plenum Press, New York, pp. 689-702.

Campbe11, J.E. et a1. (1978) "Risk Methodology for Geologic Disposal of Radioactive Waste: Interim Report," SAND/8-0029, Sandia National Laboratories, Albuquerque, New Mexico.

Chikalla, T. D., and J. A. Powell (1981) "Nuclear Waste Management Quarterly Progress Report January through March 1981," PNL-3000-9, Pacific Northwest Laboratory, Richland, Washington.

Cleveland, J. M. (1979) The Chemistry of Plutonium, American Nuclear Society, LaGrange Park, Illinois publishers.

Cloninger, M. 0., and C. R. Cole (1980) "An Analysis of the Use of Engineered Barriers for Isolation of Spent Fuel in Three Reference Geologies," PNL-3530, Pacific Northwest Laboratory, Richland, Washington.

Cloninger, M. 0., C. R. Cole and J. F. Washburn (1980) "An Analysis on the Use of Engineered Barriers for Geologic Isolation of Spent Fuel in Reference Salt Site Repository," PNL-3356, Pacific Northwest Laboratory, Richland, Washington.

Coles, D. G., H. C. Weed and J. D. Tewhey (1980) "Geochemical Studies of Sorption and Transport of Radionuclides in Rock Media," in Task 4 Third Contractor Information Meeting, Vol. 1, edited by J. F. Relyea, PNL-SA-8571, Pacific Northwest Laboratory, Richland, Washington, pp. 357-434.

Coles, D. G., and L. D. Ramspott (1982) ${ }^{1106} \mathrm{Ru}$ Migration in a Deep Tuffaceous Alluvium Aquifer, Nevada Test Site: Discrepancy Between Field Observations and Prediction from Laboratory Measurements," Science, Vol. 215, pp. 1235-1237.

Cowan, G. A. (1977) "Migration Paths for OKLO Reactor Products and Applications to the Problem of Geologic Storage of Nuclear Wastes," LA-UR-77-2787, Los Alamos National Laboratory, Los Alamos, New Mexico.

Daniels, W. R. et al. (1981) "Laboratory Studies of Radionuclide Distributions Between Selected Ground Waters and Geologic Media, October 1, 1979 September 30, 1980," LA-8586-PR, Los Almos Scientific Laboratory, Los Alamos, New Mexico. 
Davis, J. A., R. 0. James and J. 0. Leckie (1978) "Surface Ionization and Complexation of the Oxide/Water Interface I. Computation of Electrical Double Layer Properties in Simple Electrolytes," J. of Colloid Interface Sci., vol. 63, pp. 480-499.

Davis, J. A., and J. 0. Leckie (1978) "Surface Ionization and Complexation at the 0xide/Water Interface II. Surface Properties of Amorphous Iron 0xyhydroxide and Adsorption of Metal Ions," J. Colloid Interface Sci., Vol. 67, pp. 90-107.

DeMier, W. V. et a1. (1979) "GETOUT -- A Computer Program for Predicting Radionuclide Decay Chain Transport Through Geologic Media," PNL-2970, Pacific Northwest Laboratory, Richland, Washington.

Deutsch, W. J. (1980) "Geological Modeling of the Nuclear-Waste Repository System - A Status Report," PNL-3518, Pacific Northwest Laboratory, Richland, Washington.

Deutsch, W. J., E. A. Jenne and K. M. Krupka (1981) "Solubility Equilibria in Basalt Aquifers: The Columbia Plateau, Eastern Washington," PNL-SA-9166, Pacific Northwest Laboratory, Richland, Washington.

Dillon, R. T., R. B. Lantz and S. B. Pahwa (1978) "Risk Methodology for Geologic Disposal of Radioactive Waste: The Sandia Waste Isolation Flow and Transport (SWIFT) Model," SAND78-1267, Sandia National Laboratories, Albuquerque, New Mexico.

Dosch, R. G., and A. W. Lynch (1980) "Radionuclide Transport in a Dolomite Aquifer," in Scientific Bas is for Nuclear Waste Management Vol. 2, Plenum Presss, New York, pp. 617-624.

Eisenbud, M. et al. (1981) "Mobility of Thorium from the Morro de Ferro," in Migration in the Terrestrial Environment of Long-lived Radionuclides from the Nuclear FueT Cycle, IAEA-SM-257/49 (proceedings from knoxvitle, TN, 27-31 JuTy 1981 symposium; in press).

Erdal, B. R. et al. (1979) "Laboratory Studies of Radionuclide Distributions Between Selected Ground Waters and Geologic Media," in Task 4 Second Contractor Information Meeting Vol. II, edited by R. J. Serne, PNL-SA-7352 Vol. II, Pacific Northwest Laboratory, Richland, Washington, pp. 4-160.

Erdal, B. R., et al. (1980) "Laboratory Studies of Radionuclide Distribution Between Selected Ground Waters and Geologic Media," in Task 4 Third Contractor Information Meeting Vol. 1, edited by J. F. Relyea, PNL-SA-8571, Pacific Northwest Laboratory, Richland, Washington, pp. 435-525.

Erdal, B. R. et al. (1981) "Nuclide Migration Field Experiments: Program Plan," LA-8487-MS, Los Alamos National Laboratory, Los Alamos, NM. 
Francis, C. W., and M. Reeves (1978) "Soil Chromatograph Kd Values," in Waste Isolation Safety Assessment Program Task 4 Contractor Information Meeting Proceedings, R. J. Serne editor, PNL-SA-6957, Pacific Northwest Laboratory, Richland, Washington, pp. 403-431.

Francis, C. W. et al. (1979) "Chromatographic Kd Values of Radionuclides and the Effect of Redox Potentials on Sorption of Radionuclides by Geologic Media," in Task 4 Second Contractor Information Meeting Vol. I, R. J. Serne editor, PNL-SA-7352 Vol. I, Pacific Northwest Laboratory, Richland, Washington, pp. 330-403.

Francis, C. W., and E. A. Bondietti (1980) "Sorption of Long-Lived Radionuclide Species on Geologic Media FY79 Annual Report," in Task 4 Third Contractor Information Meeting, Vol. II, J. F. Relyea editor, PNL-SA-8571, Pacific Northwest Laboratory, Richland, Washington, pp. 81-133.

Frink, C. R. (1971) "Fixation of ${ }^{137}$ Cs by Soil Clays," U.S. AEC Report, NYO-2955-25.

Gancarz, A. (1980) "99 Tc, Pb and Ru Migration Around the OKLO Natural Fission Reactors," in Scientific Basis for Nuclear Waste Management, Vol. 2 , Plenum Press, New York, pp. 601-608.

Gee, G. W., and A. C. Campbell (1980) "Monitoring and Physical Characterization of Unsaturated Zone Transport-Laboratory Analyis," PNL-3304, Pacific Northwest Laboratory, Richland, Washington.

Gee, G. W., A. C. Campbe11, P. J. Wierenga and T. L. Jones (1981) "Unsaturated Moisture and Radionuclide Transport: Laboratory Analysis and Modeling," PNL-3616, Pacific Northwest Laboratory, Richland, Washington.

Giletti, B. et al. (1978) "State of Geological Knowledge Regarding Potential Transport of High-Level Radioactive Wastes from Deep Continental Repositories," PB-289-947, U.S. Department of Commerce, Washington, D.C.

Harada, M. et al. (1980) "Migration of Radionuclides through Sorbing Media, Analytical Solutions-I," LBL-10500, Lawrence Berkeley Laboratory, Berkeley, California.

Hill, M. D. (1980) "The Effect of Variations in Parameter Values on the Predicted Radiological Consequences of Geologic Disposal of High-Level Waste," in Scientific Bas is for Nuclear Waste Management, Vol. 2, Plenum Press, New York, pp. 753-762.

Hinkebein, T. E., and P. F. Hlava (1978) "Microstructural Interactions of Geologic Media with Waste Radionuclides," SAND78-0108, Sandia National Laboratory, Albuquerque, New Mexico, also in Waste Isolation Safety Assessment Program Task 4 Contractor Information Meeting Proceedings PNL-SA-6957, R. J. Serne editor, pp. 477-502. 
Hinkebein, T. E., and P. F. Hlava (1979) "Interactions of Simulated Waste Radionuclides and Rocks," in Scientific Basis for Nuclear Waste Management Vol. 1, Plenum Press, New York, pp. 419-422.

Hoffman, D. C., R. Stone, and W. W. Dudley, Jr. (1977) "Radioactivity in the Underground Environment of the Cambric Nuclear Explosion at the Nevada Test Site," LA-6877-MS, LoS Alamos National Laboratory, Los Alamos, NM.

Hoffman, D. C. (1979) "A field Study of Radionuclide Migration," in Radioactive Waste in Geologic Storage, ACS Symposium No. 100, edited by S. Fried, Washington, DC, pp. 149-166.

Hoffman, D. C., and W. R. Daniels (1980) "Migration from Nuclear Explosion Cavities," LA-UR-80-3031, Los Alamos National Laboratory, Los Alamos, NM.

Hostetler, D. D., R. J. Serne and A. Brandstetter (1979) "Status of Sorption Information Retrieval System," PNL-3139, Pacific Northwest Laboratory, Richland, Washington.

Hostetler, D. D. et al. (1980) "Status Report on SIRS: Sorption Information Retrieval System," PNL-3528, Pacific Northwest Laboratory, Richland, Washington.

Inoue, Y., and W. J. Kaufman (1963) "Prediction of Movement of Radionuclides in Solution through Porous Media," Health Physics, Vol. 9, pp. 705-715.

Interagency Review Group (1978) "Subgroup Report on Alternative Technology Strategies for the Isolation of Nuclear Waste," TID28818.

Interagency Review Group (1979) "Report to the President by the Interagency Review Group on Nuclear Waste Management," NTIS Report TID29442.

Isherwood, D. et al. (1980) "Program Plan: Field Radionuclide Migration Studies in Climax Granite," LLNL Report UCID-18838, Lawrence Livermore National Laboratory, Livermore, CA.

James, R. 0., and T. W. Healy (1972) "Adsorption of Hydrolyzable Metal Ions at the Oxide/Water Interface," J. of Colloid Interface Sci., Vol. 40, pp. 65-81.

James, R. 0., and T. W. Healy (1975) "Analys is of Models of Adsorption of Metal Ions at 0xide/Water Interfaces," J. Chem. Soc. Faraday Trans, Vol. 59, pp. 142-156.

Jenne, E. A. (1972) "Surface Charge Density Dependency on $\mathrm{Al}_{2} \mathrm{O}_{3}$ Content in Imogolite," Clays and Clay Minerals, Vol. 20, pp. 101-103.

Jenne, E. A. (1977) "Trace Element Sorption by Sediments and Soils - Sites and Processes." In Symposium on Molybdenum in the Environment, Vol. 2, eds. W. Chappel and K. Peterson, M. Dekker, Inc. New York, pp. 425-553. 
Jenne, E. A., Editor (1979) Chemical Modeling in Aqueous Systems, ACS Symposium Series 93, American Chemical Society, Washington, D.C.

Jenne, E. A. (1981) "Geochemical Modeling: A Review," PNL-3574, Pacific Northwest Laboratory, Richland, Washington.

Kaiser Engineers (1979) "Conceptual Design Report-National Waste Terminal Storage Repository for Storing Spent Fuel in a Bedded Salt Formation."

Kaszeta, F. E., and F. W. Bond (1980) "The Complex Relationship Between Ground Water Velocity and Concentration of Radioactive Contaminants," in Scientific Basis for Nuclear Waste Management, Vol. 2, Plenum Press, New York, pp. $739-746$.

Kaufman, W. J. (1960) "The Containment of Radioactive Wastes in Deep Geologic Formations," in Disposal of Radioactive Wastes II, International Atomic Energy Agency, Vienna, Austria, pp. 535-546.

Klingsberg, C., and J. 0. Duguid (1980) "Status of Technology for Isolating High-Level Radioactive Wastes in Geologic Repositories," DOE/TIC 11207 (draft).

Kuhn, W. L., and R. D. Peters (1981) "WRIT Leaching and Transport Modeling," in Waste/Rock Interactions Technology Program FY-80 Information Meeting, J. F. Relyea editor, PNL-3887, Pacific Northwest Laboratory, Richland, Washington, pp. 268-276.

Landstrom, 0. (1978) "In Situ Experiments on Nuclide Migration in Fractured Crystalline Rocks," KBS Technical Report 110, Stockholm, Sweden.

Logan, S. E., and M. C. Berbano (1978) "Development and Application of a Risk Assessment Method for Radioactive Waste Management," EPA 520/6-78-005, U.S. Environmental Protection Agency.

Marsily, G. de, E. Ledoux, A. Barbreau and J. Margat (1977) "Nuclear Waste Disposal: Can the Geologist Guarantee Isolation?" Science, Vol. 197, No. 4303 , pp. 519-527.

McVay, G. L., D. J. Bradley and J. F. Kircher (1981) "Elemental Release From Waste Forms." in Advances in the Science and Technology of the Management of High-Level Nuclear Waste Vol. 1, to be published by ONWI.

Meyer, R. E. et al. (1978) "Systematic Study of Nuclide Sorption on Select Geologic Media," in Waste Isolation Safety Assessment Program Task 4 Contractor Information Meeting Proceedings, R. J. Serne editor, PNL-SA-6957, Pacific Northwest Laboratory, Richland, Washington, pp. 343-369.

Meyer, R. E. (1979) "Systematic Study of Metal Ion Sorption on Selected Geologic Media," in Task 4 Second Contractor Information Meeting Vol. 1 , edited by R. J. Serne, PNL-SA-7352, Vol. 1, Pacific Nor thwest Laboratory, Richland, Washington, pp. 231-329. 
Meyer, R. E. (1980) "Systematic Study on Nuclide Adsorption on Selected Geologic Media," in Task 4 Third Contractor Information Meeting Vol. II, J. F. Relyea editor, PNL-SA-8571, Pacific Northwest Laboratory, Richland, Washington, pp. 1-79.

Meyer, R. E. et al. (1981) "Systematic Study of Nuclide Adsorption on Selected Geologic Media," in Waste/Rock Interactions Technology Program FY-80 Information Meeting, J. F. Relyea editor, PNL-3887, Pacific Northwest Laboratory, Richland, Washington, pp. 151-182.

Moody, J. B. (1981) "Radionuclide Migration/Retardation: Research and Development Technology Status Report," ONWI-321, Office of Nuclear Waste Isolation, Columbus, Ohio.

Mucciardi, A. N. et al. (1979) "Statistical Investigation of the Mechanics Controlling Radionuclide Sorption, Part II," in Task 4 Second Contractor Information Meeting Vol. II, R. J. Serne editor, PNL-SA-7352, Vol. II, Pacific Northwest Laboratory, Richland, Washington, pp. 333-425.

Mucciardi, A. N., T. C. Johnson and J. Saunier (1980) "Statistical Investigation of the Mechanics Controlling Radionuclide Sorption, Part III," in Task 4 Third Contractor Information Meeting, Vol. 1, J. F. Relyea editor, PNL-SA-8571 Vol. 1, Pacific Northwest Laboratory, Richland, Washington, pp. 1-75.

Neretnieks, I. (1980) "Diffusion in the Rock Matrix: An Important Factor in Radionuclide Retardation?" J. Geophysical Res., Vol. 85, pp. 4379-4386.

Nielsen, D. R., and J. W. Biggar (1961) "Miscible Displacement in Soils: I. Experimental Information," Soil Sci. Amer. Proc., Vol. 25, pp. 1-5.

Office of Nuclear Waste Management and U.S. Geologic Survey (1980) "Earth Science Technical Plan for Disposal of Radioactive Waste in a Mined Repository," DOE/TIC-11033 (draft).

Office of NWTS Integration (1981) "NWTS Program Criteria for Mined Geologic Disposal for Nuclear Waste - Program Objectives, Functional Requirements, and System Performance Criteria [DOE/NWTS-33(1)] and Site Performance Criteria," [DOE/NWTS-33(2)].

Onishi, Y., R. J. Serne, E. M. Arnold, C. E. Cowan and F. L. Thompson (1981) "Critical Review: Radionuclide Transport, Sediment Transport, and Water Quality Mathematical Modeling; and Radionuclide Adsorption/Desorption Mechanisms," NUREG/CR-1322 or PNL-2901, Pacific Northwest Laboratory, Richland, Washington.

Parsons, P. J. (1963) "Migration from a Disposal of Radioactive Liquid in Sands," Health Phys., Vol. 9, pp. 333-342. 
Passioura, J. B, and D. A. Rose (1971) "Hydrodynamic Dispersion in Aggregated Media II. Effects of Velocity and Aggregate Size," Soil Sci. Vol. 111, pp. 354-352.

Pickens, J. F., R. E. Jackson, K. J. Inch and W. F. Merritt (1981) "Field Measurements of Distribution Coefficients Using a Radial-Injection Dual-Tracer Test," Water Resources Res., Vol. 17 No. 3, pp. 529-544.

Pigford, T. H. et al. (1981) "Migration of Radionuclides Through Sorbing Media Analytical Solutions-II," LBL-11616, Lawrence Berkeley Laboratory, Berkeley, California.

Pines, D. (1978) "Report to the American Physical Society by the Study Group on Nuclear Fuel Cycles and Waste Management Review of Modern Physics," Vol. 50, No. 1, Part III, pp. 121-128.

Rai, D., and W. T. Franklin (1978) "Effect of Moisture Content of Ethylene Glycol Retention by Clay Minerals," Geoderma, Vol. 26, pp. 75-79.

Rai, D., and R. J. Serne (1978) "Solid Phases and Solution Species of Different Elements in Geological Environments," PNL-2651, Pacific Northwest Laboratory, Richland, Washington.

Rai, D., R. J. Serne and D. A. Moore (1980a) "Solubility of Plutonium Compounds and Their Behavior in Soils," Soil Sci. Soc. of Am. J., Vol. 44, No. 3, pp. 490-495.

Rai, D., R. J. Serne and J. L. Swanson (1980b) "Solution Species of Plutonium in the Environment," J. of Envir. Qual., Vol. 9, No. 3, pp. 417-420.

Rai, D., R. J. Serne and D. A. Moore (1980c) "Interactons of Plutonyl(VI) with Soil Minerals," PNL-SA-8448, Pacific Northwest Laboratory, Richland, Washington.

Rai, D., and J. L. Swanson (1981) "Properties of Plutonium(IV) Polymer of Environmental Importance," Nuclear Tech., Vol. 54, No. 1, pp. 107-112.

Rai, D. et al. (1981) "Influence of an Americium Solid Phase on Americium Concentrations in Solutions," Geo. Cosmo. Chim. Acta., Vol. 45, No. 11, pp. 2257-2265.

Relyea, J. F. editor (1980) "Waste Isolation Safety Assessment Program Task 4 Third Contractor Information Meeting Vol. 1 and 2," CONF-7910160 or PNL-SA-8571, Pacific Northwest Laboratory, Richland, Washington.

Relyea, J. F. editor (1981) "Waste/Rock Interactions Technology Program FY-80 Information Meeting," PNL-3887, Pacific Northwest Laboratory, Richland, Washington. 
Relyea, J. F., R. J. Serne, D. Rai and M. J. Mason (1978) "Batch Kd

Experiments with Common Minerals and Representative Ground Waters," in Waste Isolation Safety Assessment Program Task 4 Contractor Information Meeting Proceedings, R. J. Serne editor, PNL-SA-6957, Pacific Northwest Laboratory, Richland, Washington, pp. 125-150.

Relyea, J. F. et a1. (1979a) "Batch Kd Experiments with Common Minerals and Representative Ground Waters," in Task 4 Second Contractor Information Meeting Vol. II, R. J. Serne editor, PNL-SA-7352, Vol. II, Pac if ic Northwest Laboratory, Richland, Washington, pp. 259-330.

Relyea, J. F., D. Rai and R. J. Serne (1979b) "Interaction of Waste Radionuclides with Geomedia: Program Approach and Progress," in Scientific Bas is for Nuclear Waste Management, Vol. 1, Plenum Press, New York, pp. 379-394.

Relyea, J. F., and R. J. Serne (1979) "Controlled Sample Program Publication Number 2: Interlaboratory Comparison of Batch Kd Values" PNL-2872, Pacific Northwest Laboratory, Richland, Washington.

Relyea, J. F., R. J. Serne and D. Rai (1980a) "Methods for Determining Radio nuclide Retardation Factors: Status Report," PNL-3349, Pacific Northwest Laboratory, Richland, WA.

Relyea, J. F. et a1. (1980b) "Laboratory Studies of Pu-237 Sorption on Selected Minerals Under Anoxic Conditions," in Task 4 Third Contractor Information Meeting Vol. II, edited by J. F. Relyea, PNL-SA-8571, Pacific Northwest Laboratory, Richland, Washington, pp. 135-158.

Rickert, P. G. (1981) "Americium Migration in Basalt and Implications to Repository Risk Analysis," in Waste/Rock Interactions Technology Program FY-80 Information Meeting, J. F. Relyea editor, PNL-3887, Pacific Northwest Laboratory, Richland, Washington, pp. 86-99.

Robertson, D. E. (1968) "Role of Contamination in Trace Element Analysis of Sea Water," Anal. Chem., Vol. 40, No. 7, pp. 1067-1072.

Robertson, J. B. (1977) "Numerical Modeling of Subsurface Radioactive Solute Transport from Waste -- Seepage Ponds at the Idaho National Engineering Laboratory," ID0-22057, Idaho Operations Office (AEC), Idaho Falls, Idaho.

Routson, R. C., and R. J. Serne (1972) "One Dimensional Model of the Movement of Trace Radioactive Solute Through Soil Columns: The PERCOL Model," USAEC Report BNWL-1718, Richland, Washington.

Schnindler, P. W., B. F. Furst, R. Dick and P. U. Wolf (1976) "Ligand Properties of Surface Silanol Groups I. Surface Complex Formation with $\mathrm{Fe}^{3+}$, $\mathrm{Cu}^{2+}, \mathrm{Cd}^{2+}$ and $\mathrm{Pb}^{2+}, " \mathrm{~J}$. of Colloid Interface Sci., Vol. 55, pp. 469-475. 
Seitz, M. G., P. G. Rickert, S. Fried, A. M. Friedman and M. J. Steindler (1978) "Transport Properties of Nuclear Wastes in Geologic Media" in Waste Isolation Safety Assessment Program Task 4 Contractor Information Meeting Proceedings, edited by R. J. Serne, PNL-SA-6957, Pacific Northwest Laboratory, Richland, Washington, pp. 309-342.

Seitz, M. G. et al. (1979) "Transport Properties of Nuclear Wastes in Geologic Media Annual Report for October 1, 1977 to September 30, 1978," in Task 4 Second Contractor Information Meeting Vol. 1, R. J. Serne editor, PNL-SA-7352 Vol. 1, Pacific Northwest Laboratory, Richland, Washington, pp. 405-508.

Seitz, M. G. et al. (1980) "Transport of Radionuclides in Geologic Media Annual Report October 1978 to September 1979," in Task 4 Third Contractor Information Meeting Vol. 1, J. F. Relyea editor, PNL-SA-8571 Vol. 1, Pacific Northwest Laboratory, Richland, Washington, pp. 77-154.

Serne, R. J. (1978a) "An Overview of Task 4: Nuclide Transport Data" in Proceedings of the Task 4 Contractor Information Meeting Waste Isolation Safety Assessment Program September 20-23, 1977, ed. R. J. Serne, PNL-SA-6957, pp. 57-87.

Serne, R. J. editor (1978b) "Waste Isolation Safety Assessment Program Task 4 Contractor Information Meeting Proceedings," PNL-SA-6957, Pacific Northwest Laboratory, Richland, Washington.

Serne, R. J. editor (1979) "Waste Isolation Safety Assessment Program Task 4 Second Contractor Information Meeting Vol. 1 and 2," PNL-SA-7352, Pacific Northwest Laboratory, Richland, Washington.

Serne, R. J., R. C. Routson and D. A. Cochran (1974) "Experimental Methods for Obtaining PERCOL Model Input and Verification Data," USAEC Report BNWL-1721, Pacific Northwest Laboratory, Richland, Washington.

Shiao, S. Y., Y. Egozy, and R. E. Meyer (1981) "Adsorption of CS(I), Sr(II), $\mathrm{Eu}(\mathrm{III}), \mathrm{Co}(\mathrm{II})$, and $\mathrm{Cd}$ (II) by $\mathrm{Al}_{2} \mathrm{O}_{3}$, "Manuscript Available from Authors, Oak Ridge National Laboratory, Oak Ridge, Tennessee.

Shiao, S. Y., and R. E. Meyer (1981) "Adsorption of Inorganic Ions on Alumina from Salt Solutions: Correlations of Distribution Coefficients with Uptake of Salt," Manuscript Available from Authors, Oak ridge National Laboratory, Oak Ridge, Tennessee.

Silva, R. J., L. V. Benson and J. A. Apps (1979) "Theoretical and Experimental Evaluation of Waste Transport in Selected Rocks - 1978 Annual Report," in Task 4 Second Contractor Information Meeting Vol. 1, R. J. Serne editor, PNL-SA-7352 Vo1. 1, Pacific Northwest Laboratory, Richland, Washington, pp. $97-185$.

Silva, R. J. et al. (1980) "Theoretical and Experimental Evaluation of Waste Transport in Selected Rocks," in Task 4 Third Contractor Information Meeting, Vol. 1, J. F. Relyea editor, PNL-SA-8571, pp. 249-355. 
Silva, R. J., A. F. White and A. W. Yee (1981) "Sorption Modeling Studies and Measurements," in Waste/Rock Interactions Technology Program FY-80 Information Meeting, J. F. Relyea editor, PNL-3887, Pacific Northwest Laboratory, Richland, Washington, pp. 204-214.

Smith, M. J. et al. (1980) "Engineered Barrier Development for a Nuclear Waste Repository Located in Basalt: An Integration of Current knowledge," RHO-BWI-ST-7, Rockwe 11 Hanford Operations, Richland, Washington, pp. 2-119 to $2-131$.

Smyth, J. R., J. L. Thompson and K. Wolfsberg (1980) "Microautoradiographic Studies of the Sorption of $U$ and Am on Natural Rock Samples," Radioactive Waste Management, Vol. 1 No. 1, pp. 13-24.

Stearns-Roger Engineeriing Co. (1979) "Conceptual Design Report-National Waste Terminal Storage Repository fo Storing Reprocessed Wastes in a Dome Salt Formation."

Stearns-Roger Services Inc. (1980) "Technical Conservatisms in NWTS Repository Conceptual Desitns - National Waste Terminal Storage Repository No. 1-Special Study No. 4," ONWI-222.

Sternau, R. J. et al. (1967) "Radioisotope Tracers in Large-Scale Recharge Studies of Groundwater," in Isotopes in Hydrology, International Atomic Energy Agency, Vienna, Austria, pp. 489-505.

Strickert, R. G. (1980) "Sorption of Redox-Sensitive Elements-Critical Analys is," PNL-3432, Pacific Northwest Laboratory, Richland, Washington.

Strickert, R. G., A. M. Friedman and S. Fried (1980) "The Sorption of Technetium and Iodine Radioisotopes by Various Minerals," Nuclear Technology, Vol. 49, pp. 253-266.

Struempler, A. W. (1973) "Adsorption Characteristics of Silver, Lead, Cadmium, Zinc and Nickel on Borosilicate Glass, Polyethylene and Polypropylene Container Surfaces," Anal. Chem. Vol. 45 No. 13, pp. 2251-2254.

Thompson, J. L., and K. Wolfsberg (1979) "Applicability of Microautoradiography to Sorption Studies," in Task 4 Second Contractor Information Meeting Vol II, R. J. Serne editor, PNL-SA-7352 Vol. II, Pacific Northwest Laboratory, Richland, Washington, pp. 145-160.

Travis, C. C. (1978) "Mathematical Description of Adsorption and Transport of Reactive Solutes in Soil: A Review of Selected Literature," ORNL-5403, 0ak Ridge National Laboratory, Oak Ridge, Tennessee.

Triolo, R., N. Harrison and K. A. Kraus (1979) "Use of the Axial Filter to Measure Low Distribution Coefficients," J. of Chromatography, Vol. 197, pp. 19-35. 
Triolo, R., and M. H. Lietzke (1980) "Adsorption on Mixtures of Ion Exchangers," J. Inorg. Nucl. Chem., Vol. 42, pp. 913-917.

U.S. Department of Energy (1979) "Environmental Impact Statement for the Management of Commercially Generated Radioactive Waste," DOE/EIS-0046-D.

U.S. Department of Energy (1980) "Final Environmental Impact Statement Management of Commercially Generated Radioactive Waste, Vol. I-II," DOE/EIS-0046-F.

U.S. Environmental Protection Agency (1979) "Alternative Disposal Concepts for High-Level and Transuranic Radioactive Waste Disposal," ORP/CSD 79-1.

Vandergraaf, T. T., D. R. M. Abry and C. E. Belanger (1981) "Autoradiography of Radionuclides Sorbed on Thin Sections of Rocks Representative of Plutons in the Canadian Sheild," in Waste/Rock Interactions Technology Program FY-80 Information Meeting, J. F. Relyea editor, PNL-3887, Pacific Northwest Laboratory, Richland, Washington, pp. 288-307.

VanGenuchten, M. Th., J. M. Davidson and P. J. Wierenga (1974) "An Evaluation of Kinetic and Equilibrium Equations for the Prediction of Pesticide Movement in Porous Media," Soil Sci. Soc. Am. Proc., Vol. 38, pp. 29-35.

VanGenuchten, M. Th., P. J. Wierenga and G. A. O'Conner (1977) "Mass Transfer Studies in Sorbing Porous Media: III. Experimental Evaluation with $2,3,5,-T, "$ Soil Sci. Soc. Am. J., Vol. 41, pp. 278-285.

Vine, E. N., W. R. Daniels, R. J. Rundberg and J. L. Thompson (1981) "Current Status of Crushed Rock and Whole Rock Column Studies," in Waste/Rock Interactions Technology Program FY-80 Information Meeting, J. F. Relyea editor, PNL-3887, Pacific Northwest Laboratory, Richland, Washington, pp. 183-193.

Washburn, J. F. (1979) "Methodology for Release Consequence Analysis -- Part IV Multicomponent Mass Transport Mode1," PNL-3179, Pacific Northwest Laboratory, Richland, Washington.

Westfa11, J. C., J. I. Zachary and F. M. M. Morel (1976) "MINEQL - A Computer Program for the Calculation of Chemical Equilibrium Composition of Aqueous Solutions," Technical Note No. 18, Department of Civil Engineering, Massachusetts Institute of Technology, Cambridge, Massachusetts.

Wolery, T. J. (1979) "Calculation of Chemical Equilibrium Between Aqueous Solution and Minerals: The EQ3/6 Software Package," UCRL-52658, Lawrence Livermore Laboratory, Livermore, California.

Wolery, T. J. (1980) "Chemical Modeling of Geologic Disposal of Nuclear Waste: Progress Report and a Perspective," UCRL-52748, Lawrence Livermore Laboratory, Livermore, California. 
Wolery, T. J. (1981) "Chemical Modeling of Irreversible Reactions in Nuclear Waste-Rock Systems," in Waste/Rock Interactions Technology Program FY-80 Information Meeting Proceedings, PNL-3887, Edited by J. F. Relyea, Pacific Northwest Laboratory, Richland, Washington.

Wood, B. J., and D. Rai (1981) "Nuclear Waste Isolation: Actinide Containment in Geologic Repositories," PNL-SA-9549, Pacific Northwest Laboratory, Richland, Washington. 


\section{DISTRIBUTION}

No. of

Copies

$\underline{\text { OFFSITE }}$

A. A. Churm

DOE Patent Division

9800 South Cass Avenue

Argonne, IL 60439

27 DOE Technical Information Center

Dave Brooks

U.S. Nuclear Regulatory Commission

MS 905-SS

High Level Waste Tech. Deve lopment

Washington, DC 20555

John A. Apps

Lawrence Berkeley Laboratory

University of $\mathrm{California}$

One Cyclotron Road

Building 90/1140C

Berkeley, CA 94720

Argonne National Laboratory

Reference Library

9800 South Cass Avenue

Argonne, IL 60439

10
No. of

Copies
Gary Bea11

Radian Corporation

8500 Shoal Creek

Austin, TX 78766

Larry Benson

Lawrence Berkeley Laboratory

University of California

One Cyclotron Road

Building 90/1140G

Berkeley, CA 94720

George Birchard

Nuclear Regulatory Commission

Office of Nuclear Research

Mailstop 1130-SS

Washington, DC 20555

Dr. John Bird

Geology Department

Corne11 University

Ithaca, NY 14853

Ernest Bondietti

Environmental Sciences Division

Oak Ridge National Laboratory

Bldg. 1505

Oak Ridge, TN 37830

A. Brandstetter

Office of Nuclear Waste Isolation

Battelle Memorial Institute

$505 \mathrm{King}$ Avenue

Columbus, $\mathrm{OH} 43201$

Brookhaven National Laboratory

Reference Section

Information Division

Upton, Long Island, NY 11973

Douglas G. Brookins

Department of Geology

University of New Mexico

Albuquerque, NM 87131 
No. of

Copies

George Jansen

Office of Nuclear Waste Isolation

Battelle Memorial Institute

505 King Avenue

Columbus, $\mathrm{OH} 43201$

J. L. Burnett

DOE Office of Basic Energy Sciences

Washington, DC 20545

Wayne Carbiener

Office of Nuclear Waste Isolation

Battelle Memorial Institute

505 King Avenue

Columbus, $\mathrm{OH} 43201$

Leslie Casey

DOE-NPO

505 King Avenue

Columbus, $\mathrm{OH} 43201$

H. Clyde Claiborne

Oak Ridge National Laboratory

P.0. Box $X$

Oak Ridge, TN 37830

Jess Cleveland

Denver Federal Center

U.S. Geological Survey

P.0. Box 25046

MS -412

Lakewood, C0 80225

Peter Columbo

Brookhaven National Laboratory

Nuclear Waste Management Group Upton, NY 11973

Carl R. Cooley

DOE Division of Waste Isolation

Washington, DC 20545

Jared Davis

U.S. Nuclear Regulatory

Commission

Washington, DC 20555
No. of

Copies

Stan Davis

6549 W. BOx Cyn Dr.

Tucson, AZ 85705

Les Dole

Oak Ridge National Laboratory

P.0. Box $X$

Oak Ridge, TN 37830

R. G. Dosch

Sandia Laboratories

Division 4512

Albuquerque, NM 87185

Geoffrey Eichholz

Regent's Professor of Nuclear Engineering

School of Nuclear Engineering Georgia Institute of Technology

Atlanta, GA 30332

Warren Eister

DOE Division of Waste Isolation

Washington, DC 20545

Environmental Protection Agency

Office of Radiation Programs

Technical Assessment Division Aw559

Washington, DC 20460

Bruce R. Erdal

Los Alamos Scientific Laboratory

CNC-11, MS -514

Los Alamos, NM 87545

Sherman Fried

Agronne National Laboratory

9700 South Cass Avenue

Argonne, IL 60439

A. Friedman

Argonne National Laboratory

9700 South Cass Avenue

Argonne, IL 60439 
No. of

Copies

Alex Gancarz

Los Alamos Scientific Laboratory

CNC-11, Mailstop 514

Los Alamos, NM 87545

Robert G. Garvin

E. I. duPont deNemours Co.

Savannah River Laboratory

Aiken, SC 29801

Richard L. Hahn

Oak Ridge National Laboratory

P.0. Box $X$

Oak Ridge, TN 37830

R. J. Hall

Office of Nuclear Waste Isolation

Battelle Memorial Institute

505 King Avenue

Columbus, $\mathrm{OH} 43201$

Phillip Helmke

1525 Observatory Dr. University of Wisconsin

Madison, WI 53706

Bill Highland

Dames \& Moore

Suite 200

250 E. Broadway

Salt Lake City, UT 84717

Peter Hofmann

Office of Nuclear Waste

Isolation

505 King Avenue

Columbus, $\mathrm{OH} 43201$

H. D. Holland

Dept. of Geological Sciences

Harvard University

Cambridge, MA 02138
No. of

Copies

Norman Hubbard

Office of Nuclear Waste Isolation

Battelle Memorial Institute

505 King Avenue

Columbus, $\mathrm{OH} 43201$

Dana Isherwood

Lawrence Livermore Laboratory

P.0. Box 808

MSL-224

Livermore, CA 94550

J. K. Johnstone

Sandia Laboratories

Albuquerque, NM 87107

G. R. Kilp

Advanced Energy System Division West inghouse Electric Corp. P.0. Box 10864

Pittsburgh, PA 15236

John F. Kircher

Office of Nuclear Waste Isolation

Battelle Memorial Institute

505 King Avenue

Columbus, $\mathrm{OH} 43201$

George A. Kolstad

DOE Division of Energy Research

Washington, DC 20545

Kurt Kraus

110 Ogontz Lane

Oak Ridge, TN 37830

Don Langmuir

Dept. of Chemistry and Geochemistry

Colorado School of Mines

Golden, CO 80401 
No. of

Copies

Ron Lantz

Intera Environmental

Consultants

11999 Katy Freeway

Suite 610

Houston, TX 77079

R. B. Laughon

Office of Nuclear Waste Isolation

Battelle Memorial Institute

505 King Avenue

Columbus $\mathrm{OH} 43201$

Lawrence Berkeley Laboratory

Reference Library

University of California

Berkeley, CA 94720

Lawrence Livermore Laboratory

Reference Library

P.0. Box 808

Livermore, CA 94550

Stan E. Logan

Los Almos Technical Associates, Inc.

P.0. Box 410

Los Alamos, NM 87544

Tom Longo

DOE Division of Waste Isolation

Washington, DC 20545

Los Alamos Scientific Laboratory

Reference Library

P.0. Box 1663

Los Alamos, NM 87544

Richard W. Lynch

Manager, Department 4530

Sandia Laboratories

P.0. Box 5800

Albuquerque, NM 87185
No. of

Copies

I. Wendell Marine

E. I. duPont DeNeumours Co.

Savannah River Laboratory

Aiken, SC 29801

J. B. Mart in

Asst. Director for Radioactive Waste Mgmt. Branch

NRC Division of Materials and

Fuel Cycle Facility Licensing

Washington, DC 20555

Jeff L. Means

Battelle Columbus Laboratory

505 King Avenue

Columbus, $\mathrm{OH} 43021$

Robert E. Meyer

Oak Ridge National Laboratory

P.0. Box X

Oak Ridge, TN 37830

Martin A. Molecke

Nuclear Waste Experimental

Programs

Division 4512

Sandia Laboratories

Albuquerque, NM 87185

J. E. Monsees

Office of Nuclear Waste Isolation

Battelle Memorial Institute

505 King Avenue

Columbus, $\mathrm{OH} 43201$

Judith Moody

Office of Nuclear Waste Isolation

505 King Avenue

Columbus, $\mathrm{OH} 43201$

Jim P. Murray

Harvard University

Pierce $\mathrm{Hall}$

Cambridge, MA 02138 
No. of

Copies

R. L. Nebeker

Exxon Nuclear Idaho

P.0. Box 2800

Idaho Falls, ID 83401

Jeff 0 . Neff

DOE Columbus Program Office

505 King Avenue

Columbus, $\mathrm{OH} 43201$

Jim Neiheisel

Environmental Protection Agency

$\mathrm{CM}-2$, Office of Radiation

Program, ANR 460

Washington, DC 20460

Edward Norr is

Los Alamos Scientific Laboratory

Group CNC-11 MS-514

P.0. Box 1663

Los Alamos, NM 87545

E. J. Nowak

Sandia Laboratory

Division 5824

Albuquerque, NM 87131

Oak Ridge National Laboratory

Central Research Library

Document Reference Section

Oak Ridge, TN 37830

Edward O'Donne 11

U.S. Nuclear Regulatory

Commission

Office of Standards Development

Washington, DC 20555

W. M. Pardue

Office of Nuclear Waste

Isolation

Battelle Memorial Institute

$505 \mathrm{King}$ Avenue

Columbus, $\mathrm{OH} 43201$
No. of

Copies

George A. Parks

Stanford University

Department of Applied Earth Sciences

Stanford, CA 94305

L. D. Ramspott

Lawrence Livermore Laboratory

P.0. Box 808

Livermore, CA 94550

Gary A. Robbins

Department of Geology

Texas A\&M University

College Station, TX

John B. Robertson

USGS National Center

Office of Radiohydrology

MS-410

Reston, VA 20292

R. A. Robinson

Office of Nuclear Waste Isolation

Battelle Memorial Institute

505 King Avenue

Columbus, $\mathrm{OH} 43201$

Savannah River Laboratory

Reference Library

Aiken, SC 29801

Martin Seitz

Argonne National Laboratory

9700 South Cass Avenue

Argonne, IL 60439

Robert Silva

Lawrence Berkeley Laboratory

University of California

One Cyclotron Road

Building 70A/1160

Berkeley, CA 94720

David B. Stewart

National Center 959

U.S. Geological Survey

Reston, VA 22092 
No. of

Copies

Daryl Tweeton

U.S. Bureau of Mines

P.0. Box 1660

Twin Cities, MN 55111

Robert L. Watters

DOE Division of Ecological

Sciences

Washington, DC 20545

$H$. Weed

Lawrence Livermore Laboratory

P.0. Box 808, MS-L233

Livermore, CA 94550

Allen Weiss

Brookhaven National Laboratory

Building 830

Upton, NY 11973

William B. White

Materials Research Laboratory

Pennsylvania State University

University Park, PA 16802

R. F. Williams

Electric Power Research

Institute

3412 Hillview Avenue

P.0. Box 10412

Palo Alto, CA 94303

W. A. Williams

Office of Radiation Programs

Environmental Protection Agency

Washington, DC 20460

Wilste Library

U.S. Nuclear Regulatory

Commission

Washington, DC 20555

P. S. Witherspoon

University of California

Berkeley

Geologic Engineering

1842 Monterey Avenue

Berkeley, CA 94707
No. of

Copies

T. J. Wolery

Lawrence Livermore Laboratory

P.0. Box 808

Livermore, CA 94550

Kurt Wolfsberg

Los Alamos Scientific Laboratory

CNC-11, MS -514

Los Alamos, NM 97545

B. Wood

Department of Geology

Arizona State University

Tempe, AZ 85281

H. Tom Yolken

National Bureau of Standards

Physics Building/B320

Washington, DC 20234

ONSITE

5 DOE Richland Operations Office

0. J. Elgert

H. E. Ransom

J. J. Schreiber

F. R. Standerfer

M. W. Shupe

9 Rockwell Hanford Operations

G. S. Barney

D. Brown

C. H. Delegard

R. B. Kasper

W. H. Price

R. C. Routson

P. F. Salter

M. J. Smith

M. I. Wood

Hanford Engineering Development Laboratory

R. J. Cash 


\section{Pacific Northwest Laboratory}

L. L. Ames

E. M. Arnold

H. C. Burkholder

D. J. Bradley

T. D. Chikalla

M. O. Cloninger

D. G. Coles

W. J. Deutsch

F. H. Dove

J. S. Fruchter

G. W. Gee

D. C. Girvin

J. H. Jarrett

E. A. Jenne

T. L. Jones

F. N. Hodges

M. R. Kreiter

K. M. Krupka

W. L. Kuhn

D. E. Larson

J. L. MCElroy/

R. E. Nightingale
G. L. McVay

J. E. Mende 1

P. R. Partch

R. A. Peters

D. Rai

J. F. Relyea

W. A. Ross

J. L. Ryan

R. J. Serne (10)

J. W. Shade

D. R. Sherwood

J. A. Stott lemyre

R. G. Strickert

J. L. Swanson

R. P. Turcotte/D. M. Strachen

R. W. Westerman

J. H. Westsik

Water and Land Resources

Library (15)

Technical Information

Library (5)

Publishing Coordination (2) 
$\therefore$

$\therefore$

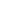

